\title{
What is the I that I am? An Enquiry into the Self
}

\author{
By \\ Jennifer Leigh Gosnell
}
A thesis submitted to the Victoria University of Wellington in fulfilment of the requirements for the degree of
Masters of Arts
in Philosophy

Victoria University of Wellington

2013 
Dedicated to...

\author{
My Parents, \\ Jan and Mark Gosnell, \\ for hours of contemplations and discussions
}

And to...

My Husband,

Alex Jebson,

for supporting me tirelessly 
Title: What is the I that I am? An Enquiry into the Self

Completed By: Jennifer Leigh Gosnell

Dated: 16 September 2013

Submitted: Victoria University of Wellington, New Zealand

\section{Abstract:}

This dissertation is an elucidation of the nature of the self. It consists of two major parts.

The first part is an investigation of the necessary and sufficient conditions of the self, appealing to four theses: the Conceivability Thesis, the Equilibrium Thesis, Panpsychism and the Multiple Selves Doctrine and the Locus Thesis. Proponents of these views are examined in detail, including Descartes, Avicenna, Strawson, Parfit and Dennett. The conditions of selfhood are established through an examination of the individual's perception and how they arrange their perceptions. The second part of the dissertation discusses the influences of the outside or others' perception of a self, and how this can influence an individual's own impression of the self. This is considered using as examples the psychological disorders of autism and schizophrenia. The primary aim of this dissertation is to establish criteria for the presence of the self in the individual and to examine some of the ways in which the self can be expressed. Furthermore, this dissertation begins to clarify the importance of the contribution the self makes towards a person's successful functioning within his/her selected community. 


\section{Table of Contents}

Abstract...

Table of Contents... 2

$\begin{array}{ll}\text { Introduction... } & 3\end{array}$

1. Conditions for the Self through the Individual Perspective... 5

I. The Conceivability Thesis... 5

$\begin{array}{ll}\text { II. Equilibrium Thesis... } & 15\end{array}$

III. Panpsychism and the Multiple Selves Doctrine... 23

IV. The Locus Thesis... 33

V. Self Criteria and Distinctions... 45

2. Insights into the Self through the Perspective of the Other ... 57

VI. Finding the Self in a Complex World... 57

VII. Disorders Elucidate the Self: Autism... 63

VIII. Disorders Elucidate the Self: Schizophrenia... 75

IX. The Function of the Self... 85

$\begin{array}{ll}\text { Conclusion... } & 93\end{array}$

$\begin{array}{ll}\text { Bibliography... } & 97\end{array}$ 


\section{What is the I that I am?}

\section{An Enquiry into the Self: Thoughts Based on the Individual and the Perceptions of the Other}

"We have all a better guide in ourselves, if we would attend to it, than any other person can be." Jane Austen

"You need chaos in your soul to give birth to a dancing star."

Friedrich Nietzche

"The soul can never be corrupted with the corruption of the body, but it is like the wind which causes the sound of the organ, and which ceases to produce a good effect when a pipe is spoilt."

Leonardo Da Vinci, Thoughts on Art and Life

This dissertation examines the self; that aspect of an individual which is specifically and irrevocably him/her. It is an attempt to remove all extraneous detail and identify what it is that makes an individual distinctly him/her. The intention is to define what this essence of the individual is, so that, with understanding, an examination of human nature can occur. This examination has the central goal of establishing what a self is and how can it be identified in an individual. An understanding of the nature of a self and its different expressions allows for an examination of unusual cases of persons with a deeper understanding of those faculties which contribute towards an individual's apparent distinctiveness.

An understanding of the nature of the self proves necessary for philosophical theories of cognition, personhood and ethical rights. This dissertation tackles the central issue of what a self is and the requirements for such a classification. It then examines some cases where the ascription of self is called into question. This aspect of the dissertation begins to demonstrate how external perceptions of an individual self can be misleading and can result in the possible exclusion of individuals from the ethical rights owed to one with a self.

This dissertation follows a relatively simple structure: it is divided into two parts: the first is an examination of the self within the individual, and the second is an examination of the self as perceived by others. In this case, the first part of the dissertation examines a series of philosophical approaches to the self which are discovered through internal reflections on the idea of self through exercises in thought and an examination of the responses an individual offers with respect to the individual's own perceptions. The 
views of the self that will be examined include those of Rene Descartes, Avicenna, Galen Strawson, Derek Parfit, and Daniel Dennett. As these methods of thought are elucidated, a set of consistent features used to define the nature of the self become apparent, thus offering the basis for a set of criteria for the self. The second part of this dissertation examines how others' perceptions of an individual's self can lead to a variety of assumptions about an individual. An examination of the nature of the self in individuals with psychological disorders highlights how others' perceptions can be misleading in regards to the establishment of awareness that there is a self within the observed individual.

Others' perceptions of a self offer a unique perspective of how the self interacts with the world; what the function of a self is to an individual in the world; and what sort of reasoning currently leads the average mind to an identification of another self.

This dissertation attempts to establish a foundation of understanding about the self, which can then be used to clarify ethical thinking around beings with and without a self. One of the primary assumptions of this dissertation is that the being in question is human. However, the ultimate goal would be to establish the requirements of self in a cognitive form so that any being that has such faculties can be described as having a self.

Two primary delimitations of this dissertation are: firstly, the potential for studying other beings which may have a self (such as elephants, dolphins or chimpanzees). Secondly, there is an opportunity for a comprehensive study on ethical implications of an absence of self classification for care treatment within a single species such as humans.

Some of the central questions examined in this dissertation are:

1. What is the self?

a. Does a self exist?

b. If so, what is its nature?

2. How can the self be identified? And...

3. What is the function of the self? 


\title{
PART ONE
}

\section{Conditions for the Self through the Individual Perspective}

\author{
Chapter One
}

The Conceivability Thesis

The Conceivability Thesis is based on the principle that if ' $\mathrm{X}$ ' is conceivable then it is possible that ' $\mathrm{X}$ '. This approach is used to establish that the self is conceivable and therefore possible; not only possible according to some philosophers, but definitely the case. For Descartes, this approach leads to a type of dualism called "substance dualism." In the next chapter a dualism of substance and subsistence, a variant of substance dualism, is discussed. While other philosophers using the Conceivability Thesis reach different conclusions when considering the nature of the mind, consciousness and self, nevertheless the basis is a shared one.

Descartes' Approach to the Self

Descartes is an Interactionist Substance Dualist, meaning he believes that not only is the mind/self an independent substance from the body (which is also a substance) but that the two substances interact causally.

\section{The Approach - Dubito}

Descartes' philosophical goals were to establish a series of beliefs which he could then use as foundations to examine the world. These foundations were to be without the fallibilities usually found in a life time's accumulated beliefs. Descartes approaches his task of inner 'spring cleaning' by first removing all those concepts and beliefs which can be held in contention. ${ }^{1}$ By using doubt as a marker he whittles away at the foundations of his own belief system until he believes that he has isolated what it is that he can rely on; that is, he believes that he has found the foundation which is 'doubtless'. Descartes' doubtless foundation is that he thinks and, therefore, a thinker must exist.

Descartes does not specify that the 'I', while necessary for the thought, is required to be consistent and persistent. In fact, he is willing to concede that while each thought has an ' $\mathrm{I}$ ' it is not necessary that the same ' $\mathrm{I}$ ' preside over bundles of thought such as those which he perceives as his. However, before entering into a discussion on multiply 'I's (an

\footnotetext{
${ }^{1}$ Cottingham, John, Ed., (1996). Descartes: Meditations on First Philosophy: With Selections from the Objections and Replies. Cambridge University Press
} 
idea which will be discussed later in reference to Galen Strawson $)^{2}$ it is necessary to take a closer look at Descartes' method of reassessment.

Descartes begins by identifying a foundation and then examining it for doubt. If there is doubt then the idea is considered insupportable. ${ }^{3}$ Initially, this seems like an impossible task as each adult has accumulated innumerable beliefs and ideas. However, each idea is based on a few fundamental assumptions. One of the most important is that our sensory perceptions provide the data on which all other assumptions are based. Thus, if it can be shown that the sensory data is doubtful then, by default, those beliefs reliant on that data are doubtful and can be discarded. This method of elimination is reductive in nature. In this case a reductionist removes all things that are not the self; that is, those things which are doubtful and considers that the self will be found in what is left.

Descartes begins from a Dualistic position ${ }^{4}$, that is, he believes in a body and a soul. He begins his process of reduction using this logic: all ideas and beliefs are presented to us through our senses. Our senses are not reliable as demonstrated by dreams and hallucinations. Therefore what is brought to us through our senses contains doubt and must be held provisionally as erroneous. From this position the argument can go in two possible ways: firstly, that the content of the sensory data is incorrect or, secondly, that the processing of the sense data is faulty. A secondary but significant question arises: just what aspect of Descartes is considering the relative value of the sensory data? The apparent answer is his thought, but would his thought not be the sensory data itself? If this is the case two possible scenarios present themselves: that within the faculty of thought there are multiple levels; or, that there are two faculties at work in this type of reasoning - the faculty of thought and then the faculty that is aware of the thought and is assessing it. Later in this chapter there will be a discussion as to whether Descartes' self is just thought or more than thought. For now, let us focus on the reliability of the sensory data.

Descartes' distrust of the sensory data is well placed because information gained from sensory input is frequently confused. It is hard to identify just where the assessed data begins and the unanalysed sensory data ends. The following scenarios are chosen as examples not because this distinction can be made easily but because they clearly demonstrate the involvement of either a processing error or that the data itself is inaccurate. The first scenario is that of a hallucination commonly perceived to be visual and auditory. This is a misconception as hallucinations can also occur from any of the other sensors:

\footnotetext{
${ }^{2}$ Strawson, G., (2005). The Self?. Blackwell Publishing, Chapter 4, pp 63-86

${ }^{3}$ Cottingham, John, Ed.. (1996). Descartes: Meditations on First Philosophy: With Selections from the Objections and Replies. Cambridge University Press

${ }^{4}$ Blackburn, S., (2005) Oxford Dictionary of Philosophy. Oxford University Press, p.105
} 
taste, smell and touch. ${ }^{5}$ During a hallucination the person experiencing it perceives the hallucination just as if it were a regular perception even if the content may not follow the normal rules of physics. Despite this and the fact that the brain analyses the input in the same way it would for normal input it is clear that the hallucination's input is incorrect. The sensory data of the hallucination is completely elicited from the brain within the person experiencing the hallucination. The possibility of hallucinations demonstrates that mistakes can be made.

Consider the effect of Boundary Extension. Boundary Extension is an effect where the perception faculties of the brain interpret the sensory data and rather than examining precisely what is present, rearranges the sensory data to make sense of it, and that rearrangement is what the mind believes it sees. ${ }^{6}$ For instance, when a person sees a car behind a picket fence they do not query whether the object behind the fence is a car because they cannot see the full outline of the vehicle; rather, the mind fills in the gaps so it appears that the person sees both a car and a picket fence. Studies such as Woodman et al. (2003), on visual masking demonstrate how visual input does not always equate to an individual's perception. Object-substitution masking illustrates how an individual can experience visual input but not perceive all of the visual input. That is the individual only reports the perception of part of the information presented during the experiment but their neural responses indicate that the individual identified the other visual stimuli. ${ }^{7}$ These cases show clearly why sensory input and its perception contain doubt and therefore the beliefs based on it, lack integrity and must be discarded.

Once what has been of doubt is removed Descartes' intention is to identify what remains. Descartes does not consider the possibility that nothing may remain; rather, he concludes that thought remains. Most processes modelled in human thought or by the world that we 'know' assume a framework that begins with a starting point. For Descartes the combination of his dualist position together with his human desire for a reason or starting point results in his decision to choose thought as a consistent and definite point. Descartes concludes that the thinking, considering thing is the self. This, however, can be questioned. The closest Descartes comes to considering an alternative to the self is when he posits a hypothetical deceiving daemon. ${ }^{8}$ Descartes offers the basic notion that for every

\footnotetext{
${ }^{5}$ Barlow, D. H.; Durand, V. M., (2009). Abnormal Psychology: An Integrative Approach - Firth Edition. Wadsworth Cengage Learning, pp 408-409

${ }^{6}$ Hubbard, T. L.; Hutchison, J. L.; Courtney, J. R., (2010). Boundary Extension: Findings and Theories, The Experimental Psychology Society. pp 1-28

${ }^{7}$ Woodman, G. F.; Luck, S. J. (2003). Dissociations among Attention, Perception, and Awareness during Object Substitution Masking. Psychological Sciences, Vol. 14, No. 6. American Psychological Society ${ }^{8}$ Cottingham, John, Ed., (1996). Descartes: Meditations on First Philosophy: With Selections from the Objections and Replies. Cambridge University Press
} 
perception there is a perceiver. The basic predicate of the evil daemon hypothetical is that, in some way, the cognitive faculties of an individual are flawed so that what may appear within our perceptions as clear and distinct and, therefore, eliciting a sense of assent and affirmation should, in fact, be held in doubt. For this epistemic pessimism to be the case, it requires a deceiver and a deceived according to Descartes. Descartes claims that the deceived is the self, while the evil daemon is the deceiver. These conclusions follow a reductionist form. One of the problems with this type of argument is deciding when the simplest form has been identified. It is possible to make a case that the daemon is imagining a world just like ours together with the types of thoughts which would belong to the individuals in such a world. In this case Descartes' scenario could be an accurate account but rather than the daemon and the self being the existing perceivers only the daemon is the perceiver; that is, the daemon is the only thinking being.

The Cogito

Descartes makes the statement Cogito Ergo Sum-I think, therefore I am. The statement is simple in structure, but this belies a complex meaning. The first consideration is to question whether the 'I' referred to is more than or equivalent to the thought. Descartes reasons that if there is thought there is a thinker whatever the thinker may be. Discussion of the thinker whom Descartes calls 'the self' gives the impression of a more substantial thing than just thought. Descartes describes several different types of thought from wills to desires, imagination, sensory perceptions and doubt. What is clear is that once each of these thoughts is elucidated as was done with sensory perception, doubt can be found within each. However, Descartes makes a distinction between the content of the thought and the action of the thought; the former being doubtful, the latter not. Descartes feels that thought, as in the action of thought, is certain and beyond doubt. He reaches this conclusion by reasoning that if a deceiver had deceived all the thoughts including the thought that there was thought, it still requires a thinker.

Let us now consider Descartes' self and whether this self is thought alone (as it would seem it should be from his writings) or whether it is more than that. Three questions will be asked of this self: what is the self; where, as in where can the self be located/isolated (thus what is the substance which comprises the self); and, why is thought the basis of the self? The what is simple - the self is thought. While the content is questionable, its existence is not. The where has a dualistic response, specifically, that thought is non-physical. This is known by the fact that all apparent physical features require sensory input thus that content and process of accumulation is doubtful. Descartes' self seems to originate from within the body despite the body being in doubt. This suggests 
that it would be worthwhile using the three question series to assess the mind. However, before discussion turns to the mind let us consider the final question of why. Thought is Descartes' starting point because it is certain. However, it is also likely that thought is the starting point because it is necessary that something be Descartes or that Descartes be something.

The characteristics which Descartes attributes to the self such as thought and emotions are characteristics often attributed to descriptions of the mind. His religious background imbues the self with a sense of the soul. For Descartes it would seem that the term 'soul' used in a religious sense is related to the person but has a fluidity that makes it different from the body, while the term 'mind' gives the impression that it is linked more closely to the body than the soul. Over the course of Descartes' Meditations his idea of the self seems to move from being analogous with the soul to being analogous with the mind. He sees the mind as an overlay of the brain; a non-physical overlay such as a cloud hovering above the brain. While the mind and the soul are certainly linked for Descartes, it is important that the self is not taken to be the same as the soul or mind.

\section{The Contribution of Descartes' Self to a discussion of the Self}

Descartes' Meditations on First Philosophy (1996) highlight the importance of thought. The advent of self-aware thought is considered to be related to the beginning of consciousness. Society's successful functioning as well as an individual's survival relies on the ability of people to have thought. Descartes emphasises the value of reasoning and how the examination of our internal being can shed light on what it is that makes us who we are. This reasoning led him to an examination of the self and an understanding of what the self may consist of; specifically the types of thought such as desires, will, judgements, imagination and sensory perceptions. Descartes also shows just how tenuous our link is to certainty. Although the content of our thoughts can be misleading this does not mean that discoveries cannot be made. In later chapters discussion will arise again on the mistake of misnaming who the thinking being is. Descartes identifies the thinking being as the self. That is, the deceived being is the self. However, he offers no account for a possible scenario whereby the thoughts are that of a evil daemon where the daemon is imagining a self and the thoughts of the self - this is an issue. This chapter will be used as a guideline for the discussion as it continues in later chapters as well as when considering a critical assessment of the self at the end of Part One. The inquiry into Descartes' self shows us two things: firstly, that thought is an integral part of understanding the self and secondly, that this process may require us to consider difficult ideas which may lead us in unexpected directions. 
D.M. Armstrong presents an account of the mind-body problem in which rather than presenting a non-physical and physical combination as an explanation, he relies on a description which sits comfortably beside scientific theories about the physical. This approach is called Central State Materialism. Armstrong disagrees with the commonsense approach of assuming that because behaviours which give the impression of the self are distinct and sophisticated they are special and thus will have a special cause; a cause different from that of other simpler behaviours. ${ }^{9}$

Armstrong considers the scientific approach to be the most valuable method by which information can be validated and disputes settled. Through the process of empirical evaluation consensus of thought can be established due to the collection of evidence. However, when using consensus as an indicator there are two considerations that must be factored in: the first is that intellectual consensus does not remove the fallible nature of the ideas. Rather, it acts as a good authority. The second is that the collection of consensus is not necessarily indicative of truth.

Armstrong, like Descartes, uses the Conceivability Thesis to create a base by which he examines the nature of the mind. His conception of the mind is the same as the self. One could extrapolate that the 'Self' would be the name given to the mind by people who abide by Descartes' intuitive approach to the mind-body problem. Armstrong, who does not want to use intuition to decipher knowledge, uses the term 'Mind'. He calls for theorists to conceive the possibility that a mind is possible in a world which is wholly physicochemical in nature. He disregards other approaches on the grounds that the attacks on such theories indicate that the conceivability of such a resolution of the mind-body problem is without full conceptualisation and therefore cannot make the move to possibility.

\section{Armstrong's Synthesis Expanded}

The evolution of the mind-body problem by which thought is a pivotal key is as follows.

Process: The Thesis: the mind is an inner arena (Descartes' Dualism) $\rightarrow$ The Antithesis: the mind is outward behaviour (Ryle's Behaviourism ${ }^{10}$ ) $\rightarrow$ The Synthesis: the mind is the inner principle defined by outward behaviours (Armstrong's Central State Materialism). ${ }^{11}$

\footnotetext{
${ }^{9}$ Armstrong, D. M., (1981). Minds, Bodies, and Persons. The Nature of Mind and Other Essays. Cornell University Press, pp 295-302

${ }^{10}$ Ryle, G., (1949). The Concept of Mind. Barnes \& Noble Inc, New York

${ }^{11}$ Ibid
} 
Accordingly, the mind, when thought about carefully, can be understood to be an inner principle to which we are led through an examination of outward behaviours. Note that careful thought can lead to other conclusions such as those made by Descartes. Mental states, according to Armstrong, are the internal expression of our perceptions which are physical states; that is, they are physical states of the central nervous system. Given the position that dispositions are states of objects, the mind is then an inner cause of a range of behaviours, thus a necessary part of the physical causes which make up an action. For Armstrong, it is important that dispositions are actual states thus they can have actual power to influence physical behaviours. ${ }^{12}$

With dispositions as actual states (although it is not yet known what are the intrinsic nature of these states), Armstrong feels it is clear that dispositions are actual causes, thus causal factors - factors which, given the correct conditions, bring about the manifestation of the disposition itself or the behaviour. Therefore the mind or self is a cause, an inner principle by which actions are produced and behaviour is expressed. This conclusion is relevantly similar to that held by Dennett ${ }^{13}$ discussed in Chapter Four. Within this approach consciousness is simply the perception of our own state of mind. ${ }^{14}$ Armstrong's approach fits in with Searle's position that mental phenomena make up lower neural processes and that consciousness is part of high cognitive processes. ${ }^{15}$ For Armstrong, consciousness, the result of dispositional states, is the behaviour of a scanning mechanism of the central nervous system's other expressions or behaviours. The self or mind is the inner cause of that range of behaviours.

\section{E.J. Lowe's Non Cartesian Substance Dualism}

E. J. Lowe presents a thesis in accordance with Descartes' view as far as both the person or self and the organic body are substances. ${ }^{16}$ Where he deviates from Descartes' thesis is in the interaction between the self and the body not being one of free interaction, nor is it one where the two substances are capable of independent existence. For Lowe, the person or self and the physical body are distinct substances. A substance being something which maintains its existence across time and which bears distinct properties. The Lowean

\footnotetext{
${ }^{12}$ Ibid

${ }^{13}$ Dennett, D. C., (2005). Sweet Dreams, Philosophical Obstacles to a Science of Consciousness. The MIT Press, Cambridge

${ }^{14}$ Armstrong, D. M., (1981). Minds, Bodies, and Persons: The Nature of Mind and Other Essays. Cornell University Press, pp 295-302

${ }^{15}$ Searle, J. R.. Why I Am Not A Property Dualist.

http://faculty.wcas.northwestern.edu/ paller/dialogue/propertydualism.pdf, pp 1-6, accessed 10th June 2013

${ }^{16}$ Lowe, E. J., (2006) Non-Cartesian Substance Dualism and the Problem of Mental Causation', Erkenntnis, Springer, DOI: 10.1007/s 10670-006-9012-3, pp. 5-23
} 
self cannot exist independently of the body; rather, it is part of its body. The body is the physical aspect by which the self can be described but none the less it is a distinct substance in its own right. ${ }^{17}$ This is an important distinction between Lowe and Descartes because the type of relationship suggested by Lowe eliminates the Cartesian tendency to lead the thinker to fallible beliefs on the nature of the interaction between the self and the physical.

Physicalism cannot explain the unique teleological and intentional nature that one finds in the self. While this approach tries to adequately account for the distinction of the self it must walk a path between Reductionism and Eliminativism. ${ }^{18}$ The Lowean self has a physical property, that is, it has its body. Lowe identifies the physical aspect of the self and the autonomous nature of mental causation. ${ }^{19}$ It is in this identification that he feels his approach is stronger than Descartes' version of the self or the Physicalist approaches such as Armstrong. Lowes' strength is in the position that the self is not a purely mental substance.

\section{John R. Searle - The Soul and the Flesh}

Searle's position is that of biological naturalism: the thesis that mental phenomena are caused by lower neural processes and that these processes are, in turn, realised in the brain's higher level functions such as those of consciousness and intuition. This is frequently mistaken for property dualism. Theories on the mind-body problem according to Searle often make the mistake that the self and body are distinct due to language which alludes to a difference (a problem discussed in Chapter Four in connection with Anscombe's views) and conceptual confusion coupled with intellectual ignorance of the brain.

There are two central theses in Searle's philosophy: that the material world is public and the conscious world is private. The material or physical world can be known objectively and measured, while the internal world of our consciousness is private and subjective. It is using the measure of personal subjective conviction that we know of the self. Through the objective and the subjective, consciousness and matter are known to be

\footnotetext{
${ }^{17}$ Robinson, H., (Winter 2012 Edition). Dualism. The Stanford Encyclopaedia of Philosophy, Edward N. Zalta(ed.), URL = http://plato.stanford.edu/archives/win2012/entries/dualism/, accessed the 11 June 2013

${ }^{18}$ Lowe, E. J., (October 1993). Mind. The Causal Autonomy of the Mental. Vol. 102, 408, Oxford University Press

${ }^{19}$ Robinson, H., (Winter 2012 Edition). Dualism. The Stanford Encyclopaedia of Philosophy. Edward N. Zalta(ed.), URL = http://plato.stanford.edu/archives/win2012/entries/dualism/, accessed on the 11 June 2013
} 
different and distinct phenomena, because they are not reducible to any lesser form. ${ }^{20}$ Searle presents this reasoning with respect to the relative reducibility of consciousness and matter. First, if consciousness can be reduced into physical descriptions then it would be Materialism. Likewise, if the physical world could be reduced to a description of consciousness then Idealism would be realised. Searle states that Materialism and Idealism are false. Therefore Dualism must be true. ${ }^{21}$

Searle considers the problem of Dualism (how the self and the body interact) through a consideration of causality. In doing so two types of causal explanations are identified. An explanation of a raised hand could come in the form of a neural and muscular description or in the form of desires and beliefs. The result of having more than one legitimate cause for any given action is causal over-determination. ${ }^{22}$ It is ill-advised to consider using one's subjective perception and the objective state of the external world that only two foundational categories of metaphysics exist: that of consciousness and matter. A conclusion drawn from the case of the raised hand is that any individual can choose to describe an action by any number of interpretations, therefore, to conclude that there are only two is an injudicious step. ${ }^{23}$ This illustrates the influence of the Conceivability Thesis in Searle's thinking; that is, this conclusion arises from the acknowledgement that any number of interpretations are conceivable thus any number are possible. Searle suggests a reconsideration of what it is to be reducible. He suggests that consciousness could be reduced causally to the imprint it leaves on the physical brain; that the mental phenomena which constitute consciousness can only be measured by their imprint - the causal activation of lower neural processes. Thus the definition of the mental phenomena should be described by their action, for what is an object if not its effect on the world, its persistence across time and it properties as seen by its action and interaction with its environment?

\section{The Conceivability Thesis Conclusion}

The purpose of this chapter is to begin to indicate some of the range of possible approaches to the question of the self and its position within the world. The Conceivability Thesis describes a principle by which conceivability results in possibility. This type of thesis can tend towards the flaw of in absurdum. To ensure against this the facts must be

\footnotetext{
${ }^{20}$ Searle, J. R. Why I Am Not A Property Dualist. http://faculty.wcas.northwestern.edu/ paller/dialogue/propertydualism.pdf, pp 1-6, accessed on the 10 June 2013

${ }^{21}$ Ibid

${ }^{22}$ Ibid

${ }^{23}$ Ibid
} 
strictly adhered to and steps forward taken only in the presence of conviction, for as Armstrong explains, conviction is a good authority despite it fallibility. 


\section{Chapter Two}

\section{The Equilibrium Thesis}

The Equilibrium Thesis offers a yin and yang approach to the self. According to this view, the self is the product of the unique intermingling of phenomenological and abstract impressions. Phenomenological impressions occur through our interaction with the world and the world with us. These impressions come to us through our physical senses while abstract impressions arise from the internal workings of our brains. It is the very particular relationship between the two which gives rise to the self. The self is the ultimate expression of the merging between the external world and the internal world of humans. We are led to this view by the examination of the causes behind behaviour. Avicenna, the central figure in this approach, explains that behaviours can be accounted for through either phenomenological or abstract faculties. Abstract faculties belong to the internal part of the person while the phenomenological belongs to the external. Avicenna argues that a balance between the internal and external influences of the person combine to make the contributions of the self or soul. Other major contributing proponents of this Equilibrium view include David Hume and Thomas Aquinas.

\section{The Debate Begins with a Dalliance with Dualism}

The Floating Man Thought Experiment illustrates the parallels between the views of Descartes and Avicenna. Avicenna posits this hypothetical:

1. A perfect man is suspended in space.

2. This man is unable to use any of his sensory faculties.

Philosophers have drawn distinct conclusions from this hypothetical. Some have concluded that (i) the floating man experiences nothing. Others have concluded to the contrary that (ii) the floating man experiences something

The third part of this thought experiment is the nexus from which many arguments arise. Only one of these arguments will be examined in this piece but some others will be mentioned.

Physicalists endorse Conclusion (i): that the man experiences nothing without his senses. They believe that true sensory deprivation would mean that even internal sensations such as a stomach gurgling would not be felt. A Dualist may argue that despite the lack of sensory input the floating man will still experience some sort of internal dialogue. This approach is based on the belief that a non-physical thing, quite unrelated to 
the outside world other than through the body, interacts with the body. Debates have raged over the nature of these non-physical objects but for Avicenna the non-physical aspect of the body is the soul. ${ }^{24}$

There are two possible responses to Avicenna's belief in the body and a soul which arise as a result of his support for Conclusion (ii). These responses are what constitute Avicenna's Floating Man Hypothesis. The first response is that the floating man does have experiences and that these experiences are evidence for the hypothesis that the soul is independent of the body. To clarify - the soul, while residing in the body because of the benefits it gains from the sensory faculties, is not part of the body. Rather, a mutually beneficial relationship forms between the body and the soul. The body benefits in that the soul allows the body to learn and respond in a considered manner to its environment, while the soul benefits by being able to become intellectus in habitu. ${ }^{25}$ The second response that arises from an affirmative answer is that some type of self-awareness is present within the body. For Avicenna, this self-awareness is the soul because it denotes what distinguishes a living body from a dead body. Incidentally, this means that according to Avicenna's philosophy as long as the floating man is alive, regardless of his environment, he must have a soul within. ${ }^{26}$

Avicenna's dualistic thesis means that he accepts these responses which result from the Floating Man Hypothesis. A new question arises: how do we know that the thinking or self-aware being is the self? The soul or self in Avicenna's philosophy is independent of the body within which it resides. However, it is possible to imagine at least one scenario where the knowing self is not the self to which Avicenna's theory alludes. Rather than Avicenna's soul being devoted to its individual body, it may in fact be a fragment of a greater soul, such as a daemon, who is imagining a set of interactions involving Avicenna. This daemon is playing out elaborate characters all of whom perceive themselves to be unique and individual when, in fact, they are part of a greater being. Avicenna, like Descartes, does not respond to this question of distinguishing precisely what the supposed soul is. Descartes suggests that even if a daemon were attempting to deceive him he still must exist to be deceived. ${ }^{27}$ An argument such as this is fundamentally a discussion of

\footnotetext{
${ }^{24}$ McGinis, J., (2010). Avicenna. Oxford Scholarship Online, http://www.oxfordscholarship.com.helicon.vuw.ac.nz, Chapter 4-5, accessed on the 10 June 2013

${ }^{25}$ Avicenna, F. Rahman. ed. (1952) Avicenna's Psychology. An English translation of Kitāb al-Najāt, Book II, Chapter VI, with Historico-Philosophical Notes and Textual Improvements on the Cairo edition. London: Oxford University Press, Geoffrey Cumberlege, Chapter VI, pp 35-37

${ }^{26}$ McGinis, J., (2010). Avicenna. Oxford Scholarship Online, http://www.oxfordscholarship.com.helicon.vuw.ac.nz, Chapter 4-5, accessed on the 10 June 2013 ${ }^{27}$ Cottingham, J., Ed., (1996). Descartes: Meditations on First Philosophy: With Selections from the Objections and Replies. Cambridge University Press
} 
whether what we perceive through internal examination or external evidence is sufficient to make a conclusive statement. In the fourth section of Part One of this dissertation this problem will be examined.

Avicenna and Descartes have several similarities and differences in their theories regarding the self. Avicenna approaches the discussion through the natural sciences with a focus on how the soul could explain more fully the condition of humanity. Descartes comes from an epistemological perspective. Both philosophers remove the confusing information and attempt to isolate the self. Avicenna seeks to find the simplest explanation for what he knows of the physical world. Descartes removes all things that contain doubt and settles on what is left. Avicenna searches for a simple clear explanation, while Descartes searches for an idea which is reliable and can act as the foundation for his philosophy. A further difference between the two philosophers is that for Descartes the importance of the self is intimately linked with the question of God while despite Avicenna's education and upbringing his focus is on physiological clarity.

Avicenna brings at least two important points to the examination of the self. His discussion of the relationship between the body and the soul demonstrates the level to which the two topics of physiology and the self or soul are linked. For Avicenna, they are inextricable despite being independent in theory. Secondly, his theory raises the same problem found in Descartes: whether the knowing subject is the self or the soul. Although neither philosopher untangles this issue they both make the same assumption that the thinking subject is the self. It is an important issue to keep in mind as this dissertation questions this presupposition as it tries to establish an adequate definition of self.

\section{Avicenna's Shape of the Soul}

Avicenna's theories, like Descartes', follow a reductionist method in isolating the presence of the self. For Avicenna the terms 'self' and 'soul' can be used interchangeably. This is possibly due to the quality of translation from the original Arabic to English. For instance, the term 'nafs' at the time of Avicenna's writing meant soul, the self or person. ${ }^{28}$ A similar term 'ruh' meant divine quality. These are religious terms found in both Islamic and Christian teachings. ${ }^{29}$ Avicenna is not using the term 'soul' for its potentially metaphysical meaning; rather he is using it to distinguish between states: a body without life compared to one with life. ${ }^{30}$ Although Descartes uses the term 'self' as opposed to the

\footnotetext{
${ }^{28}$ http://www.muslimphilosophy.com/ei2/nafs.htm: NAFS - from the Encyclopaedia of Islam (1999) Koninklijke Brill NV, Leiden, The Netherlands, accessed 14 October 2012 
term 'soul' there are certainly references in his Meditations to ideas commonly associated with the soul. While Descartes uses the term 'soul', it is only in conjunction with the meaning he uses for the term 'self.' For him the terms 'soul' and 'self' are synonyms which stress different aspects of the same idea.

Avicenna's soul (specifically the human soul) consists of an accumulation of the animal and the vegetable soul as well as several other faculties. He is not suggesting that the human has three souls; the vegetable, the animal and the human; rather, he is suggesting that all living things have a soul and that depending on the complexity of the living thing that soul will be relative to its body's complexity. (This is an older Platonic idea.) Avicenna states

"the soul is like single genus divisible in some way into three parts." 31

His approach to the soul involves the examination of simpler life forms and what are necessary for their existence. It is important to appreciate that the use of the term 'soul' is not necessarily referencing a conscious being. His expertise in natural science led Avicenna to take a physiological approach in understanding the soul, that is, slowly adding faculties as they became apparent in his examination of his three levels of soul: vegetable, animal and human. Avicenna sees the vegetable soul as a group of faculties which, when collected together, epitomise what it is to be a plant. By then adding the faculties of a plant to others found in animals, what it is to be an animal. In this way an animal soul is identified. Likewise, he takes the faculties of the animal and adds to them further faculties found in humans to identify a human soul. The idea of other physical items containing souls is similar to Galen Strawson's Panpsychism which will be discussed in the next chapter. Avicenna describes two major intellects in his human soul: the Practical Intellect and the Theoretical Intellect. These two intellects can be loosely described as a predominately physiological intellect and a predominantly abstract intellect. ${ }^{32}$

Avicenna's description of the soul involves the interaction between the physiological sense and the abstract abilities of the soul. The soul and body are entwined in that the soul affects the body and the body informs the soul. Perception provides the evidence for Avicenna's belief in the existence of the soul. Perception provides his first insight into the relationship between the physiological and the abstract which is his basis for the soul. Sight was described by many thinkers of his time as a projection of a ray onto

\footnotetext{
${ }^{31}$ Avicenna, F. Rahman. ed.(1952). Avicenna's Psychology. An English translation of 'Kitāb al-Najāt', Book II, Chapter VI, with Historico-Philosophical Notes and Textual Improvements on the Cairo edition. London: Oxford University Press, Geoffrey Cumberlege, Chapter I, p 25

${ }^{32}$ Ibid, Chapter VI, pp 35-37
} 
the outside world and then the retrieval of this ray with information. Avicenna hypothesized that rather than the eye projecting something, the eye absorbs information from its surroundings through the faculty of 'Representation'; specifically that the eye receives the form of the object rather than the matter of the object. The faculty of 'Imagination' reconciles the abstract nature of the form with its material counterpart. The 'Representative' faculty distinguishes between the direct physiological implications of the form and the more abstract implications. For instance, the form will tell the soul that the object is a lion while the abstract implications are that the lion is dangerous and not to be patted like its cousin, the domestic cat. It also informs the 'Appetitive' faculty of the soul. The Appetitive faculty governs the responses of the body to the object. This group of faculties is called 'Anterior' and when these are combined with the 'Posterior' the information of the form and the abstractions of it can be conserved and preserved. 'Perception' provides evidence for the soul in that it demonstrates what Avicenna thinks to be a clear example of the physical and non-physical interacting. The example of sight depicts the interaction between the physiological and abstract. From this Avicenna endorses the idea that it is the soul which controls this relationship. To perform as a mediator between the physiological and the abstract Avicenna anticipates that the soul must be non-physical.

Aristotle spoke of entelechy, the essence which brings a being into realisation and equates to Avicenna's 'Divine Spirit'. ${ }^{33}$ The Divine Spirit or 'Light' flows through the faculties to initiate the 'Intellect' and brings activation into an otherwise physiological construct. Avicenna focuses on the physiological when he gives accounts of the soul because he believes that the soul is responsible for the activity of the living body. ${ }^{34}$ The final act of unification between the abstract interpretations of the theoretical intellect and the matter of the practical intellect is made by the Divine Spirit. This final step illustrates why the soul can be existent without the body but that the body is necessary for the soul's expression. ${ }^{35}$ Before the soul is linked with the body it is pure quiddity ${ }^{36}$. ${ }^{37}$ The soul needs the body because it is through the body that the soul has its expression. A soul with no

\footnotetext{
${ }^{33}$ Ibid.

${ }^{34}$ McGinis, J., (2010). Avicenna. Oxford Scholarship Online, http://www.oxfordscholarship.com.helicon.vuw.ac.nz, Chapter 4-5, accessed on the 10 June 2013

${ }^{35}$ Avicenna, F. Rahman. ed. (1952) Avicenna's Psychology. An English translation of Kitāb al-Najāt, Book II, Chapter VI, with Historico-Philosophical Notes and Textual Improvements on the Cairo edition. London: Oxford University Press, Geoffrey Cumberlege, pp. 68-69.

36 "The real essence or nature of a thing: that which makes it the kind of thing that it is..." Blackburn, S., (2005). Oxford Dictionary of Philosophy. Oxford University Press,.p 304

${ }^{37}$ Avicenna, F. Rahman. ed. (1952) Avicenna's Psychology. An English translation of Kitāb al-Najāt, Book II, Chapter VI, with Historico-Philosophical Notes and Textual Improvements on the Cairo edition. London: Oxford University Press, Geoffrey Cumberlege, pp 57
} 
body has no way to make its presence known. The abstract aspects of the soul have no way by which they can be exhibited without a way of affecting the physical world. So the soul acts like a bridge between the non-physical and the physical world. Avicenna advocates the tabula rasa theory. ${ }^{38}$ Tabula rasa is the idea that an individual is born with no innate ideas; they are a blank page. ${ }^{39}$ Within the structure of Avicenna's soul this occurs through the disconnection between the Practical Intellect and the Theoretical Intellect. There are three states or ways that the Theoretical Intellect can be elicited. The first is absolute potentiality or material intellect; the second, partial potentiality or relative potentiality; and, finally, perfect potentiality or intellectus in habitu. These states describe levels of mastery of learnable skills, not levels of capacity to have a soul. When the soul interacts with its Practical Intellect the Theoretical Intellect progresses from absolute potentiality. Before it receives information from the Practical Intellect, which in essence records and interprets the forms presented by the environment, the Theoretical Intellect is like a cup containing no liquid - an empty shell, an object which cannot fulfil its function, an empty slate (thus tabula rasa).

\section{Thomas Aquinas and the Equilibrium Thesis}

Thomas Aquinas uses the term 'soul' rather than 'self' to denote the essence of what it is to be human. He, like Avicenna, discusses three aspects of the soul and it is the third and final aspect which is considered to be the soul in its fullest sense. It is this advanced version of the soul which Aquinas considers interchangeable with the self as discussed in other parts of this dissertation. Aquinas advocates two theses about the human animal. ${ }^{40}$ Firstly, he says that it has substance - a physical presence in the world. Secondly, he claims that once its substance has passed it has something which remains, a subsistent. For Aquinas the soul or self is subsistent to the human body; when parted from the body, it is not whole and therefore cannot be considered to be substance independent of the body. The body provides an interface by which the soul can express itself.

The Intellect for Aquinas, as for Avicenna, is vital to the understanding of the soul and the human. When considering human behaviour, Aquinas suggests that the Intellect acts knowingly and willingly to examine its sensory impressions. Due to the incomplete nature of our sensory impressions, the Intellect acts as a processor of this information. The

\footnotetext{
${ }^{38}$ Baker, D. B. (Ed), (2012). The Oxford Handbook of the History of Psychology: Global Perspectives. Oxford University Press, Chapter 21, p 443

${ }^{39}$ Locke, J., (1996). An Essay Concerning Human Understanding. Kenneth P. Winkler (ed.), Hackett Publishing Company, Indianapolis, IN

${ }^{40}$ McInerny, R. and O'Callaghan, J., (Winter 2010 Edition). Saint Thomas Aquinas. The Stanford Encyclopedia of Philosophy. Edward N. Zalta (ed.), URL = <http://plato.stanford.edu/archives/win2010/entries/aquinas/>., accessed on the 10 June 2013
} 
pattern of this assessment is a series of interacting arguments which lead to the position the individual will act on in response to the sensory input. This interchange is that which Aquinas considers unique to the human animal and he describes it as 'Rationality'. ${ }^{41}$

Aquinas is in agreement with Avicenna and his emphasis on the Intellect; specifically he maintains that the 'Human Intellect' is rational. He also supports the concept that humans have accumulated all three expressions of the soul, although he names them slightly differently: the vegetative soul, the sensitive soul and the rational intellect soul. The Vegetative aspect of the soul interacts specifically with the physical body. The Sensitive aspect causes action within the physical body by the interpretations of the sense impressions. It allows the being to not only exist but to act wilfully within its existence and perceive its existence. For Aquinas the highest aspect of the soul is the 'Rational Intellect'. He describes it as the ability to go beyond collection and retention of data to reason. It is not reliant on any physical organ; rather it is the engagement of higher order cognitive function. ${ }^{42}$

According to the Equilibrium Thesis it is the intermingling of the phenomenological impressions with the higher order abstract impressions which leads to the expression of the soul. Aquinas' lower aspects of the soul, the Sensitive and the Vegetative, deal directly with responding to the physical needs of the beings they are found in. The Rational Intellect, on the other hand, deals with what the Equilibrium Thesis calls the abstract impressions. It is the combined presence of each of these three aspects which contribute to the existence of the self. While it is possible for the soul or self to exist without the body it would have no form with which to interact with the world. Therefore, it is through its relationship with the physical body that the self has expression. ${ }^{43}$

\section{A Brief 'Humean' Approach to the Equilibrium Thesis}

David Hume's works describe a self which acts as a reference point for multiple impressions and ideas as opposed to just one idea or impression. In his discussions on knowledge he elucidates the nature of knowledge and the types of impressions which lead to ideas. For him impressions come in two forms: sensations and reflections. ${ }^{44}$

\footnotetext{
${ }^{41} \mathrm{Ibid}$

${ }^{42}$ Reflections on the Soul. Avicennian Psychology of the Soul and its Relation to Similar Discourses from AlFarabi, St Thomas Aquinas and Aristotle. http://arabicphilosophyjkh.wordpress.com/category/st-thomasaquinas-and-the-nature-of-the-soul/, accessed on the 5 June 2013

${ }^{43}$ McInerny, R. and O'Callaghan, J., (Winter 2010 Edition). Saint Thomas Aquinas. The Stanford Encyclopedia of Philosophy. Edward N. Zalta (ed.), URL = <http://plato.stanford.edu/archives/win2010/entries/aquinas/>., accessed on the 10 June 2013

${ }^{44}$ Schwerin, A., (2007). Hume and the Self: A Critical Response. Monmouth University, Volume 5, Page 15-30
} 
Sensations are those experiences which come to us through our senses. Sensory information is akin to Avicenna's and Aquinas' external sensations or phenomenological impressions. It is the data which is received from the world around us. Reflections are the product of our minds or brains; they are the consideration of our internal world. Together, reflections and sensations constitute the impressions which, in turn, are the source of our ideas. $^{45}$

Our ideas and perceptions lead us to the self. According to Hume, our perceptions are not infinitely divisible. The parts or perceptions are all there is. There is no greater whole. It cannot be broken down into smaller and smaller parts. Rather, there is a finite expression of each perception. ${ }^{46}$ Hume explains that, like a chain, perceptions cannot be broken down in order to isolate the self. This being the case, he extends his explanation to say that the self is its parts or perceptions. He claims that we cannot directly experience ourselves; rather we can only experience that which we are experiencing in any given moment. $^{47}$

\section{The Bipartite Conclusion}

The essence of the Equilibrium approach is that it is the relationship between the impressions of the external world and the internal world which gives rise to what is known as the self. The self epitomises the interchange between the impressions resulting from the perceptions of our sensory input and our internal reflections. Phenomenological or sensory impressions together with abstract reflections provide the parts of the puzzle which expresses the self. The self cannot be found within individual parts nor in what remains once the parts are taken away. Rather, the self is its parts.

\footnotetext{
${ }^{45}$ Ibid

${ }^{46}$ Hume, D., (2000). A Treatise of Human Nature, Oxford University Press

${ }^{47}$ Ibid
} 


\section{Chapter Three}

\section{Panpsychism and the Multiple Selves Doctrine}

\section{Panpsychism}

Panpsychists hold the position that if it is possible for a body to have a mental life then it is possible that other types of matter may also have a mental life and, if that is the case, then perhaps not just some matter but possibly all matter have mental lives. While Panpsychism is not a formal theory of the mind it still has distinct parameters. Thomas Nagel proposes that it has four premises: that dualism, reductionism, elminativism, and emergence are not true. ${ }^{48}$ Dualism has a variety of expressions, some of which have been discussed in Chapter One. Reductionism is the theory that all things can be reduced to a simple form. In the case of theories of mind, reductionism holds that all features of the mind or self, such as consciousness, can be reduced to physical phenomena. Eliminativism, with respect to mind theory, holds that the psychological descriptions of the self, such as narrativity theories ${ }^{49}$ will be replaced as more is understood of the physical world. Emergence is the theory that the self is the product of social immersion: it is social interactions that result in the product or appearance of the self. None of these four theories provides a description of how the self may be expressed within the world. Panpsychism offers an account whereby things in the world are best described by a complex system which allows for both physical descriptions of the person as well as mental aspects - the self. ${ }^{50}$ The mind or the self is a form of universal concept. Panpsychism also holds that not only do complex systems comprise a combination of both mental and physical attributes but that the mental aspect has a unifying capacity which provides a singular coherence or illusion. $^{51}$

\section{Galen Strawson's Approach to the Self-its Assumptions and Perspectives}

Strawson is a panpsychist who endorses a view of the self whereby multiple descriptions or types of selves are possible and each type has the potential to evolve and deepen. Throughout many of his articles on the Narrativity Thesis Strawson gives an impassioned rejection of the idea that the psychological Narrativity Thesis is the only description of the self and the only path to living the 'good life'. Strawson's work relies on

\footnotetext{
${ }^{48}$ Nagel, T. (1979). Panpsychism. In Mortal Questions. Cambridge: Cambridge University Press, pp 181-95

${ }^{49}$ The Narrativity Theses essentially claim that each person has a narrative or story account of who they are, this story is their description of their self.

${ }^{50}$ Skrbina, D. (2007). Panpsychism, http://www.iep.utm.edu/panpsych/, accessed on the 17 June 2013

${ }^{51}$ Ibid
} 
a group of assumptions the acknowledgement of which allows for a smooth transition into his more detailed position on the self. Due to his beliefs concerning the self being in tension with those beliefs held by the wider community, he spends more time describing his theory than examining it in a wider context. The first of his assumptions is that there is a self. This assumption is based on his endorsement of panpsychism which is the claim that physical reality consists of an object's apparent physical properties together with its instantiated phenomenal properties. ${ }^{52}$ What this means is that in order for a nonphysical feature such as consciousness to exist it must be a property of an object or substance. In the case of the self it is consciousness which is the property that Strawson attributes to all physical or natural things. Panpsychism states that there is something that it is like to be any physical object or substance. The unity of such objects as those that comprise a human being result in consciousness which in turn is the expression of the self. Panpsychism can lead to hylozoism: the belief that all matter has life; ${ }^{53}$ although Strawson does not appear to pursue this.

The second assumption or judgement on which Strawson's theories rely is the distinction between two views. ${ }^{54}$ The first view is that discussion of the human being as a whole is different from discussion of a view where the individual is the self. This distinction is clearer when considered in conjunction with the panpsychist perspective. The human being as a whole includes both physical properties and consciousness; while the self is the consciousness alone. It is the ultimate expression of the person rather than the being. These distinctions become important during the discussion of diachronic versus episodic people and narrative versus non-narrative people later in this chapter.

The Temporal Temperament ${ }^{55}$

The Psychological Narrativity Thesis ${ }^{56}$ establishes a narrative view of the self. The self is our individual narrative which is constructed by our autobiographical memories. According to this view, the self is the chief character in the autobiographical narrative. A person perceives who they are as a continuous stream; each event intimately and necessarily linked with other events although not necessarily in the chronological sequence of their advent. The Psychological Narrative Thesis is frequently accompanied by the an ethical theses whereby not only is the Psychological Narrative Thesis how people

\footnotetext{
52 Goff, P., (2009). Why Panpsychism doesn't Help Us Explain Consciousness. Blackwell Publishing Ltd., Oxford, pp 1-23

${ }^{53}$ Blackburn, S. (2005) Oxford Dictionary of Philosophy. Oxford University Press, p 174

${ }^{54}$ Strawson, G., (2010). Narrativity and non-Narrativity. John Wiley \& Sons, Ltd., pp 775-780

${ }^{55}$ Ibid

${ }^{56}$ Strawson, G., (2005). The Self?. Blackwell Publishing, Chapter 4. Against Narrativity. pp 63-86
} 
experience the world but it is the right or proper way to experience the world. ${ }^{57}$ Strawson's alternative proposal widens the description of the self. He breaks down what it is to be narrative and explains that there are two processes at work. The first is that a "narrative person' is diachronic, that is, his/her sense of self persists across time. The adult self is the same self as in the five year old girl, and will be the same self in the older woman to come. Each experience only adds and expands the understanding and knowledge that that person has of his/her self. The second aspect of narrative persons is that they are narrative in their diachronicity; the way they describe their persistent self is through narrative. It is not necessary that a person who is diachronic in nature must be narrative. However, this is often the case, according to Strawson.

After considering the Psychological Narrativity Thesis, Strawson expands his own concept of the self to include two spectrums of temporal temperament. His theory establishes a self that can be defined by the presence or absence of a series of descriptive categories. These categories are: non-diachronic/episodic or diachronic; and narrative or non-narrative. When defining the categories of 'Diachronic' and 'Episodic' the definitions prescribe the second view, that is, that of a person considering who they are as the 'self'. The diachronic person's perception of his/her self is persistent through time, while an episodic person sees his/her self as in the current moment. The current moment self does not consider itself to be the same self as that present in the person's past or that will be present in the person's future. Rather each self in any given moment is completely different while being of the same individual. The episodic person considers the self in direct relation to his/her current circumstances. Included in this will be any experience that informs that circumstance for him/her. The psychologist Erik $\mathrm{H}$ Erikson described a person's development like this:

"we do not consider all development a series of crises. We claim only that psycho-social development proceeds by critical steps. 'Critical' being a characteristic of turning points, of moments of decision between progress and regression, integration and retardation." 58

This description holds true for both the episodic and the diachronic person although the description is closer to a diachronic view. These features of selfhood can arise in any combination enabling the inclusion of many possible types of self. Strawson offers an unusual alternative to the current literature which is dominated by the Narrativity Thesis.

\section{Multiple Selves Doctrine}

\footnotetext{
57 Ibid

${ }^{58}$ Erikson, E., (1965). Childhood and Society. Harmondworth, UK: Penguin Books, p 262
} 
The episodic nature can be described as having multiple selves. This idea results from the notion that the self of the immediate present is different from the self of the past and will be different from that of the future. Given the number of moments which make up a person's life this leads to the idea that the person as a whole is made up of multiple selves. This clearly illustrates the difference between the two views. The idea that a person is a collective of selves was voiced briefly in the chapter on the Conceivability Thesis. Descartes' position that thought implies a thinker was not justified by the claim that all thoughts share a common thinker. Rather, it could be possible that the 'he' to whom Descartes refers is the human being taken as a whole while the thinker, in congress with the thought, could be a reference to the self. Thus the human being as a whole is comprised of bundles of selves or 'I's. Psychology discusses the notion of multiple selves in different ways: some as discussed in previous chapters and others found in developmental psychology where selves can be discussed as 'trying on outfits'. ${ }^{59}$ A diachronic theory, by contrast, does not lend itself to the ideas of a multiple self.

Strawson suggests that a definition or explanation for the self can be garnered by an inclusive description. He states that the view of the Psychology Narrative Thesis is limiting and exclusive in nature. If the Ethical Narrativity Thesis and the Psychological Narrativity Thesis are to be taken as true then a potentially destructive outlook is introduced into the therapeutic environment. The passion with which Strawson pursues the broadening of 'self' definitions to include the episodic is the result of his own experience. He uses his own personal account of his internal reflections to illustrate the episodic perspective.

"I need to say more about the Episodic life, and since I find myself to be relatively Episodic, I'll use myself as an example. I have a past, like any human being, and I know perfectly well that I have a past. I have a respectable amount of factual knowledge about it, and I also remember some of my past experiences 'from the inside', as philosophers say. And yet I have absolutely no sense of my life as a narrative with form, or indeed as a narrative without form. Absolutely none. Nor do I have any great or special interest in my past. Nor do I have a great deal of concern for my future. That's one way to put it - to speak in terms of limited interest. Another way is to say that it seems clear to me, when I am experiencing or apprehending myself as a self, that the remoter past or future in question is not my past or future, although it is certainly the past or future of GS the human being. This is more dramatic, but I think it is equally correct, when I am figuring myself as a self. I have no significant sense that I - the I now

\footnotetext{
${ }^{59}$ Miller, Y., (April, 2007). A Phenomenological Exploration of Brief Art Therapy through Folding TwoDimensional Drawings Created by an Adult Population. http://idea.library.drexel.edu/bitstream/1860/2959/1/Miller.pdf, Thesis: Drexel University, pp 38, 41, accessed 14 June 2013
} 
considering this question - was there in the further past. And it seems clear to me that this is not a failure of feeling. It is, rather, a registration of a fact about what I am - about what the thing that is currently considering this problem is." 60

Strawson values and works towards the inclusion of all people when he describes the self because he understands the experience of exclusion from what is considered normal. While his motivations may be questionable his findings should be valued.

Strawson's work highlights several points. First, that theories of the self are often integrated with theories on ethics. This is because the self is considered vital to personhood and personhood is the key by which society is defined. People with unusual or abnormal personhoods are often rejected from the wider community. Therefore, careful consideration should be given to the ethical implications of any theory of the self. Secondly, that personal reflection alone cannot bring the full truth of the self to light because if it has multiple expressions, as Strawson suggests it does, then it is possible that the seeker is only one of the possible selves. The notion that there are multiple descriptions of the self is tenable given the variance between people. However, one can expect to find at least some unifying characteristics. Although not elaborated on, a third point regarding Strawson's self is that it is non-physical just as Avicenna's and Descartes' were before him. The Panpsychism position of Strawson introduces consciousness to the discussion. Consciousness is what provides sentience, but for some philosophers of self it does not necessarily provide personhood or self-consciousness. For Strawson, it is the specific combination of consciousness within the human being which results in the self. The final point which Strawson provides is the valuable distinction between the two views that one can have of one's self. The first is the consideration that one is the whole human being while the second is that the one is the internal mental entity or self.

\section{Derek Parfit}

Parfit offers a series of thought-experiments which illustrate some of the questions which arise regarding self and body unities. The focus of his work is the concept of 'person'; in this case, it is fair to use this word as equivalent to the word 'self'. Parfit offers an approach whereby the person or self and the body and brain are not independently existing entities. ${ }^{61}$ Recalling substance dualism, Parfit's view of the self is that it and the physical body are not two different substances but that the self and its body are the same substance.

\footnotetext{
${ }^{60}$ Strawson, G., (2005). The Self?. Blackwell Publishing, Chapter 4. Against Narrativity. pp 63-86

${ }^{61}$ Parfit on What Matters. The Phantom Self: A Case for Conceptual Reform. http://phantomself.org/parfiton-what-matters/, accessed on the 18 June 2013
} 
When Parfit considers the self it is in the light of the self over time; what it is to be a person who persists through time. Like Strawson, the self for Parfit is described most clearly through the internal contemplation of how it feels to the contemplator and this then is cross referenced with others' accounts of the self. Parfit then supplements this subjective information with thought-experiments which present different conundrums whereby he can posit possible outcomes which effect his perception of the person. Both Strawson and Parfit consider psychological literature in addition to their subjective examinations. Strawson discusses a type of self which does not perceive itself in a narrative form. He also describes another variant that does not consider itself to be persistent across time, in the sense that the same self does not persist. Parfit explains that personhood relies on psychological continuity and connectedness. ${ }^{62}$

\section{Psychological Continuity and Connectedness}

Parfit endorses Strawson's episodic self in that he agrees that a self is distinct and complete in a moment and that any preceding or future moments' self is not the same as that of the current moment; therefore for every person there are multiple selves. Parfit uses psychological continuity and connectedness to express the relationship between the selves. These two concepts provide the structure by which an individual's person is collected together. It provides the grouping of the self. Later the problem of 'time slices' will be discussed in more detail but for now it is sufficient to say that when the mind-body problem is reduced to its simplest form - multiple selves are realised. Consequently, a theory has to be offered to explain why the selves should be considered to be of the same person, for if they are completely independent selves inhabiting the same body (if at different times) then they cannot be held accountable for the actions of other selves. The problem of accountability is often discussed by philosophers looking at ethical issues associated with the self.

Parfit proposes that each individual will have selves which are related by psychological continuity and connectedness. The distinction between psychological continuity and psychological connectedness is proximity. Selves are psychologically connected when they share most of the same psychological states. Selves that are psychologically continuous share no psychological expression rather they are related through those other selves which are connected to them. If at some point across an individual's timeline two selves could be shown to share a common self thus are connected in their relationship, then the selves in question can be said to be continuous. A

\footnotetext{
${ }^{62}$ Parfit, D. (1984) Reasons and Persons. Part Three, Clarendon Press, Oxford
} 
psychological continuity holds if at some point the two selves shared a common link however distant. ${ }^{63}$ The individual's time line stretches behind and in front for every individual and it has an infinite number of moments and, therefore, selves past, current and potential/future. Those selves who frequent moments close together on the timeline will have almost identical psychological natures. Their difference is what makes them independent selves but their similarities are what connects them. With respect to future selves, Parfit emphasises that despite the selves being different one must not discount the possibility of them one day having their psychological expression. He warns that a person must respect his/her future selves, preparing for and considering their potential and recognising that they may come into expression. This is based on the grounds that if it is ethically immoral to mistreat another person then so too must it be immoral to mistreat one's own future person. ${ }^{64}$ Past selves can be divided into a series of categories: recently past selves, past selves and ancestral selves. An ancestral self is not connected to the current self; it shares no psychological expression. Instead, the ancestral self is only continuous with the current self because it shares a relationship through a chain of connectedness. ${ }^{65}$

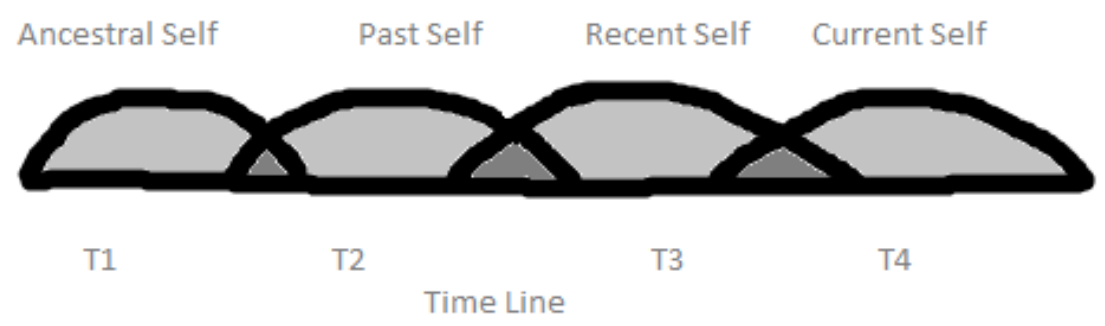

Parfit is essentially reductionist in his position on the self. He posits that the person is the same at two points in time if, and only if, the two points share the same psychological existence - memories and personality traits. It is not possible for selves of two moments to be the same in this sense because it takes only the smallest detail between the two moments to be different for the selves to experience different things and, therefore, differ in psychological essence. It is mental continuity and connectedness which unifies these states of a person into their full expression. Survival of the individual does not rely on whether someone is the same person but whether they share psychological continuity and connectedness with that person. ${ }^{66}$

\section{Time Slices -David Lewis}

\footnotetext{
${ }^{63}$ Personal Identity, mind.ucsd.edu, accessed on the 17 June 2013

${ }^{64}$ Parfit, D., (Jan 1971). Personal Identity. The Philosophical Review, Vol. 80, No. 1, pp 3-27 65 Ibid

${ }^{66}$ Parfit on What Matters, The Phantom Self: A Case for Conceptual Reform, http://phantomself.org/parfiton-what-matters/, accessed on the $18^{\text {th }}$ June 2013
} 
Strawson introduced the concept of multiple selves. Parfit argues that psychological continuity and connectedness are necessary for personshood. He explains that a person is not the same person from moment to moment but by using mental connectedness and continuity the nature of the person can be collected and described. Lewis provides an alternative picture of the way in which multiple selves can be unified into a single coherent being.

Lewis agrees with Parfit that psychological continuity and connectedness are vital for survival. ${ }^{67}$ However, he disagrees with Parfit's decision to disregard personal identity as necessary for survival of the self or person across time. Parfit believes that relational degrees are a necessary aspect of survival. Like Lewis, Parfit believes that in order for identity to be necessary part of survival it must have a 1:many relational interaction. However for Parfit identity has a 1:1 relational interaction while Lewis can define identity as having degrees of relation.

Mental continuity and connectedness allows for relational degrees. So long as a percentage of the same nature is shared between the selves they can be grouped together 1: many or many: 1 ratio. ${ }^{68}$ Lewis disagrees with this description of identity and theorises that together identity, mental continuity and connectedness are necessary for survival.

Lewis' description of the boundaries of a person is contained within lawful causal dependence ${ }^{69}$ that is, that each mental state is causally reliant on those preceding it for its psychological and physical nature. For Lewis, survival of an individual can be described in two ways. First case: the individual survives(that is, his/her mental life persists) if the future individual shares, in addition to recently gained psychological factors, the same psychological essence which makes the person distinct in that original moment. Second case: the individual survives if the same person survives - thus it is identity that matters. Lewis looks to unify these two forms of thought through a discussion of R-relational and Irelational approaches to time slices.

Mental continuity and connectedness comprise the relational nature between stages of persons or moments, time slices. Identity is the relationship between temporally extended continuant persons with stages at different times. ${ }^{70}$ When considering the Case One survivor of the current person with respect to mental continuity and connectedness, the question is whether the survivor is R-related to the current person; that is, whether the survivor shares any of the same psychological stages which are present in the current

\footnotetext{
${ }^{67}$ Lewis, D., (2003, online \& 1983, print). Survival and Identity. Philosophical Papers Volume 1. Oxford Scholarship Online, DOI: 10.1093/0195032047.003.0005, accessed on 17 June 2013

${ }^{68}$ Ibid

${ }^{69}$ Ibid

70 Ibid
} 
person. The Case Two current person survives if the survivor is I-relational to the current person: that is, that the survivor shares those person stages which comprised the current Case Two person. The survivor will also have those person stages which evolved to get to the surviving state. I-relational is not quite the 1:1 relationship that Parfit perceives Identity to have. Lewis feels that I-relational is the persistence of identity because enough of those traits which distinguish identity are present in I-relation.

For Lewis, a person is a maximal I-interrelated aggregate; that is, a person can only be all of its person stages - stages which are I-relational. To be I-relational is to be Rrelational, because no case, according to Lewis, of lawful causal dependence, lacks Irelation or R-relation. Therefore an individual is a person if, and only if, it is a maximal Rrelated aggregate of person stages. ${ }^{71}$

\section{Conclusion of Panpsychism and Multiple Selves Doctrines}

Panpsychism offers an informal theory of self which attempts to avoid the problems of Dualism, Reductionism, Eliminativism and Emergence theories in regards to self. Some self theories share the conclusions which Strawson draws using Panpsychism as his foundation. The focus of this chapter was primarily the mind-body problem of multiple selves, where other chapters have considered the problem of more than one type of substance existing in a person. Strawson, Parfit and Lewis require their readers to do an internal examination of themselves into how they perceive themselves and what aspects of themselves are necessary for their perceived existence or survival. It is these reflections when combined with the more formal theories of the self such as Reductionism for Parfit and Lewis and Panpsychism for Strawson that lead to a consideration of time slices and multiple selves. The question of multiple selves, like the two substance issue, has the potential to be a dissertation on its own. However, what can be taken from this brief look at the subject is that the self is not necessarily singular, despite its method of bringing unity to our perceptions. Unification is not the same as singularity. 


\section{The Locus Thesis of Self}

The basic claim of the Locus Thesis is that the self is an abstract idea which exists because it is a productive and informative way of providing an account for the individual. The self is neither physical nor non-physical; rather it is the illusionary product of a naturally narrative consciousness. It is a tool by which coherence can be brought to the onslaught of impressions from our world. Daniel Dennett is the central author and proponent of this approach with his work on the Convenient Lie. ${ }^{72}$ Other contributors to this thesis include John Locke, David Hume, Patricia Churchland, Paul Churchland and Elizabeth Anscombe. According to Dennett and the Locus Thesis, although the presence of self is a convenient and productive illusion, it can affect the world around it by being an abstractum, a fictional object. It plays a similar role in the person as the centre of gravity plays in the physical sciences. ${ }^{73}$ The final conclusion which Dennett presents is that the narrative nature of consciousness gives rise to the sense of self as an explanatory function to understand the world.

Geisteswissenschaft (Soul-Science)

Soul-sciences are philosophies and theories that arise from a number of different subjects such as psychology and history. They are theories that seek to account for human behaviour and nature with bases in the soul. Such theories can also be classified as Folk Psychology. Avicenna and Descartes can be said to ascribe to Soul-sciences as their philosophies use the soul as the underlying principle or explanation by which the most productive account can be given of human nature. Soul-sciences begin with the premise that the self is a most fruitful surmise from information gleaned from experiments which illustrate the nature of a person's perceptions. ${ }^{74}$ It is informative, productive and simple. People feel and believe with certainty that they have a self, for how else have they been thinking about and reading these sentences? There must be a self doing these things. Soulsciences explain that when thought is given to the faculty which is unique to that person, a self is evident - that is, when interpreting an individual's experiences and internal perceptions it is apparent that a self is present. Daniel Dennett argues that this approach is an illusion. He cautions theorists of the self and soul to look beyond what seems to be

\footnotetext{
72 Dennett, D. C., (2005). Sweet Dreams. Philosophical Obstacles to a Science of Consciousness. The MIT Press, Cambridge

${ }^{73}$ Encyclopædia Britannica Online. Centre of Gravity. http://www.britannica.com/EBchecked/topic/242556/centre-of-gravity, accessed 13 November 2012 ${ }^{74}$ Such perception experiments are discussed in detail later on.
} 
obvious. He argues that what appears to be certain in perception, internally and externally, is not to be trusted. The belief that perceptions are not to be trusted is shared by many philosophers. This is why Descartes uses doubt as a method of discernment. This type of methodology arises from the realisation that we and our senses can be deceived. It can be said of Avicenna that he falls into the trap of the Soul-sciences, that is, it seems apparent to him that the body has a soul because of the evidence provided from the senses.

\section{Connectionism - Motivating the Locus Thesis}

Connectionism developed as an explanation for human cognition. It can be loosely described as a theory which attempts to describe the brain and mind using mathematical models. Connectionists do not, however, describe the interfaces between neural processing units with any great clarity. Rather, there is a focus on the outcomes of these processes, that is, higher cognitive activities such as reasoning. Two Connectionists, Paul Churchland and Patricia Churchland, use connectionism to support the claim that

"thoughts are just points in hyper-dimensional neural state space and sequences of thoughts are trajectories through this space.,"75

The Churchlands hope to displace the Folk Psychological description of the brain, which says that the mind is homuncular in development. ${ }^{76}$ The idea of the mind as homuncular translates into the self governing of the brain.

The Locus Thesis, as Dennett expresses it, has the basis that the self, while fictional, provides a concept of a fixed point by which people can slowly develop a framework of interpretation. The Churchlands' description of thoughts within the mind gives the impression of randomness, if with apparent causality. Dennett combines the idea of a Connectionist brain with the concept of a tool by which mental impressions can be made distinct and coherent. He espouses this position because it provides a platform from which higher cognitive functions can arise and because he believes that this account offers a coherent explanation of our perceived impression of our experience of the world.

\section{Dennett - Connectionism Premise combined with the Self Tool}

Dennett's position, that the sense of self is given through perceptions, is simple. Memory and current perceptions provide what appears to be a clear biography of a self or a self narrative. Dennett's perspective of the self is diachronic in nature. ${ }^{77} \mathrm{~A}$ diachronic description looks at a topic and its progression over time. In the case of the self, Strawson's

\footnotetext{
${ }^{75}$ Waskan, J., (2010) Connectionism, http://www.iep.utm.edu/connect/\#H7, accessed 31 May 2013

${ }^{76}$ Ibid

${ }^{77}$ Strawson, G., (2005). The Self?. Blackwell Publishing, Chapter 4. Against Narrativity. pp 63-86
} 
diachronic self has the nature of being persistent across time. That is, the same self presides over the individual's entire life and that the self evolves and changes as additional experiences are added thereby deepening its definition. A synchronic description is similar to a diachronic description but should not be confused as equivalent. A synchronic description is made through an analysis of a topic at a single point of time. It does not examine its progression across time. The synchronic description is more closely related to Strawson's episodic self. The episodic self examines the self at one point in time and does not include a progressional development in its description; rather, just those features that are necessary to describe the self in that moment. Such features are not restricted to current issues and can originate from anywhere on the individual's timeline. The idea that Dennett's self is diachronic is not stating that Dennett perceives the self to arise through a diachronic development rather that Dennett's self tool appears to create a diachronic description of self.

Consider the following three cases of Daniel, a computer, and a zombie. Daniel, a man and a person, examines his experiences through internal reflection and interprets his experiences as those of a self. The computer, like a Turing Machine ${ }^{78}$, receives all the information from its immediate environment and its output is precisely what one would expect if the machine were a person. For instance, in its output it would refer to itself as a person and it would make the same types of observations expected of a person such as "I am hungry" or "The draught from the window is making me cold and therefore I would like it closed." These expressions are indistinguishable from those of a person although they are clearly coming from within a computer. So, the computer produces output which looks as if it comes from a person yet it has no understanding of the meanings of its output. The third case is that of a philosophical zombie. The zombie presents as identical to a person except that it lacks qualia. Qualia are those phenomena which distinguish an experience had by a complete person versus a zombie who, although it does not know what it is like to be a human, responds precisely as if it did know what it is like to be a person. So, the zombie provides the appearance of a self by its statements but has no knowledge of this self. These three characters all share a commonality: their output or their expressions of their experiences are identical. Thus what is available for interpretation is the same. The assumption which would follow is that each of the three has a self. Yet philosophers will debate whether the computer or the zombies do. Some will argue that while the zombie and the computer have no self, the person Daniel does. In fact it is his consciousness laced with qualia that distinguishes him from the other two. Dennett examines these three cases from

\footnotetext{
${ }^{78}$ Copeland, J., (1993). Artificial Intelligence: A Philosophical Introduction. Blackwell Publishing, p 135
} 
the perspective that they are each characters and it is the interpretation either of the observer or of the self that appears to provide the self.

He offers a solution in this way. He explains that the selves who appear to be present in the zombie and the computer are akin to fictional characters. On receiving information from the zombie and the computer, the receiver interprets the information by creating an illusion of characters to which the 'I' pertains. For Dennett, Daniel is identical to the zombie and the computer. The output from him gives the impression of a self to both the external receiver and to himself. Through reflection Daniel interprets a self and the receiver of the information also interprets a self. Both Daniel and the receiver create a fictional character of this self. Dennett maintains that the brain does not know that it is doing this because it is a narrative machine. The brain according to Dennett uses narratives to predict and glean information from the world around it. It examines itself using this same method thus producing a self. It is interesting that while Dennett does not believe in the self other than as a useful tool of interpretation, his description of it is diachronic. That is, Dennett's description of the nature of his self tool shares one of the forms of self anticipated by Strawson. ${ }^{79}$

\section{Consciousness in the Locus Thesis}

Initial thought regarding the soul (an antique phrase for the self according to Dennett $^{80}$ ) arose to provide an explanation for those distinguishing features which identify a person as unique. The soul accounted for a person's nature, mannerisms, morals and goals. Dennett explains that the self, can be used to provide an account for consciousness. This reasoning is Dualistic in nature. Avicenna ${ }^{81}$ and Descartes ${ }^{82}$ also accept methods which are dualist in nature. The Locus Thesis anticipates that, like the rest of the body, consciousness is a mechanism, possibly very complex but nevertheless one with mechanistic bases and quite clearly of the body. The behaviour exhibited by consciousness makes it appear to be non-physical when it is, in fact, a complex selection of physical functions.

When considering consciousness and the self, there is a useful approach to distinguish what is referenced as the self by the Locus Thesis versus other theories ${ }^{83}$ of the

\footnotetext{
${ }^{79}$ Chapter Three, Panpsychism and the Multiple Selves Doctrine

80 Dennett, D. C., (2005). Sweet Dreams. Philosophical Obstacles to a Science of Consciousness. The MIT Press, Cambridge

${ }^{81}$ McGinis, J., (2010). Avicenna. Oxford Scholarship Online, http://www.oxfordscholarship.com.helicon.vuw.ac.nz, Chapter 4-5, accessed on the 10 June 2013

82 Blackburn, S. (2005) Oxford Dictionary of Philosophy. Oxford University Press, p.105

${ }^{83}$ Cottingham, J., Ed., (1996). Descartes: Meditations on First Philosophy: With Selections from the Objections and Replies. Cambridge University Press
} 
self. Daniel Dennett uses an analogy of Magic to illustrate the distinction. Dennett uses this analogy written by Lee Siegel ${ }^{84}$ to demonstrate the difference between the hard problem and the simple problem:

“"'I'm writing a book on magic," I explain, and I'm asked, "Real magic?" By real magic people mean miracles, thaumaturgical acts, and supernatural powers. "No," I answer: "Conjuring tricks, not real magic." Real magic, in other words, refers to the magic that is not real, while the magic that is real, that can actually be done, is not real magic."(Net of Magic: Wonders and Deceptions in India (1991), p. 425)

Real magic represents that which Soul-science philosophers call the hard problem. ${ }^{85}$ The hard problem is that the soul is an inaccessible phenomenon. The hard problem represents the awe-inspiring nature of the self and its role in the human. Dennett, on the other hand, supports the idea that the self is certainly magic but it corresponds to the magic of the magic trick. Magic tricks are magic because they convince the viewer of something through the power of suggestion and 'sleights of hand'. They are deemed successful if an explanation is required to understand the trick. Likewise the self is similar to a magic trick in that it can be understood when it is broken down into its component parts.

A magic trick has three main components:

1. The Deception

2. The Distraction

3. The Revelation

Arguments on the self have this general format: phenomenology provides data for which the self is an explanation. The self receives all the information which our senses provide. The distraction is provided by phenomenal examples where our senses can be doubted and therefore our judgement on the self. For instance, Descartes' Cogito provides a good distraction. After all has been removed for which there is doubt, thought remains. Thought implies a thinker. Thus the revelation - a self -materialises.

Dennett believes there is a dilemma to be found in the magic trick analogy while the philosophers of Soul-sciences only perceive a lemma.

The Self Trick

1. The Deception: There is an 'I' who perceives the internal and external world around us?

2. The Distraction: The world is not always what it seems.

\footnotetext{
${ }^{84}$ Siegel, L., (1991): Net of Magic: Wonders and Deceptions in India. Univ. of Chicago Press, p 425

${ }^{85}$ Cottingham, J., Ed., (1996). Descartes: Meditations on First Philosophy: With Selections from the Objections and Replies. Cambridge University Press
} 
3. The Revelation: The self tries to make sense of the world around it.

Soul-scientists believe that philosophical examination is required for the second part of the self trick analysis. They have no issue with the first part although they recognise that the answer may not be what they necessarily anticipate, but they do not challenge the idea that there is a 'who'. The second part, that perception provides the distraction from the first part answer, is not denied by Dennett's supporters or by the Soul-scientists. Perception experiments such as Dennett's Tuned Deck ${ }^{86}$ and Change Blindness ${ }^{87}$, among others, lead philosophers and scientists to the conclusion that while our senses provide us with enormous amounts of information our trust in that information is misplaced. Tuned Deck was originally presented by the magician Mr Ralph Hull. In the trick he explains that the deck of cards is tuned and that through vibrations he can determine which card in the deck has been selected by the audience participant. Magicians tried to discern what the trick to this was but it was never discovered. It was simple. Hull simply changed his methodology between a range of simple tricks. Thus when others tried to decipher the trick it never seemed to fit into known methods. Consequently, the audience looked for a harder solution. ${ }^{88}$ Change blindness is the failure to notice changes in our environment from moment to moment. The most common change blindness experiments are the Flicker experiment (using a mask between two almost identical images) and the Mud-splatter experiment (where a visual overlay or distraction which resembles mud splatters on a car's windscreen). ${ }^{89}$ Soul-scientists conclude that where perceivers experience separation from their perceived world, they are trapped behind a veil of perception which cannot be lifted a regrettable position.

Supporters of Dennett agree that there is a delusion in perception and that despite our apparent certainty, perception is fallible. However, they also require philosophers to use the same grounds to discount part one of the self trick. Dennett argues that our sense of certainty about there being a self which resides in us contains the same illusion as our perceptions. It is the sense which brings us certainty in a self just as it is our senses which bring us certainty in our perceptions. The sense of certainty does not imply fact; this is true of both the self and perceptions. Both can be illusory.

The Locus for John Locke

\footnotetext{
${ }^{86}$ Ibid

${ }^{87}$ Rensink, R. A., J. K. O’Regan, and J. J. Clark, (1997). To See or Not to See: The Need for Attention to Perceive Changes in Scenes. Psychological Science, September, vol. 8 no. 5 pp 368-373

${ }^{88}$ Dennett, D. C., (2005). Sweet Dreams. Philosophical Obstacles to a Science of Consciousness. The MIT Press, Cambridge, Chapter 3, pp 72-74

${ }^{89}$ Rensink, R. A., J. K. O’Regan, and J. J. Clark, (1997). To See or Not to See: The Need for Attention to

Perceive Changes in Scenes. Psychological Science, September, vol. 8 no. 5 pp 368-373
} 
Locke begins his exploration of the self with the premise that the mind is tabula rasa or a blank slate. ${ }^{90}$ This premise is the idea that the mind is completely empty preceding any impressions by the world, internal and external. He claims that there are no innate ideas. Thus the mind is the product of the world's impressions. Using this premise, Locke proceeds to account for the self through the continuity of consciousness. ${ }^{91}$ For Locke, personal identity and the self are synonymous. The Narrativity Thesis, as described in the previous chapter in relation to Strawson, is the description of continuity of consciousness.

It is the mind which is conscious. Ideas for Locke are the sole objects of the mind. Knowledge is, in turn, contained within these ideas and the relationship between them. If ideas are compared with no reference to the outside world then it is possible to know with certainty. ${ }^{92}$ However, all ideas are presented within the mind and, therefore, ultimately identified and determined by sensation and reflection and thus influenced by the outside world. Every state of consciousness, according to Locke, implies the self. The assumption that there is a self gives existence to it as it provides a reference for the impression.

Locke never strictly draws a line between ideas and the self, therefore, never giving the self existence within the mind. In doing so he also anticipates that the self can never belong to the material of knowledge. So while Locke agrees with the existence of a self, he does not place it within the realm of knowledge, thus holding a comparable position to Dennett and his self trick. Locke does not go as far as Dennett in his discussion of the self; rather he limits it to his discussion of the role of ideas.

Nature of a Self according to the Locus Thesis

The self is a theoretical concept the knowledge and understanding of which allows for better predictions of behaviour. Like the centre of gravity in Dennett's analogies ${ }^{93}$, the self, while being present in each human, does not correspond to a physical element. However, although the self is not physical this does not imply that it is non-physical; rather for the Locus Thesis this means that the self is theoretical. Descartes, Avicenna and Strawson discuss the potential nature of the self in terms of the physical versus the nonphysical. The Locus Thesis proposes that while these two natures are possible they do not include the possibility of a purely abstract concept such as the centre of gravity.

\footnotetext{
${ }^{90}$ Locke, J., (1996), An Essay Concerning Human Understanding, Kenneth P. Winkler (ed.), Hackett Publishing Company, Indianapolis, IN. pp. 33-36

${ }^{91}$ Internet Encyclopaedia of Philosophy, John Locke 1632-1704, (2001) www.iep.utm.edu/locke/, accessed 1 April 2013

92 Ibid

${ }^{93}$ Dennett, D. C., (2003). The Self as a Responding - and Responsible - Artefact. Centre for Cognitive Studies, New York academy of Sciences, pp $39-50$
} 
The centre of gravity as a fictional object is purely abstract. This means that although the centre of gravity has no existence in a physical sense, it has physical effects on the physical world: it is an abstractum with spatio-temporal effects. This characteristic clearly answers the age old problem of the Soul-sciences. The discussion of how to categorise the self is important and once again the centre of gravity analogy can be used to help clarify. If the centre of gravity is assumed to be the very atom over which it resides then one would expect the atom to have those attributes and yet when the atom is removed and analysed no attributes of the centre of gravity for the original object will be found. This is because it is a category error to assume that the theoretical concept of the centre of gravity is the same as the point on the object which is under discussion. It would also be a category error to assume that the centre of gravity is a non-physical object. With this in mind, in regard to the self, to avoid the category error made by thinkers such as Descartes, the Locus Thesis and Dennett claim that it is clear that the self is not a physical object within the person; rather, it is a fictional object.

According to proponents of the Locus Thesis, the self is fictional both in its existence and in its role in the judgements it affects. Judgements regarding the self as a real and discernible thing occur because of the certainty people experience when they reflect on what they seem to be. The consciousness, in particular the stream of consciousness, weaves a story or narrative of the self and what it is. Whenever the self is considered the narrative becomes deeper and more complex. The result of this deepening is that the self is consistently becoming more determinate. The narrative nature of our consciousness provides the tools by which the illusion of the self evolves. The sense of self is, in fact, a convenient lie by which our consciousness orientates its thought for the most productive and beneficial arrangement of information regarding its world. When a person writes a book he/she creates fictional characters which readers perceive to have selves. The assumption is that the author must also have a self to create such convincing selves. The reality, however, is that through the narrative nature of the author and the reader, the characters in the book develop selves through inference. According to the Locus Thesis, the selves of the author, the reader and the characters in the book are all fictional. ${ }^{94}$

\section{Locus Thesis and Psychology}

The explanation provided by the Locus Thesis of the abstractum self and the fictional narratives which give rise to a sense of self also provides some clarity for

\footnotetext{
94 Ibid.
} 
disorders such as Multiple Personality Disorder ${ }^{95}$ (or Dissociative Identity Disorder as it is called today). This disorder is where the experiencer has a tendency to easily dissociate from their usual identity and evolve additional identities. Often people suffering from Dissociative Identity Disorder cannot recall their other personas while frequenting another persona. Under this account of the self, a person experiencing the disorder has a defective or overzealous narrative faculty. Rather than evolving one centre of gravity (aka self) the person evolves multiple selves to account for their experiences. Sometimes when a person's experiences are complex such as those which give rise to cognitive dissonance, ${ }^{96}$ they are more easily explained by dual selves. ${ }^{97}$

\section{Dennett's Two Prong Summary of the Self}

Dennett's contribution to the discussion on the self is two pronged. Firstly, he challenges the internal description of the self through the Soul-sciences as the hard problem. The hard problem of the self is analogous to the problem of explaining real magic - it is supernatural or transcendental. The challenge of the hard problem is negated by the Magic Analogy. ${ }^{98}$ Dennett shows that rather than the self being like real magic it is in fact like a magic trick. The self through the power of suggestion is perceived as if it is central and very much a fact. The certainty that people experience when considering the self or 'self trick', results in belief. Belief, in turn, results in the successful deception of what is the self's nature. It is clear that the self trick is very successful as the delusion that the self is a real thing is very prevalent and persistent. At this point it is important to realise that Dennett's description of the self as an illusion can lead to the wrong conclusion. Dennett does believe in the self but rather than a self with a physical reference, the self is a fictional abstractum. This is not an idea to be confused with the fictional nature of a unicorn. The second argument by which Dennett attacks the self delusion is an argument by analogy with the centre of gravity. ${ }^{99}$ This illustrates how the self can have spatiotemporal effects without being physical or non-physical. The analogy demonstrates the errors which can arise through incorrect categorisation.

\footnotetext{
${ }^{95}$ Dissociative Identity Disorder, http://behavenet.com/dissociative-identity-disorder, accessed 13 November, 2012

${ }^{96}$ Festinger, L. and Carlsmith, J. M., (1959). Cognitive Consequences of Forced Compliance. Journal of Abnormal and Social Psychology, 58, 203-211

${ }^{97}$ Dennett, D. C., (2003). The Self as a Responding - and Responsible - Artefact. Centre for Cognitive Studies, New York academy of Sciences, pp $39-50$

${ }^{98}$ Dennett, D. C., (2005). Sweet Dreams. Philosophical Obstacles to a Science of Consciousness. The MIT Press, Cambridge, Chapter 3

99 Dennett, D. C., (2003). The Self as a Responding - and Responsible - Artefact. Centre for Cognitive Studies, New York academy of Sciences, pp $39-50$
} 
When examining the meaning behind words, linguistic formats can be used to uncover unexpected information. Anscombe explains that the use of the word 'I' appears most often in the role of a referring expression; that is, there is an assumption that when a person uses the word 'I' they are referring to their own self. The 'I' refers to the reflexive pronoun, the self. Anscombe unpacks the meanings of the word 'I' in her essay The First Person, explaining that there is a special form of the word ' $\mathrm{I}$ ' which is not formally recognised by the English language but is in other languages. I', while often used as if it were a reflexive pronoun is, in fact, an indirect reflexive. ${ }^{100}$

The indirect reflexive case refers to scenarios where the subject appears to refer to a second subject. However, unbeknownst to the first subject the second subject is also himself. Intentionality is used in discussions using 'I,s' to show conviction or evidence. For instance, it is intention in Descartes' method of doubt that allows him to isolate the statement 'I think'. Often the word ' $\mathrm{I}$ ' is thought about in terms of a proper name because it often acts like a name. This creates a series of misleading assumptions. When ' $I$ ' is thought of as a proper name there is an assumption that it is referencing an object. Anscombe disagrees with this, explaining that ' $I$ ' is not typically used in this way. In the article G. E. M. Anscombe (1919-2001) by Duncan Richter this description of her work is given:

"In her essay 'The First Person', Anscombe argues that the word $I$ is not typically used to refer to an object, and so it does not refer to a non-physical soul or mind, but neither does it refer to a physical body. The word ' $I$ ' is not a name I call myself. It is not a name at all, even though it can appear to be one." 101

Anscombe goes on to suggest that 'I' may be the proper name of the self in that for the 'I' to reference something there must be something that it is to be an ' $\mathrm{I}$ ', such as having a self. ${ }^{102}$ Any referencing word is always used in the presence of its object, thus when an 'I' is used it is referencing its self. Each time it is reused in connection with the same self the self is re-identified - thus creating multiple selves. ${ }^{103}$ This links with Chapter Three's discussion about Strawson's accounts of the self.

\footnotetext{
${ }^{100}$ Anscombe, G. E. M., (1975). The First Person. In Samuel Guttenplan, ed.. Mind and Language. Oxford: Clarendon Press. pp. 45-65.

${ }^{101}$ Richter, D., (2012). The First Person. G. E. M. Anscombe (1919-2001). http://www.iep.utm.edu/anscombe/, accessed 30 May 2013

${ }^{102}$ Anscombe, G. E. M., (1975). The First Person. In Samuel Guttenplan, ed.. Mind and Language. Oxford: Clarendon Press. $\mathrm{p} 48$

103 Ibid, pp. 45-65.
} 
This brief discussion of the linguistic nature of the word 'I' suggests the same approach to the self as the Locus Thesis. It provides an account whereby the impression given by the language we use and our perception of this language creates a false understanding of the 'I'. This misconception is fundamental in that it is a mistake of classification to assume that the ' $\mathrm{I}$ ' is referencing the physical individual or corporeal individual when it is referencing the conception of the individual elicited by the original statement. Consequently, it is possible to elicit the same physical or corporeal being more than once in a sentence and their comparative 'I's' would not be referencing the same selves. Rather, two distinct selves may be being referenced which, at another point, may be redefined into a third and unified self when the mistake is identified. Note that this account of ' $I$ ' detaches the link between the I/self and the thinking being of the I/self.

While Anscombe's approach illustrates another way to see how the 'I' or self may provide a clarifying role in expressing the world around us, at the same time it is also the reason why our impression of the world is confused. The assumption that the ' $\mathrm{I}$ ' is oneself and that it belongs to either the corporeal or physical body of the individual is incorrect. According to Anscombe, the 'I' is referencing the self - the centre of the concept of what it is to be a person. Incidentally, this means that a self is necessary for personhood.

\section{Causation and David Hume}

Hume suggests that as humans our biological history creates an impression that causality is fact. Hume describes this assumption as inherent. This belief is instinctive in that when we examine the world around us we describe it in terms of cause and effect. ${ }^{104}$ These descriptions are supposed to provide us with a sense of certainty in that they deliver an account of why for situations. Ideally, the level of our conviction and security should arise from the relative provability of the situation. If the cause and effect could be shown to be fact and, therefore, completely knowable then we would have the highest level of conviction. However, it is not possible to know the first cause according to Hume. Therefore the very method by which we are divining knowledge of that cause and effect cannot be completely known either. Thus induction, causality is fallible. We assume, as is made evident by both Dennett and Anscombe, that we have selves. This assumption is fallible.

Hume's description of selves is that they are stable entities across time and that while we cannot be directly aware of our selves we can be aware of what we are experiencing at any given moment. Therefore our impression of ourselves and that on

${ }^{104}$ Hume, D., (2000). A Treatise of Human Nature, Oxford University Press 
which we base our assumption of self is simply a bundle of perceptions. Hume describes looking for the self beyond this collection of perceptions as akin to looking for a chain apart from its links. ${ }^{105}$

Hume uses three tools ${ }^{106}$ in his exploration of ideas and perceptions which, in turn, lead to his concept of self. Hume's first tool, the Razor, is that if a term cannot be shown to arise from an idea (which cannot be broken down into smaller ideas) then the term has no meaning. The second tool is the Microscope: the thesis that in order to understand a thing it must first be broken down into its simplest components, its simplest ideas. The third tool is called the Fork: for Hume truth is derived through sensations or through reflection.

When considering these tools it becomes apparent that sensations and reflections lead to impressions. Impressions are the results of our imaginations and memories from which ideas arise. The initial impression in its simplest form is the idea that one must begin with in order to start the process of understanding. There are many terms in our world and if a term is found not to arise from an idea then it is meaningless and therefore does not contribute to knowledge. For Hume there are multiple impressions and ideas which find reference in the concept of the self. It is not as simple as one idea. As such, when searching for evidence of the self multiple impressions will be found to contribute to its formulation.

Hume contributes to the Locus Thesis in that his discussion of the self as a bundle of perceptions and, therefore, ideas, has the fabric of the self as abstract not physical. His examination of causation offers yet another example of how starting with a fallible assumption that we have selves leaves the examiner with not only an unreliable impression but also with the false notion that the self belongs to the individual rather than being the product of a series of impressions received through the perceptions of that individual and therefore not of the individual.

\section{Conclusion of the Locus Thesis}

The essence of this Thesis in its most basic form is that the self originates from ideas in order to provide an orientation by which our perceptions of the world around us can be organised. The self does not reference a physical or non-physical object in nature. It is an abstract, fictional concept. Due to its role in interpretation of our perceptions, it is often mistakenly taken for something other than abstract. Consequently, a lot of time is needlessly devoted to what, according to the Locus Thesis, is its illusion of existence in the sense of an object.

\footnotetext{
${ }^{105}$ Ibid

${ }^{106}$ Schwerin, A., (2007). Hume and the Self: A Critical Response. Monmouth University, Vol. 5, Page 15-30, DOI 10.3366/jsp.2007.5.1.15, ISSN 1479-6651
} 


\section{Chapter Five}

\section{Self Criteria and Distinctions}

It is to be hoped that in examining the contributions of the philosophers surveyed in Part One a foundation can be established from which a working prototype for the self can be advanced. This process of assessment will be done by considering what criteria are necessary and sufficient for the self - leading us to a statement about the concept.

\section{Necessary and Sufficient Conditions}

Let us first consider Chapter One The Conceivability Thesis and those philosophers who contributed to it: Descartes, Armstrong, Lowe and Searle.

Descartes explains that through introspection and the method of doubt the self can be discovered. His position is described as Substance Dualism. The Cartesian self refers to the being that has thought. Descartes' examination of the mind-body problem leads him to the conclusion that the self and the body are distinct substances. This conclusion is drawn through the use of his perceptions which, despite his admission that they are fallible, result from his method of doubt. Substances have distinct phenomenological attributes and are persistent through time. For Descartes, the two substances are capable of independent existence and interact freely. Armstrong opposes Descartes' conclusion that the self is a different substance from the body. The idea that behaviours through which the self appears seem special does not mean that there is a special cause. Armstrong's endorsement of scientific method results in his desire to apply it to the consideration of the self. Empirical enquiry, although fallible, has what Armstrong describes as 'good authority', conviction among intellects. It is this conviction for which he searches with respect to the self. He anticipates that the world can be wholly described in physio-chemical terms thus, so too, should the self. For Armstrong, the self is the mental states that represent perceptions. Perceptions are, in turn, expressed in the body by physical states. These mental states can be called dispositions and they act as an internal cause for behaviours. Dispositions are a necessary part of physical states which cause actions. Therefore, the self appears to be part of the causal chain for actions. Within this approach consciousness is considered to be a perception of the mind.

To those conditions necessary and sufficient for the self, Descartes contributes the importance of thought. Armstrong contributes the idea that the self is necessary for actions; that its values are found in the role it plays in the causal chain. 
Lowe considers a self and a body which, despite being distinct substances, cannot exist independently of each other. The Lowean self is only perceived through its bodily expression. Without the body there would be no perception of self. The relationship Lowe posits is similar to the idea of conjunctive symbiosis. ${ }^{107}$ The self for Lowe is not a purely mental substance. John Searle supports Biological Naturalism which, according to his argument, implies that mental phenomena (those phenomena which allude to a self) are lower neural processes. These processes are realised by higher cognitive process which reflect back on the processes. This reflection appears as consciousness. Searle states that the self is often taken to be a different substance due to linguistic confusion and intellectual ignorance. Our language still contains antiquated forms of words which imply independence of body and mind. This, combined with the fact that our intellectual advancement is not complete - we have more to discover regarding our understanding of the brain - results in the confused attempts by academics to suggest that the mind is a substance different from all other substances so far identified which are all contained by physical laws. For Searle, consciousness is private and accessed by those internal contemplations. The material world is objective and publically measurable. It is those private contemplations which lead us to feel that we know the self. So, Searle, like Descartes and Armstrong, use subjective conviction to lead us to the belief of a self. Searle describes the self as the cause of lower neural activity which precedes the action of higher neural activity. These higher cognitive processes have functions such as imagination and consciousness. Consciousness being the reflection of those mental phenomena expressed in the lower neural processes.

Lowe highlights the importance of the coexistence of the self and the body. This necessary relationship is not denied by any of the theories so far suggested. Those people who believe in selves without bodies still consider them in concert with other bodies. So what is valuable to our discussion of the self is that it cannot be known without a consideration of the body. The self and the body are inextricably linked in some manner whether because they have a manner of conjunctive symbiosis or because they are one in the same thing. Either way, contemplation of one without the other is nonsensical. Searle offers a self which partakes in the causal nature of human behaviour. His theory is that while the self is not attainable it can be described by its effect on the causal flow of our bodies; that is, that the self is somewhere below our base neural processes and its expression is reflected in our internal analysis of these processes - consciousness. Searle offers the clearest form of the role reflection plays in the conception of the self. The self, a

\footnotetext{
${ }^{107}$ Oxford Reference, Conjunctive Symbiosis, www.oxfordreference.com/view/10.1093/oi/authority.20110803095632415, accessed on the 19 June 2013
} 
purely internal concept or as a substance expressed through its relationship with other substances, may be present but has no existence without the possibility of it being reflected on.

Chapter One suggests the following necessary conditions of the self:

1. That it is considered in conjunction with its physical companion - the body;

2. That thought provides the integral, if fallible, insight by which it can be described;

3. That reflection is required for its identification; and,

4. That the self is a participant of the causal chain which underpins behaviour.

The Equilibrium Thesis implies that a balance epitomises the self. Rather than two distinct concepts representing the self and the material, it is the product of a balance of the mental and physical. Avicenna, Aquinas and Hume consider this possibility.

Avicenna's soul, the archaic term for self, exists within the body to gain the benefit of being able to gather sensory data. Despite this, it is not part of the body. The two coincide because the relationship is mutually beneficial. Avicenna's search for physiological clarity leads him to establish three different forms of the self. These are the Vegetative (which refers to those faculties fundamental to being a plant), the Animal (those faculties that represent the animal) and the Intellectus (the addition of those faculties which distinguish a human from an animal: the practical intellect and the theoretical intellect). The human soul contains all three aspects. Each aspect contains physical and abstract parts the interaction of which allows for those functions vital to the being's existence. The soul resides within the body because the body provides it with physical data and expression. The body benefits from the soul because it allows the senses' information to be decoded; thus rational responses can be made to the material world. It is the balance of the abstract qualities and the physical qualities that allow for the full life that an individual experiences.

Aquinas perceives the soul or self to be the essence of what it is to be human. For him, a human is comprised of a substance (the body) and the self is a subsistent of this. It is reliant on the substances for its expression in the world despite being capable of independent existence. The body is the interface by which the self interacts with the world. Aquinas, like Avicenna, considers the soul to have three possible aspects, with the human soul comprising all three. The Vegetative type acts as the cause of the body's physical activity. The second type, Sensitive, encourages reflection on the sensory input. The third type is called Rational or Intellectus and is responsible for the knowing and willing action upon sensory input. It makes sense of sensory perceptions and creates a coherent understanding of the data so that rational action can arise. 
Hume considers the self to be the reference point of many impressions. His approach arises from an examination of the meaning of words; that each idea has references which define it. 'The Self' has many such interpretations, which is why responses to the question 'what is it?' are many and varied. Impressions come from either sensory data or from reflections. Impressions are the source of our ideas. For Hume, there is nothing greater than our perceptions (sensory input and reflections). Perceptions cannot be further reduced. For every idea there are a finite number of impressions and therefore perceptions which define it. The self is its perceptions. We cannot experience ourselves in a pure sense; we can only experience our perceptions.

Chapter Two suggests these necessary conditions of the self:

1. That the important aspect of a being is that there is a balance between the abstract and the physical. This balance allows the self and the body their fullest expression and without each other both suffer;

2. That the self and the body are necessarily linked and the self is the owner of coherency within our perceptions; and,

3. That it is our perceptions that both create ourselves and by which we know our selves. Perceptions come from reflections and the senses which form impressions. Impressions are sources for ideas.

Panpsychism and the Multiple Selves Doctrine discusses the position that all matter has mental properties; that a blend of both physical and mental attributes is present in the world. The concept of the self is often considered in conjunction with the concept of time. This can lead to the idea of multiple selves. A self appears to be present across time therefore its definition must account for this feature.

Strawson, like Hume, considers the self to have multiple impressions or expressions. The self is consciousness, the mental aspect of the human body. Consciousness deals in perceptions and thought. He opposes the psychological Narrativity Thesis claiming that it is a narrow definition which results in discrimination and potential psychological harm. Instead, he advocates two central types of self which, in turn, have subcategories. These types are diachronic and episodic. The episodic self is the self in the moment. It is not the same self that resides in any other moment because each moment is distinct and therefore the experience of the moment distinguishes the self from any previous moment's self. This type of thought is in keeping with the belief that the self is a product of its perceptions. The diachronic self perceives itself through time as the same self, ever growing but none the less, the same. Within each of these types a self may be 
narrative or non-narrative in the way it perceives itself. Strawson's self is consciousness, and his position indicates that consciousness can have different manners in which it assesses its perceptions.

Parfit's perspective is that there are an infinite number of selves because a self is distinct in any given moment from any other moment's self. He asserts that the body and the self are the same substances, the self relying on psychological continuity and connectedness for it nature. It is the psychological expression of an individual. Each time the psychological nature changes, the self is reinvented. He uses psychological continuity and connectedness in order to unify selves that share common features; that is, selves which belong to the same body. Given that the body can change in innumerable ways, Parfit describes how to relate selves using psychological parameters; it is important to collect selves in groups because it allows for accountability and being morally upstanding.

Lewis and Parfit are different in this fundamental way. ${ }^{108}$ For Parfit the question of an individual's survival comes down to whether one endorses the view that it is mental continuity and connectedness or identity which must persist in order for survival to be achieved. For Parfit these two options are distinct in their nature and are mutually exclusive options. Parfit endorses that mental continuity and connectedness are necessary for survival. Parfit perceives identity as a 1:1 relation while mental continuity and connectedness has degrees and thus can have a 1:many relation. Therefore the two options are different in nature. Lewis differs from Parfit on the central idea that identity and mental continuity and connectedness are not reconcilable, that there is a mutually exclusive relationship. One method of identifying the nature of a concept is to search for its simplest form. Another is to identify what is necessary for its survival. According to Lewis the self relies on psychological continuity and connectedness and identity for its continued existence. There are two means by which people consider themselves to be preserved; the first, is if their current psychological existence is part of their future psychological existence. The second is a wider concept, that of identity. Survival, in this case, is the continued presence of the self between the current individual and the future individual. Lewis uses his discussion of I-relation and R-relation to illustrate that all stages and aspects of a person must both be simultaneously in I-relation and R-relation with their peers for survival. For Lewis both identity and mental continuity and connectedness are necessary for an individual's survival.

However parallels between the two approaches can be identified. It is these similarities which offer an insight into the nature of the self. Both Lewis and Parfit agree

\footnotetext{
108 Lewis, D., (2003, online \& 1983, print). Survival and Identity. Philosophical Papers Volume 1. Oxford Scholarship Online, DOI: 10.1093/0195032047.003.0005, accessed on 17 June 2013
} 
that a self reliant on psychological continuity and connectedness is necessary for survival (although Lewis goes further to include identity as well). Lewis endorses a Parfitian position with respect to why a person generates multiple selves. Consequently, he recognises that in the case of both identity survival and psychological survival, the self of now and the self of the future will not be the same. To describe the manner in which a person can survive, Lewis creates two derivative cases of survival: R-relation (the two psychologically akin selves) and I-relation (the two exact and precise selves).

Chapter Three suggests these necessary traits of the Self:

1. That there is a blend of the physical and the mental in all things, therefore, the self, too, is a blend of both the mental and physical natures;

2. That the self can have many different forms of expression and manner in which it orientates the world for the individual. For example, the diachronic and episodic selves;

3. Psychological continuity and connectedness and identity are considered to be necessary for the existence of the self; and,

4. Given the possibility of an infinite number of selves, it is those traits which they share that provide coherence rather than those where they differ.

The Locus Thesis offers a different position than our previous chapters in that it describes a self which is purely theoretical. To date, this exploration has progressed from a narrow discussion of a self in isolation from the body to a fuller picture of a rounded self that is part of its body and belonging to the perception of the individual. This chapter makes the further step into a self which is purely hypothetical. This movement in Self literature can be thought of as a discarding of the homuncular folk psychology and a progression towards a detailed description of the complex products of neural activity. ${ }^{109}$

Dennett describes the self as a theoretical construct which facilitates the processing of perceptions in an advantageous manner. The self offers an account of consciousness, and consciousness, like other bodily functions, is a mechanism. The self is of the body; it is not its own thing. The consciousness narrative nature produces the self. When it is meditated it becomes an even deeper aspect of the narrative therefore encouraging the interpretation that it is a distinct thing. It is, however, an illusion that the self is something other than a theoretical reference point of a being. It provides a mechanism by which our consciousness can be perceived in a coherent manner.

\footnotetext{
${ }^{109}$ Waskan, J., (2010) Connectionism, http://www.iep.utm.edu/connect/\#H7, accessed 31 May 2013
} 
Anscombe offers the linguistic equivalent of the self illusion. She describes how the idea of self or 'I' appears to reference the corporeal body within its different forms. She explains that because the nature of the term ' $\mathrm{I}$ ' is mistakenly used as if it were a proper name it is often missed that it is referencing the concept of the person. The self is necessary to personhood because it is the concept of the individual person.

David Hume uses causation to illustrate how the self is a product of impressions, not something with an independent existence. The value of knowledge is determined by how much is understood of its causes and effects. The highest level of conviction would be attributed to that which we know all of the causes and effects. But this is an impossible hope, according to Hume, given we do not know the causes and effects of the very method of causation. Therefore, trust in causation as a measure of knowledge should elicit reservations. Thus knowledge which arises from causality is fallible. The assumption that we have selves is because of our apparent experience of self. We only experience the self in the reflection of our perceptions so it is simply a bundle of perceptions. It is abstract not physical or non-physical. The self is a product of impressions not of the individual themselves.

Locke starts his explanation of the self from the thesis of tabula rasa. He explains that ideas are the content of the mind and these ideas and the relationships between them result in knowledge. Ideas are the product of impressions. Impressions come in two forms: reflections and sensory input. The state of consciousness implies a self in the nature of its orientation. The self does not belong to the material of knowledge, rather it is something else. It is through conscious reflection that a self appears; therefore, the self belongs to the content of the mind.

The fourth chapter offers these necessary conditions for the self:

1. That it is a theoretical concept which facilitates the productive interpretation of our sensory input and reflections; and,

2. That it is the product of perceptions. Perceptions arise in two forms sensations and reflections.

\section{Chosen Stance}

Part One of this dissertation offers an examination of different ways in which the self has been defined so that a summary stance can be established. To recap: the self is that which seems to be essentially you. It is what the term 'I' references when it is used in discussions. The aim of this section is to identify those essential themes which the authors present in their discussions of the self. It is hoped that these themes will provide a coherent 
image of the self which can be used when examining psychological disorders wherein the sense of self seems impaired.

\section{Expression of Self:}

The contention over the body/self relationship provides our first necessary condition for the self. That is, the relationship between the body and self is necessary to the degree that they are equally reliant on each other for their fullest expressions. ${ }^{110}$ The relationship between body and self is different from those conditions necessary for the self because it is a relationship of equality; it is like the symbiotic mutualistic service-service relationship between the sea anemone plant and the anemone fish. ${ }^{111}$ What is apparent time and again is that the self is seen through the body. The nature of this relationship is not entirely clear but what is obvious is that the self and the body are necessarily connected. The discussion of body and self in Part One maps the progress of the self between theses where it is a non-physical substance ${ }^{112}$, the same substance as the body ${ }^{113}$, a different substance to that of the body, and finally an abstract aspect of the body, a theoretical idea which facilitates the creation of a coherent manner by which the body's perceptions can be processed $^{114}$. Each of these forms requires the presence of the physical body in order for the self to be expressed in the physical world. While some seek to establish that it may be capable of independent existence apart from the body, none of these positions anticipate that it can affect the physical world without the body. Therefore, in order for the self to exist in the physical world it needs a physical portal such as the body. The body is something which receives sensory perceptions. It is a necessary and sufficient condition for the self's expression in our perceivable world. Without the body nothing can be known of the self. So the body will form our precursor requirement for the self.

The Three Necessary and Sufficient Criteria of a Self are:

1. The being is conscious (awake and experiencing).

\footnotetext{
${ }^{110}$ Avicenna, F. Rahman. ed. (1952). Avicenna's Psychology. An English translation of Kitāb al-Najāt. Book II, Chapter VI, with Historico-Philosophical Notes and Textual Improvements on the Cairo edition. London: Oxford University Press, Geoffrey Cumberlege, Chapter I, p 25 \& Chapter VI, pp 35-37, pp 68-69, p 57

${ }^{111}$ Bronstein, J.. Mutualism and Symbioses. http://www.oxfordbibliographies.com/view/document/obo9780199830060/obo-9780199830060-0006.xml, accessed on the 25 June 2013

${ }^{112}$ Cottingham, J., Ed., (1996). Descartes: Meditations on First Philosophy: With Selections from the Objections and Replies. Cambridge University Press

${ }^{113}$ Strawson, G., (2010). Narrativity and non-Narrativity. John Wiley \& Sons, Ltd., http://idea.library.drexel.edu/bitstream/1860/2959/1/Miller.pdf, Thesis: Drexel University

${ }^{114}$ Dennett, D. C., (2005). Sweet Dreams. Philosophical Obstacles to a Science of Consciousness. The MIT Press, Cambridge
} 
The first criterion is one that distinguishes that which is alive but inert (a lack of internal mental activity), such as plants, from that which is alive and experiencing things, such as infants. This is a difficult criterion as it skirts arguments for what it is to be alive as well as arguments of what it is to experience. However, for the sake of this description, the words are to be taken at face value. At first glance this criterion may appear to include too many things to be of any use in narrowing down what it is to be a self. It does, in fact, significantly reduce the amount of work which could arise from later questions, such as excluding people who are dead. The first criterion also excludes people who are in a brain dead state but may have a functioning body. This is because the brain acts as a necessary part of the physical being for the collection and preservation of sensory information.

This yet to be addressed aspect of the self is that it is aware, as in conscious that it is absorbing sensory input. The recurring theme in all of the theses has been that in order to make any progress with the discussion on self, the being must absorb and hold onto perceptions. Each of our chapters considers theses where it is clear that our perceptions are fallible. ${ }^{115}$ However, perceptions form the foundation by which the self is expanded. Hume explains that perceptions both create and expose the self. ${ }^{116}$ The perceptions create the self because their rational interpretation is necessary for the being's survival. Consequently, the self functioning as the interpretive tool was devised. ${ }^{117}$ Perceptions expose the self in that it is only when our perceptions are examined that the concept of the self becomes clear. It is in the perceptions that we perceive a self. Perceptions are divided into two categories those which are senses and those which are reflections (Both forms of perception will be addressed in the Criteria for a self.). ${ }^{118,119}$ Perceptions from the senses are simple external input from the physical world. Reflections are the more complicated form of perception which originate from internal interactions with the sensory data. Thoughts are the contents of the consciousness. Impressions have two forms: reflections and senses. Impressions form our ideas. Ideas lay the ground for the content of our consciousness. ${ }^{120}$ The perception of perception leads us to our second necessary condition of the self: reflection.

2. The being has a reflective consciousness; a consciousness which can be reflected on.

\footnotetext{
${ }^{115}$ Cottingham, J., Ed., (1996). Descartes: Meditations on First Philosophy: With Selections from the Objections and Replies. Cambridge University Press

116 Hume, D., (2000). A Treatise of Human Nature. Oxford University Press, 2000

${ }^{117}$ Dennett, D. C., (2005). Sweet Dreams, Philosophical Obstacles to a Science of Consciousness, The MIT Press, Cambridge

${ }^{118}$ Hume, D., (2000). A Treatise of Human Nature. Oxford University Press

${ }^{119}$ Internet Encyclopaedia of Philosophy. John Locke 1632-1704. (2001). www.iep.utm.edu/locke/, accessed 1 April 2013

${ }^{120}$ Hume, D., (2000). A Treatise of Human Nature. Oxford University Press
} 
A reflective consciousness is the development discussed earlier of having two types of consciousness in order to side step the infinite regress. It is a state of consciousness which allows consideration of what one is conscious of. The first criterion has the person being aware of the taste of food in his/her mouth, the pressure of the chair under his/her bottom, the touch of clothes. The second criterion allows for a consideration and examination of these experiences. It allows the person to realise that the taste of the food is unpleasant and to be avoided in future. A reflective capacity allows for storing and learning from phenomenal experiences. It is key to having that sense of ' $I$ think'. ${ }^{121}$

Consciousness is the perception of our own state of mind. ${ }^{122}$ Perceiving our perceptions implies reflection. Reflection is the central manner in which the self can be observed. Descartes' method of doubt begins with the isolation of perceptions of which he could be certain. ${ }^{123}$ Reflection is the method by which the self can be identified. The reflective consciousness is not only required for identification but it is the process by which perceptions are examined and sorted. Without the reflective capacity our perceptions will remain simply that, they will not have descriptions. Descriptions of our perceptions allow for logical categorisation which, in turn, facilitates informed action. The self forms part of the causal chain which is responsible for our behaviours. ${ }^{124}$

Reflections are the second form of impression which makes it one of the sources of our ideas or thoughts. ${ }^{125}$ Each of the theses regarding thought identifies the capacity to reflect as vital. Some do not put it in terms of reflection, such as Parfit and Lewis whose descriptions of psychological continuity and connectedness and identity rely on the capacity to look back through time at what has been and recall what has previously been considered. Or, in an alternative form, the ability to project potential future scenarios requires the skill to recall past cases which are similar and project variants of the case being considered. The ability to examine potential scenarios or past cases requires reflective consciousness thereby making it a necessary principle of the processes needed for survival as seen by Parfit and Lewis. Criteria One and Two refer to thoughts. Thoughts are the currency of impressions and are fundamental to the faculties which exhibit the self.

\footnotetext{
${ }^{121}$ Cottingham, J., Ed., (1996). Descartes: Meditations on First Philosophy: With Selections from the Objections and Replies. Cambridge University Press

${ }^{122}$ Armstrong, D. M., (1981). Minds, Bodies, and Persons. The Nature of Mind and Other Essays. Cornell University Press, pp 295-302

${ }^{123}$ Cottingham, J., Ed., (1996). Descartes: Meditations on First Philosophy: With Selections from the Objections and Replies. Cambridge University Press

${ }^{124}$ Searle, J. R.. Why I Am Not A Property Dualist. http://faculty.wcas.northwestern.edu/ paller/dialogue/propertydualism.pdf, pp 1-6, accessed on the 10 June 2013

${ }^{125}$ Hume, D., (2000). A Treatise of Human Nature. Oxford University Press
} 
3. The being is aware that it is him/herself that contains the first two consciousnesses and not just the universe as such.

The third and possibly the final criterion is, in some ways, the most important as well as the most complex. It allows individuals to become aware of themselves as separate beings within a greater environment. Up until this point the person is everything. All the phenomenal information and internal assessment is that which fills the world. All input is for the purpose of acting on the individual as opposed to the individual being like a phenomenon within a great host of phenomena. Awareness is that which allows persons to realise firstly, that they are not the universe and secondly, that they are not alone in the universe. Each child goes through this stage as he/she learns to influence actions of a parent; realises that the parent, when not in sight, is still in existence; and learns to lie. Each of these discoveries leads the child to realise and evolve a sense of personal self.

The third criterion necessary for selfhood is the ability to identify the two consciousnesses as being of the individual. It is important that the individual isolates him/herself as distinct from the world. This process occurs when individuals establish their personal perception of themselves. A personal concept of self can be established in a variety of ways. Strawson describes how different forms of self evolve. He describes a diachronic and an episodic self and how these forms can help shape a person's processing of the world. ${ }^{126}$ The principle of identifying oneself is to understand what it is that is required for survival. The Multiple Selves Thesis illustrates two forms through which survival is considered successful. The first is psychological continuity and connectedness and the second is the broader form of identity. People value those things which allow that which they consider to be themselves to be continued. Psychological continuity and connectedness refers to those mental aspects of persons that express who they consider themselves to be. In each state of being there is a unique measure of what it is to be that person in that moment. ${ }^{127}$ What it is to be a person is different from moment to moment therefore it is a different person in each of those moments. An individual's persons are grouped by their similarities; those sharing almost all of the same psychological expression have psychological connectedness, that is, there is an overlap in what it is to be those people. Those sharing a limited amount of psychology are considered to be psychologically continuous. They share the same stream, in that at some point, the two distant peoples' connected persons share a connection. These connections may be multiple

\footnotetext{
${ }^{126}$ Strawson, G., (2010). Narrativity and non-Narrativity. John Wiley \& Sons, Ltd., http://idea.library.drexel.edu/bitstream/1860/2959/1/Miller.pdf, Thesis: Drexel University

127 Parfit, D., (Jan 1971). Personal Identity. The Philosophical Review. Vol. 80, No. 1
} 
times removed. Identity, like psychological continuity and connectedness, is the other form that people consider when hoping to survive. ${ }^{128}$ It offers a manner which includes a physical as well as psychological expression in the perception of what an individual pertains to be. The manner of survival is not as important as the fact that the person has isolated the idea of his/her self and desires whatever that is to be preserved. When individuals can acknowledge themselves as distinct from the world around them they gain the capacity to determine their actions with the motivation to survive rather than simply exist. Identification of self allows for deliberate and focussed action; it offers motivations and desires.

\section{The Criteria of the Self}

Three criteria of self have been established and one symbiotic necessity for the expression of self.

\section{Expression of Self:}

The expression of a self needs a body. The body and the self are inextricably linked. The three necessary and sufficient criteria of a self are:

I. Consciousness (being awake and experiencing).

II. Reflective consciousness; the consciousness which can be reflected on.

III. Awareness; the being is aware that it is him/herself that contains the first two consciousnesses and not just the universe as such.

\footnotetext{
${ }^{128}$ Lewis, D., (2003, online \& 1983, print). Survival and Identity. Philosophical Papers Volume 1., Oxford Scholarship Online, DOI: 10.1093/0195032047.003.0005, accessed on 17 June 2013
} 


\title{
PART TWO
}

\section{Insights into the Self through the Other}

\author{
Chapter Six
}

Finding the Self in a Complex World

In this section the two central approaches that have directed thinking in the study of the self will be examined: the social description and the evolutionary or phenomenal description. An outline of the approaches will be given, followed by an examination of the self using the approach together with the philosophers and psychologists who take this line. In the discussion it will become clear that there are significant overlaps between the two theories as they attempt to source the self.

\section{The Social Description}

The social description is one which has been used by psychologists and philosophers alike but which has remained more prevalent in psychological descriptions of the self. In essence, it is the claim that a self is developed and provided by an individual's social immersion. ${ }^{129}$ Some psychologies describe infants as 'clean' or 'empty impressions'. ${ }^{130}$ They explain that it is through the infant's experiences that individuality is impressed and a character begins to emerge from the reactive behaviours. Philosophers such as Locke have also presented tabula rasa ideas. The result of an empty slate concept for an infant is that it is the environment together with social interactions that provide the building blocks which culminate in a sense of self. Such an approach to the self is cumulative but the approach has not yet distinguished the nature, number or combination of experiences required for the development of a self, just that there are imprinted experiences. This means that prior to the unidentified set of experiences; the infant is without a self.

The clean slate notion suggests that a self will appear with the addition of experiences. Locke explains that the essence of tabula rasa is that an individual is the author of his/her own soul. ${ }^{131}$ The social approach goes further in that it contends that the

\footnotetext{
${ }^{129}$ Self-Other Differentiation, http://www.nature-nurture.org/index.php/ontogeneticdevelopment/development-of-sense-of-self/self-other-differentiation/, accessed 22 January 2013

${ }^{130}$ Locke, J., (1996). An Essay Concerning Human Understanding. Kenneth P. Winkler (ed.), Hackett Publishing Company, Indianapolis, IN, pp. 33-36

${ }^{131}$ Ibid
} 
self comes from the experiences which assume a self in their gestures. ${ }^{132}$ When watching interactions between any adult and infant there is a clear assumption of self in the child by the adult. This is due to the viewer's belief that the baby is human and thus is as much a person as the viewer is and therefore will think and behave like him/her. ${ }^{133}$ This is a type of personification seen in many situations such as a pet owner claiming their pet missed them while they were away on holiday. However, as the child, if all of your experience with the world leads you to believe that you are a self then it makes sense that your internal perception of yourself will appear indicative of having a self. Thus society does appear to play an influential role regarding the recognition of a sense of self and how that self might be expressed and connected to its environment. ${ }^{134}$

Developmental psychologists propose timelines of developmental stages, which illustrate how an individual's psychology or mental state evolves. Michael Lewis proposes five periods of development with direct consideration of a Self-Other relationship. ${ }^{135}$ The Self-Other relationship is that which exists between the individual in question and the people interacting with them. In the following chapters some time will be spent discussing cases where individuals' selves start to suffer and there is a loss of the ability to identify others as selves.

Lewis's Five Periods can be enumerated as follows: ${ }^{136}$

1. The first period covers zero to three months, during which infants learn to differentiate between themselves and their primary caregiver. They begin to evolve a means-ends relationship. As the caregiver and the infant evolve, a relationship through "need satiation' ${ }^{137}$ begins to bloom. This type of relationship lays the foundations for tender relationships in the future. Through the interactions between the infant and primary care giver the infant's physical needs and mental needs are satisfied through positive interactions such as kind eye contact, gentle touching and vocalisation.

2. The second period is between the ages of three months and eight months. During this stage, infants start to test the means-ends relationship by testing their

\footnotetext{
${ }^{132}$ Self-Other Differentiation. http://www.nature-nurture.org/index.php/ontogeneticdevelopment/development-of-sense-of-self/self-other-differentiation/, accessed 22 January 2013

${ }^{133}$ Argument By Analogy. http://www.unc.edu/ theis/phil32/argsbyanalogy.html, accessed 22 January 2013

${ }^{134}$ Interestingly, this type of thought is western in manner. The Western world views the self as separate and contained within the individual, their society defines a person by that person's individual traits, successes and failures. Whereas, Eastern cultures define a person by their position within the social group; the person's role and how they profit the group. The result of this perspective is that for some people their sense of self is held by the community not by themselves.

${ }^{135}$ Self-Other Differentiation. http://www.nature-nurture.org/index.php/ontogeneticdevelopment/development-of-sense-of-self/self-other-differentiation/, accessed 22 January 2013

136 Ibid

${ }^{137}$ Need Satiation: means that the basic needs such as love, food, water and rest are satisfied.
} 
environment and its responsiveness to their own actions. This feedback results in them developing a sense of themselves as an object with a sense of personal agency. The caregiver's responsiveness helps evolve the social agency which will later be used in building other relationships. It is also at this stage that social anxieties appear because the child can start to distinguish between familiar and unfamiliar care givers.

3. In the third period (eight to twelve months) it becomes clear that the type of self the infant is experiencing is not one which is private or one which is isolated just to the body of the infant. Rather, the self is something that has social meaning; other people are necessary to its expression and existence and they are not physically attached to the individual.

Lewis describes how over the first three periods the infant's sense of self slowly develops initially through its connection to the primary caregiver, in many ways sharing the self provided by that person until slowly distinguishing its own self from that of the care giver and realising its position in the world around it. During this period the infant begins to understand that inner experiences can be shared with another individual. The infant also begins to monitor the attention of others with respect to itself- an ability which when combined with 'reading' and sharing emotional information with others begins to provide feedback to the child about its lovability and worth.

This period also involves the beginning of object permanence. At about nine months old the infant begins to recognise that an object is permanently present regardless of whether the object can be seen. This understanding is applied to the primary care-giver as infants begin to recognise the location of the primary caregiver as they move around. It is also beginning to be applied to themselves for it is during this period of development that infants start to respond to their own appearance and facial expressions in the mirror, thereby beginning to develop personal self permanence.

4. The fourth period covers 12 to 18 months and involves the development of stronger internalisation of objects and people that assists in problem solving skills. The child begins to develop consistent recognition of itself in the mirror. It also begins to exhibit social individualisation and a sense of self-consciousness together with the starting of regular self recognition. 
5. The fifth and final period involves the completion but not termination of the fusion between the self of the caregiver and the child. These two selves are reliant and share a self reference point as the child begins to individualise and develop its own self reference point. If this process happens prematurely then the child is susceptible to low self esteem and chronic stress.

Analysis of psychologists' studies of developmental processes such as this five stage developmental progression provides a background and insights for how a self comes into actuation. The developmental process provides sign posts for the self, in that as the behaviours develop, the self seems to appear. This is the point at which the origin and nature becomes complicated in the discussion of the self. ${ }^{138}$ It will also provide some understanding when consideration is given later in this dissertation as to why certain people have not developed selves and why others have lost them.

\section{The Phenomenological Description}

Both philosophical and psychological proponents agree that the phenomenological description or introduction to the nature of the self is an established starting point providing understanding of the self. This approach is simply that it is our phenomenological experiences that inform us of the self or of our selves. It is a person's senses - sight, touch, hearing, smell and taste - that lead him/her to the conclusion that there is a self which is receiving these phenomenal influences. This self is not just a body that receives these sensations because there are internal sensations such as hunger and still more deep and personal sensations such as what it feels like to think and what it is like to be sad. These phenomenal experiences appear to show that there is a self housed within the body - an experiencing, perceiving thing which owns the phenomenal input.

Phenomenological information is pressing in on our senses every moment of our lives with the strongest and most prevalent registering on our receptors. However, when experience is considered it is apparent that certain phenomenal information is prioritised, which means that the information is filtered and brought together in a cohesive arrangement so that what is considered most important is identified. Those parts of our perception which are considered 'most important' are identified through a combination of deliberate and directed focus as well as what is considered important by our natural instincts. A self could either be what unifies our phenomenological information or be a product of unified phenomena. According to Dennett the self is that which allows for a

\footnotetext{
${ }^{138}$ Hume, D., (2000). A Treatise of Human Nature. Oxford University Press
} 
unifying interpretation of the world around you; that is the self provides a theoretical concept by which the phenomenological can be made into a coherent informative picture. $^{139}$

If the self is what unifies phenomenal information then this provides a strong evolutionary reason as to why there is a self. A self allows individuals to make sense of their environment and of themselves within that environment. People who can assess and prioritise their situation are much less likely to become overwhelmed by it and therefore be better equipped to survive. However, this would suggest that any being with a unified method of dealing with phenomenological information would have a self. This is an extremely inclusive way of defining the self and opens the way for a wide range of prospects which must now be considered to have selves. From snakes to geniuses a self is common and present. This is hard to conceive given that a self is commonly considered to be a complex high level cognitive capacity which is not wide spread or present in all creatures. Looking at the thesis that the self is a result of unified phenomenology we see that unification and sorting of information result in a sense of locus or a focal point. Sorting and assessing information is a patterning which in turn suggests a motivation. Between a motivation and a locus, a sense of uniqueness and individuality arises which are precisely the types of characteristics people describe when trying to express what they feel their self might be.

The phenomenological description firmly places the self as originating from within the body, which means that you could not leave yourself behind. This is certainly an intuitively appealing idea, however, it is not entirely consistent with the social description's presentation of the self. The social description depicts a self which is intimately linked to its social environment. It suggests that the people and interactions experienced by a self are what provide a sense of self. The self is more a social existence or participant than a body part. The result of this is that the link between the body and the self is more tenuous than the phenomenological approach would imply.

There are two aspects of the phenomenological approach that weaken its ability to provide a convincing account of the self. The first is that of fringe feelings and the second is that an explanation must be provided for the link between two moments each full of phenomenal data. Up to this point, discussion of phenomenal input has been of a direct cause and effect type of experience. I feel pain because I have a tack in my foot. A fringe

\footnotetext{
${ }^{139}$ Dennett, D. C., (2003). The Self as a Responding - and Responsible - Artefact. Centre for Cognitive Studies, New York Academy of Sciences, pp $39-50$
} 
feeling ${ }^{140}$ is something which has a less apparent cause; it is harder to describe and isolate. It is like the feeling of having a word on the tip of one's tongue but not being able to say it. The problem with fringe feelings is not that they debase an idea of self; in fact, they are used to reinforce the existence of self. Rather, they are a problem because their phenomenal roots are less clear and, therefore, they threaten the premise that it is phenomenology alone which provides and defines selfhood. The second issue is that of connecting phenomenal information together in a coherent manner. Two questions arise here: how to collate multiple sets of input from one object to provide a complete image of that object; and, how to connect phenomenological input from one instance to another in order to express a coherent story. Dainton provides an explanation for the latter question but his account is ad hoc in nature. ${ }^{141}$ The consequence of this problem is that again the phenomenal approach while adding much to the description of self does not give a full and cohesive explanation.

Apart from these two main approaches there is a third which can lead people to study the self - personal experience or specific medical case studies. These studies, while bringing a colourful angle to the study of the self, will not be used as a primary platform; rather, they are best used to illustrate the more unusual features of the self. For instance, cases such as Phineas Gage ${ }^{142}$ provide a clear example of how major change in the neurological make-up does not necessarily have predictable effects on the behaviour of the individual. This type of case informs understanding both of brain plasticity and topographical descriptions of the brain. In what follows, consideration will be given to the two psychological disorders of autism and schizophrenia. Viewing them in the light of the phenomenological and social approaches will, it is hoped, further contribute to the understanding of the self.

\footnotetext{
${ }^{140}$ Dainton, B. (2004). The Self and the Phenomenal. Ratio: An International Journal of Analytic Philosophy, 17: 365-389

141 Ibid

${ }^{142}$ The Incredible Case of Phineas Gage. http://neurophilosophy.wordpress.com/2006/12/04/theincredible-case-of-phineas-gage/., accessed 23 January 2013
} 
Disorders Elucidate the Self: Autism

Autism and schizophrenia can be described as disorders of the self in that their expression interrupts those anticipated behaviours in which the self is usually expressed; that is, these two disorders affect people's ability to express themselves using language and behaviour. Thus, not only is the individual's perception affected but also the perception of others towards them. The following two chapters will examine autism and schizophrenia. This section aims to look at each disorder to learn what manner of self, if any, can be identified within these individuals. Looking for a self in people with disabilities has practical implications since it promises to include them in contexts from which they might otherwise be excluded. Offering inclusion to someone with a disability is akin to offering them a chance of acceptance.

\section{The Self in Introspection and Communication}

One of the challenges in discussing the self is that it is both identified and expressed through introspection (reflection) and communication (behavioural expressions such as language). That is, a self can be located through words as well as through a thoughtful consideration as to who or what persons perceive they are as they look at the idea of the self. The words and thoughts allow one to discover the existence of a self as well as providing a trail for an examiner to identify that self. While they are only expressions of the self, they also provide us with the evidence of its presence. This is further complicated by the fact that according to theories of developmental psychology it is the infant's communication with its more fully cognitively developed carers that teaches and assists the infant's brain to develop and evolve. When primary care givers interact with infants they immediately personify the infant and extend the assumption that the infant must have a self because of the belief that every infant will grow into someone like the carers. This brings us to a common misconception held within our society. Because verbal communication is the mode by which the self is identified within people, it is often assumed that an individual without the ability to communicate verbally has no self. (Introspection was not mentioned above because we only know the introspection of another through their verbal communication of it.) This is a misconception because it involves two false presuppositions: firstly, that verbal communication is the only key to the self and, secondly, that if an individual cannot communicate his/her private world in a way that is readily understood, it is assumed that he/she is without that world and what comes 
with it; such as a self. However, linguistic communication is not the only method of demonstrating the self. Non-linguistic behaviour can also provide cues by which the self can be identified. In using autism as a case study, where those faculties of communication which classically bring us the knowledge of self are impaired or absent, attention can be focussed on other faculties which may indicate its presence.

People often use communication as the primary guide to believing another individual has a self. Without communication (in a form recognised and anticipated by the perceiver) people are often judged as less than whole; without a self. The assumption that verbal communication is the only way of knowing a self and that without such communication there is no self causes people to disregard others who have unusual manners of communicating. This is flawed reasoning, but it is also the reasoning which underpins most of the classical examples of discrimination found in history. People with psychological disorders often have differing behaviours which result in society's censure and their partial or full exclusion from that society. ${ }^{143}$ The problem in the reasoning is that the onus of evidence is placed on the wrong point. This logic states that because one of the modes by which a subject is expressed is absent, the subject itself must also be absent. Likewise, verbal communication, while a method by which the self can be expressed, is not a trait of the self. This is a case of using fallacious reasoning: denying the antecedent.

\section{The Equilibrium of the Self}

Equilibrium between the internal/private world and the phenomenal/external world is what allows for normal development. People who can perceive both worlds and use this understanding to assist their function do not have those deficits experienced by an individual with autism. This can be seen in the types of symptoms classic to the disorder of autism specifically those associated with social interactions. ${ }^{144}$ People who do not have a balanced interface between these worlds experience a fracturing in function within the external world. However, lacking an equilibrium does not necessarily result in the lack of either world. ${ }^{145}$

First, let us examine how communication acts as the interface between the internal and external worlds. The phenomenal world is the physical world or external world, discussed in Part One of this dissertation. Part One conveyed how information can be

\footnotetext{
${ }^{143}$ Richer, J., (1978). Autism: A Reappraisal of Concepts and Treatment. The Partial Noncommunication of Culture to Autistic Children-An Application of Human Ethology. Springer US, DOI: 10.1007/978-1-46840787-7_3, pp 47-6

144 Barlow, D. H.; Durand, V. M., (2009). Abnormal Psychology: An Integrative Approach - Firth Edition. Wadsworth Cengage Learning

${ }^{145}$ Stanghellini, G., \&Ballerini, M., (September, 2004). Autism: Disembodied Existence. Philosophy, Psychiatry, \& Psychology. Vol 11, No. 3, DOI: 10.1353/ppp.2004.0069, pp 259-268
} 
gleaned about the self through that world. Descartes concluded that as the self is not physical it must be non-physical. We learn from the flaws in his theory that because one characteristic is not the case it does not mean that its opposite is the case. It is possible that the ' $\mathrm{I}$ ' is simply a cohesive mechanism by which logic can be applied to our phenomenal world. $^{146}$

Avicenna explains that behaviours can be accounted for either through phenomenological or abstract faculties. Abstract faculties belong to the internal part of the person while the phenomenal belongs to the external. Avicenna proposes that balance between the internal and the external influences on the person combine to make the aspects of the self. ${ }^{147}$ We will be using his thesis about the balance between the phenomenal world and the internal world as we further the discussion. Strawson proposes that introspection can inform us as to the shape of and the nature of the self. It provides insight into how each personal self is of best service to its owner. He also maintains that despite the different forms of self appearing to lead to specific ethical and good life criteria, different shapes of self do not imply error or a complete lack of self shapes. ${ }^{148}$ So, the personal expression of the self leads us to some knowledge of it as a philosophical concept. It would appear that the self is a personal element which has evolved within each person to provide guidance and coherence to their own particular expression of life. Dennett disputes the idea of the self as a non-physical or physical thing. He submits the thesis regarding the centre of gravity as a parallel for the role that the self plays for a person. The self is a theoretical concept by which the brain can make sense of the world. The theoretical concept allows for a more succinct approach to interpreting the phenomenal world. The self concept also creates a tool that helps to predict the behaviour of others. ${ }^{149}$

G. Stanghellini and M. Ballerini (2004) introduced the term 'idios kosmos'. 150 meaning the private world of the individual. They described the autistic tendency to reside solely in this private world and how those individuals with schizophrenia fluctuate between 'residing within' their idios kosmos and the phenomenal world. The idios kosmos or private world becomes the reality for someone who is residing in this state. An individual who has

\footnotetext{
${ }^{146}$ Dennett, D. C., (2005). Sweet Dreams. Philosophical Obstacles to a Science of Consciousness. The MIT Press, Cambridge

${ }^{147}$ Avicenna, F. Rahman. ed. (1952). Avicenna's Psychology. An English translation of Kitāb al-Najāt. Book II, Chapter VI, with Historico-Philosophical Notes and Textual Improvements on the Cairo edition. London: Oxford University Press, Geoffrey Cumberlege

${ }^{148}$ Strawson, G., (2010). Narrativity and non-Narrativity. John Wiley \& Sons, Ltd.. http://idea.library.drexel.edu/bitstream/1860/2959/1/Miller.pdf, Thesis: Drexel University ${ }^{149}$ Dennett, D. C., (2005). Sweet Dreams. Philosophical Obstacles to a Science of Consciousness. The MIT Press, Cambridge

${ }^{150}$ Stanghellini, G., \&Ballerini, M., (September, 2004). Autism: Disembodied Existence. Philosophy, Psychiatry, \& Psychology. Vol 11, No. 3, DOI: 10.1353/ppp.2004.0069, pp 259-268
} 
developed a balance between their idios kosmos and the phenomenal world is well adjusted as they can respond to each of the worlds' expressions by tempering the two states. The disorders of autism and schizophrenia are described by Stanghellini and Ballerini as fractured. The idea of fracturing comes from their description of the idios kosmos as having four interfaces by which the balance with the phenomenal world is maintained. An individual with one of these disorders experiences deficits in these four interfaces.

The balance of the idios kosmos enables people to live in the phenomenal world as reality. For someone with autism their idios kosmos experiences emotional drifting, semantic drifting, a loss of an ethical or common stand on existence and ontological incompleteness. Below is described the effect of these four functions and their expression in the external world. ${ }^{151}$

1. Emotional Drifting is the characteristic which separates emotional feedback from physical and/or linguistic cues. For people with autism this results in a reduction of participation in the social world.

2. Semantic Drifting occurs when the individual experiences a progressive and pervasive deconstruction of their toolbox of language semantics.

3. The ethical factor expresses how people with autism move away from accepted common sense perceptions and interpretations of behaviour and phenomena resulting in peculiarities in value attributions and prioritising.

4. Ontological incompleteness is essentially a shattering of self coherency causing an imbalance between their inter-subjective and intra-subjective interpretations.

When these four areas are functioning properly in a person, a healthy balance is established between the internal and the external world. This balance allows people to live as if their perceived external world is their reality. A disruption in this processing, such as for a person with autism, results in a containment or permanent retreat within the activities of their private mental life. When the balance between the internal and external world is steady the process of expression within the idios kosmos not only allows for coherent expression of the individual in the phenomenal world but also provides the means by which the phenomenal world is coherent for the individual. Disorders of communication and social expression such as autism arise out of fractures within these faculties thus impairing the individual's ability to both interact and successfully perceive the phenomenal world. This, in turn, translates to social isolation as the expression in the external world is deemed as 'different'. The two central fractures between the idios kosmos and the social world or phenomenological world for those with autism are: firstly, that their capacity to 
correctly identify the similarities between themselves and others leading to the individual extending the assumption of selfhood to those around them is severely impaired. The second fracture is the result of a disruption of their pre-reflective and non-propositional attunement by which the idios kosmos or the private mental life of the individual are expressed. During normal development, links are developed between different words and ideas. For instance, the colour red is often associated with the word 'anger'. For someone with autism these common associations are not laid down and established in the same manner, therefore their queued responses to stimuli often differ from their normally developing peers. ${ }^{152}$ The pattern of association in the brain can be described as a mind map or keyboard. The shared keyboard of mental life provides a basis for communication which is degraded for persons living with autism; therefore their ability to respond appropriately is also disrupted. ${ }^{153}$

Is there a Self in Someone with Autism?

\section{Theory of Mind}

The Theory of Mind is an important part of the discussion about the self and autism. Theory of Mind refers to the faculty required to appreciate another person's perspective. It is the capacity to impute beliefs to others. ${ }^{154}$ This, in turn, requires second order representations; that is, the ability to hold both one's own beliefs and another's beliefs within oneself. The ability to identify another's beliefs facilitates the process of social integration. It means that the individual can know in a loose sense what another person feels, wants and believes. ${ }^{155}$ The point of contention which will be examined in this section is whether the third criterion of self is equivalent to the Theory of Mind capacity or whether they are distinct.

Second-order representations constitute part of the category of thoughts which are higher-order. A higher-order thought is one which is of another thought. That is, they bring thoughts into consciousness. A higher-order thought occurs when it confirms a lower order thought. ${ }^{156}$ For instance, when a person is hurt he/she experiences pain. When the individual can state that he or she is experiencing pain it is a higher-order thought. The thought behind the statement asserts that the pain is there. A higher-order thought is like a

\footnotetext{
152 Ibid

153 Ibid

${ }^{154}$ Baren-Cohen, S., Leslie, L. And Firth, U. (1985). Does the Autistic Child have a Theory of Mind?. Cognition, 21, pp 37-46

155 Ibid

${ }^{156}$ Droege, P., (2005). Higher-Order Theories of Consciousness. http://www.iep.utm.edu/consc-hi/, accessed on 8 July 2013
} 
testament or reinforcement of something which is already part of the person. ${ }^{157} \mathrm{~A}$ secondorder thought is where the individual is not only aware of his/her own thoughts but also of the thoughts of another. To be capable of perceiving what another person could possibly be experiencing or thinking is the distinct feature that fails to develop in autism. Theory of Mind is the result of second-order thoughts. Theory of Mind or the ability to anticipate another's intentions or beliefs form an integral part of successful social interaction. Without this ability social interactions become extremely foreign. The idea that individuals with autism treat objects and people alike arises from the deficit in their Theory of Mind. ${ }^{158}$

Autism is a disorder where its core features are impairments in socialisation, communication and spontaneous imaginative play. ${ }^{159}$ These areas of impairment are each distinctly linked to the capacity which Theory of Mind affords in an individual. Socialisation and spontaneous imaginative play requires the individual to attribute characteristics to an object or person and then interact with those characteristics. It requires the faculty of second-order thoughts. Likewise communication beyond need satiation relies on the individual understanding the value of interactions with another person. Someone who is not aware of the potential differences between him/herself and others would not experience the curiosity needed to discover more about another person. People with autism cannot imagine that other individuals have motivations, beliefs and desires different from their own and, therefore, on those grounds, do not feel compelled to communicate.

The Sally-Anne False Belief Test ${ }^{160}$

The Sally-Anne False Belief test illustrates how a child with autism experiences the world. ${ }^{161}$ It highlights the nature of social responses for a person without Theory of Mind. The participant watches a series of scenes between two dolls, Sally and Anne. In front of Sally there is a basket and in front of Anne there is a box. Sally hides a marble in the basket. When Sally leaves the room Anne takes the marble out of the basket and hides it in

\footnotetext{
${ }^{157}$ Baren-Cohen, S., Leslie, L. And Firth, U. (1985) Does the Autistic Child have a Theory of Mind?, Cognition, 1985, 21, pp 37-46

158 Ibid

${ }^{159}$ Frith, U., Morton, J., \& Leslie, A. M., (1991). The Cognitive Basis of a Biological Disorder: Autism.

Perspectives on Disease, TINS, Vol. 14, No. 10

${ }^{160}$ Williamson, G., (July, 2013). Autism and the Theory of Mind. http://www.sltinfo.com/autism-and-theoryof-mind.html, accessed on the 8th July 2013

${ }^{161}$ Baren-Cohen, S., Leslie, L. And Firth, U. (1985) Does the Autistic Child have a Theory of Mind?. Cognition. 21, pp 37-46
} 
the box. Then Sally comes back into the room. At this point the participant is asked three questions: ${ }^{162}$

1. Where will Sally look for the marble? (Belief Question)

2. Where is the marble really? (Reality Question)

3. Where was the marble in the beginning? (Memory Question)

Experiments like this are looking for responses which provide specific information about the nature of the autistic brain. As such, the experimenters do not want to measure responses which stem from intellectual impairment (autism is often co-morbid with intellectual impairment). In order to do this comparisons are made between participants with autism, down syndrome and normally developed peers. Due to the nature of autism and, to a lesser extent, down syndrome, the participants are matched by their developmental age rather than their chronological age to ensure that the experiment is measuring comparative difference rather than developmental delays. ${ }^{163}$ Using participants with down syndrome as a comparative pool means that if the responses are shared over both groups then the response is probably not different limited to the specific disorder. ${ }^{164}$

Each of the three questions in the Sally-Anne False Belief Test is targeting a specific capacity in the participant. The questions are defined as questions of memory, reality and belief. Of those participants with autism, $80 \%$ incorrectly answered the belief question assuming that Sally had the same perception of the scene as they did and would, therefore, know that the marble was now hidden in the box. All of the participants in this particular study successfully answered both the memory question and the reality question.

The Mirror Self-Recognition Test ${ }^{165}$

Psychology uses an experiment centred on the tool of the mirror to offer examples of different combinations of self exhibiting behaviours. Ideally, by contrasting the SallyAnne False Belief Test and the Mirror Test in light of the self criteria, an account can be made for the $20 \%$ of people with autism which passed the Sally-Anne Test. The use of a mirror allows for an experimenter to introduce a second being into the room so that the interactions which ensue between the original individual and the individual's reflection can be observed. This interaction can be expressed in a number of ways. If the individual recognises the reflection as his/her own then the case offers an account of self recognition

\footnotetext{
${ }^{162}$ Williamson, G., (July, 2013). Autism and the Theory of Mind. http://www.sltinfo.com/autism-and-theoryof-mind.html, accessed on the 8th July 2013

163 Ibid

164 Ibid

${ }^{165}$ Reddy, V., Williams, E., Costantini, C., \&Lan, B. (2010). Engaging with the self: Mirror behaviour in autism, Down syndrome and typical development. Autism. DOI:10.1177/1362361310370397. 14(5), pp 531-546
} 
which requires the individual to be aware of his/her own self first. If the person does not recognise the reflection as his/her own but does recognise the reflection as a person, a case can be made for self-other recognition. Finally, if the individual does not recognise the reflection as a person, distinct from the other objects in the reflection, then a case can be made that the individual does not have awareness of his/her own self or of others. ${ }^{166}$ This type of experiment is important as it begins to illustrate the difference between awareness of one's own self as distinct from the world versus awareness of other selves.

The third criterion of the self as described in Chapter Five is the awareness of one's self as distinct from the world. That is, individuals with a self can isolate themselves as separate from the surrounding objects of their environment. To distinguish one's self as distinct from one's surroundings is different from distinguishing other people from objects and then recognising that they are similar to one's self. It could be argued that the ability of self-other recognition is more basic than the ability to distinguish self-object distinctions because the first ability requires an assumption of kind where the second is an assumption of difference. However, the assumption of kind, made in the self-other case is not simple in that it requires the two-fold distinction of identifying that others may be like you but also that not all other types of object have this similarity to one's self. Therefore, it is a more complex progression than that of identifying oneself as distinct from other objects.

In the Mirror Test participants have a sticker placed on their faces by their parents. If they use the reflection to motivate a response to the sticker then it can be said that they identify themselves in the reflection. ${ }^{167}$ Not all of the participants recognised the reflection as belonging to themselves. However, some had social responses to the reflection despite not knowing it was their own. These social responses allow the inference to be made that participants had picked out their reflection as a similar being to themselves and can thus be described as having a self-other capacity. Reddy et al. (2010) found that children with autism spent as much time examining the other objects reflected in the mirror as their own reflection. They also spent little to no time interacting in a social manner with the reflection of themselves. This was true of both those children with autism who recognised their reflection and of those who did not identify with the reflection. ${ }^{168}$

The primary distinction which needs to be made here is that it is possible for individuals with autism to identify their reflection as their own without feeling the need to interact socially with it. Thus, unlike their typically developing and down syndrome peers, individuals with autism do not identify the aspect of other in their reflection. Individuals

\footnotetext{
166 Ibid

167 Ibid

168 Ibid
} 
with autism have been shown to consider themselves as distinct agents and in a different condition than those objects that can be acted upon. ${ }^{169}$ This means that it is possible for an individual with autism to fail to have the standard of Theory of Mind but to have those faculties required for our third criterion of self-that of awareness of self as distinct from the world.

Lack of Self Need Not Be Considered a Debilitation - The No-Self Thesis

The No-Self concept is a complicated idea. A person can have a 'No Self' concept when he/she does not conceive of him/herself as an individual in a world with other people. Rather he/she perceives the world in a fashion where all else is grouped. Such a person is not part of 'the others' group' but neither is he/she part of his/her own group. This is a lonely arrangement - it is very impersonal. ${ }^{170}$ However, it has sometimes been considered a positive thing. The concept that there is not a self which resides somewhere between the plain of the phenomenal world and that of the mental world is very similar to the thesis of thought which Dennett offers. ${ }^{171}$ The difference between Dennett's approach to the self and the No-Self Thesis is that Dennett's choice of language is positive in the sense that its description of the self is creative; it seems to build something. The No-Self Thesis, on the other hand, is classically described in negative terms requiring a breakdown of the false impression of self.

The concept of a No-Self type can be found in a variety of literature ranging from philosophy and psychology to religion. Psychology discusses it in relation to disorders such as schizophrenia and autism. The No-Self status describes the net result of the characteristic of impaired social communication shared by both disorders. Autism and schizophrenia affect an individual's ability to place him/herself in reality. Reality, in this case, is used to refer to the external world. The external world contains other people and their respective selves.

Individuals suffering from schizophrenia experience a loss of self because their perspective of reality when threatened by delusions becomes confused. Reality and a clear distinction of self is shaken by the individual's attempts to account for the delusions. ${ }^{172}$ Delusions such as those of non-existent people telling a sufferer what to do cause a fission

\footnotetext{
${ }^{169}$ Hobson, R. P., (1990). On the Origins of Self and the Case of Autism. Development and Psychopathology. 2.. DOI:10.1017/S0954579400000687. pp 163-181

${ }^{170}$ Giles, J., (April, 1993). The No-Self Theory: Hume, Buddhism, and Personal Identity. Philosophy East and West. Vol. 43, No. 2, pp. 175-200

${ }^{171}$ Dennett, D. C., (2005). Sweet Dreams. Philosophical Obstacles to a Science of Consciousness. The MIT Press. Cambridge

${ }^{172}$ Sass, L. A.; Whiting, J.; Parnas, J., (2000). Mind, Self and Psychopathology: Reflections on Philosophy, Theory and the Study of Mental Illness. Sage Publications, Vol. 10(1): pp 87-98
} 
of sense for the person experiencing the delusion. The person must decide whether these experiences are part of his/herself or if they are part of the external reality. If he/she choose the external reality then the boundaries between the person's self and their environment is breached with all of his/her internal experiences becoming part of the outside world reality and no longer part of him/herself.

The nature of delusions is that they are like one's internal world and, as such, it is very difficult to distinguish between a delusional thought and a legitimate thought. Consequently, the above decision for persons with schizophrenia is a problem because while they have banished the delusions into their external world they may also be pushing their legitimate thoughts into an external world as well. Thus, the person loses much of what healthy people consider to be reliable and definitive for their identities and personhood. If such persons choose to include their delusional thoughts into their sense of self they can become overwhelmed with incongruence's and multiple beliefs about a topic thereby losing that sense of consistency which is so vital to a self.

Let us now consider the person suffering from autism. Such persons are unlikely to ever develop a sense of self due to their almost complete inability to communicate socially which would have allowed them to place themselves within a social context. Instead persons suffering from autism cannot contextualise themselves consequently they are disconnected from the world. ${ }^{173}$ Autism and schizophrenia are examples where a state of No-Self is debilitating. Studies in religion and philosophy offer different views.

Philosophy discusses the No-Self status as a 'third option approach'. The third option approach is the idea that in any situation there are three basic ways of making a decision:

a. To choose a different route, to make a change to the current process of events.

b. To choose to maintain the status quo, to keep things as they have always been, to choose not to change.

c. The third choice is to do nothing, to let the flow of events progress regardless of the outcome. It is the choice not to choose how things will progress.

The third option or ' $c$ ' is like the No-Self status. It is the outcome where everything carries on and the potential actor stands outside the process. Being part of the process can only occur when the individual recognises both the process and themselves and the possible interaction between the two. ${ }^{174}$ Consequently, an individual who is not part of the process because he/she does not perceive it, has No-Self.

\footnotetext{
${ }^{173}$ Stanghellini, G., \&Ballerini, M., (September, 2004). Autism: Disembodied Existence. Philosophy, Psychiatry, \& Psychology, Vol 11, No. 3, DOI: 10.1353/ppp.2004.0069, pp 259-268

${ }^{174}$ Hobson, R. P., (1990). On the Origins of Self and the Case of Autism. Development and Psychopathology.. doi:10.1017/S0954579400000687.. 2, pp 163-181
} 
Having No-Self is different from being without a self. A person with No-Self is as such because the self has been lost or has never developed. While persons with No-Self cannot develop one because they have no cognitive potential by which a self could arise, a state of No-Self does not lack an internal life.

Buddhism explains that self language such as 'I' and 'me' are not words which represent real things rather they are words of convenience. Commentaries describe how Buddhism has two levels of speech: the conventional level which uses self language and the ultimate level which uses language such as 'sense-bases' and 'elements'. ${ }^{175}$ The religion describes how Buddhas or enlightened people speak two truths: one conventional and one ultimate. The distinction that Buddhism is drawing in its discussion of self is like that in philosophy. Firstly, while people may have an internal life which is expressed like that of a person with a self it does not follow that there is the necessity of having a self. Buddhism describes this state of No-Self as an enlightened one rather than a status resulting from debilitating disorders. Buddhists strive for this state; a state where the conventional language is seen for what it is and that what is true on the highest level is the experience of the sensations, not of what they could signify. ${ }^{176}$

\section{The Three Self Criteria Applied to an Individual with Autism}

\section{Criterion One: Consciousness}

The first criterion of the self is that the individual is awake; that they have the capacity to receive information from the phenomenal world and to process it. The fact that individuals with autism interact with themselves and their environment can lead to the safe assumption that such an individual does indeed receive sensory data.

\section{Criterion Two: Reflective Consciousness}

Individuals with autism can be classed as having reflective consciousness because tests such as the Sally-Anne False Belief test note that the participants with autism manage to successfully answer the memory question (where was the marble in the beginning?) and the reality question (where is the marble really?). This ability indicates that the person with autism has the capacity to reflect on their perceptions and manipulate ideas of time lapse; that is, they can not only reflect on current perceptions but also on past perceptions.

Criterion Three: Awareness of Self as distinct from the Physical World

\footnotetext{
${ }^{175}$ Giles, J., (April, 1993). The No-Self Theory: Hume, Buddhism, and Personal Identity. Philosophy East and West. Vol. 43, No. 2, pp. 175-200

176 Ibid
} 
The third criterion of the self is the idea that, among other things, for individuals to have a self, they must be aware that it is themselves who are conscious and reflecting on their consciousness, not that these experiences are of the universe. A different way of describing this is that the individuals must be aware that his/her thoughts and experiences, while triggered by the outside world, belong to him/her selves or his/her idios kosmos and that the experiences and thoughts while making up his/her own world are not the whole world. It is not necessary for an individual with a self to progress to the next step of Theory of Mind (Self-Other recognition) but often seen to be closely linked developmental progressions in typically developing individuals.

The successful establishment of the third criterion is important for maintaining the balance between the idios kosmos and the phenomenal world. It was stated earlier that equilibrium between these two worlds is necessary for acceptance and integration into a social life. One of the keys to this integration is recognising at some level that others have a mental life as well. For persons with autism this is very difficult. In fact, it is one of the areas in their function which has been noted as fractured. ${ }^{177}$ When people consider a young child they do not assume that it lacks a sense of self; rather, they recognise that the child will grow into a more highly cognitively capable individual. In fact, most parents and care givers do not even consciously consider this; rather, because of their own experiences and fulfilment of the third self criterion and then Theory of Mind they extend their assumption of self in others to include the young child. However, for an individual with autism this same extension is often not made. Where adults considering the toddler extend their beliefs of self on the grounds of the toddler having a potential for self, the individual with autism is assumed to have no potential and thus no self. This assumption occurs because Theory of Mind and the third self criterion appear to co-develop and are, therefore, not often perceived as distinct. To mistake a person with autism as being without a self because of a lack of Theory of Mind is possibly denying them social inclusion. ${ }^{178}$ To refuse a person with autism social inclusion but to include a young child on the grounds of potential self appears to be an ethical breach.

\footnotetext{
${ }^{177}$ Stanghellini, G., \&Ballerini, M., (September, 2004). Autism: Disembodied Existence. Philosophy, Psychiatry, \& Psychology. Vol 11, No. 3. DOI: 10.1353/ppp.2004.0069, pp 259-268

${ }^{178}$ Richer, J., (1978). Autism: A Reappraisal of Concepts and Treatment. The Partial Noncommunication of Culture to Autistic Children-An Application of Human Ethology. Springer US. DOI: 10.1007/978-1-46840787-7_3..pp47-6
} 
Disorders Elucidate the Self: Schizophrenia

This chapter will focus primarily on the nature of schizophrenia and the manner in which the disorder can offer responses for the questions: what can schizophrenia teach us about the self; and, does an individual with schizophrenia have a self?

\section{The Disorder of Schizophrenia}

\section{History of Schizophrenia}

Schizophrenia is a difficult disorder to explain in that it has a number of variants whereby the nature of its expression in any given individual can appear completely different to another individual with the same diagnosis. This, combined with a very limited knowledge of the underlying processes which contribute to the presence of the disorder, means that what is known of the disorder arises from a manifold collection of case studies and psychiatric accounts of people experiencing disorders which share a developmental similarity over their progression. Many cases share the common theme of a progressive and chronic course of cognitive and behavioural decline. ${ }^{179}$ The types of schizophrenia have been widely debated but what unifies the disorder is a psychological tone which makes them comparable. ${ }^{180}$ The term 'schizophrenia' was coined by Bleuler and was used to describe a group of disorders, of schizophrenias. ${ }^{181}$ It was also Bleuler who revised the idea that the disorder was distinguished by its course of degenerative decline and used symptoms to suggest a group of core deficits necessary to distinguish an individual as experiencing schizophrenia. At this point the distinction is first made about the positive and negative symptoms of the disorder. ${ }^{182}$ It is this idea of base symptoms which is currently used to isolate schizophrenia.

\section{The Diagnosis for Schizophrenia}

Schizophrenia is divided into two conceptual parts. The first part is its characterisation, or expression in the world. There are two types of expression: that with positive symptoms and that with negative symptoms. Negative symptoms occur when usual personality traits are reduced; a negative symptom is the loss of normal attributes.

\footnotetext{
${ }^{179}$ Jablensky, A., (September, 2010). The Diagnostic Concept of Schizophrenias: Its History, Evolution, and Future Prospects. Dialogues Clin Neurosci; 12(3): 271-287, http://www.ncbi.nlm.nih.gov/pmc/articles/PMC3181977/, accessed on 23 July 2013

180 Ibid

181 Ibid

182 Ibid
} 
Negative characterisations include: affective flattening, alogia and avolition. ${ }^{183}$ Positive symptoms are those which are added to those traits already present in the individual's personality. Positive symptoms include: hallucinations, delusions, disorganised speech, frequent derailment and incoherence and grossly disorganised or catatonic behaviour. ${ }^{184}$ The second part of the schizophrenia diagnostic criteria is that the person experiences social/occupational dysfunction. These dysfunctions in the individual's ability to maintain expected levels (for the specific individual) in areas such as work, interpersonal relations, self care and (in younger individuals) academic achievement. ${ }^{185}$

Schizophrenia comes in episodes. To be diagnosed, the individual must experience the disturbance of their symptoms for at least six months with at least one of the months where positive symptoms are present. The episodic nature of the disorder results in periods where the individual's presentation of self is disturbed. The disruptions can be so severe that the individual's entire person seems to change. ${ }^{186}$ Classical descriptions of this disorder do not use the concept of the self in their explanations; however, in an attempt to create a more unified account of the diverse nature of the disorder, there is a group of theorists looking at schizophrenia through a consideration of consciousness and the self. ${ }^{187}$

The term 'schizophrenia' has had many meanings over the course of history. It has been used as an example to argue the need for psychiatry and similarly, as an example of why psychiatry is not needed (as seen by low remedial success rates) by people who endorse the view that disorders are products of cultures not physiology. ${ }^{188}$ Schizophrenia can best be described in relation to this dissertation using clinical diagnostic descriptions and considering it as a disorder of perception. The perception that the individual presents to the world is abnormal in its nature. Those features which distinguish them as an individual are inconsistent with what is commonly expected; for instance, they have a flattened affect. The second way in which schizophrenia is a disorder of perception is that the individual experiencing the disorder has a disrupted flow of perception, whether by hallucinations and delusions or by not being able to distinguish the parameters between his/her body and the world.

\footnotetext{
${ }^{183}$ Psychotherapy and Counselling: Schizophrenia DSM IV Definition, http://psychotherapyandcounseling.org/schizophrenia-and-related-psychotic-disorderscategory/schizophrenia, accessed on the 5 July 2013

184 Ibid

185 Ibid

186 Ibid

${ }^{187}$ Sass, L. A. \& Parnas, J. (2003). Schizophrenia, Consciousness, and the Self. Schizophrenia Bulletin, Vol. 29, No. 3, pp 427-444

${ }^{188}$ Woods, A., (2011). The Sublime Object of Psychiatry: Schizophrenia in Clinical and Cultural Theory. International Perspectives in Philosophy and Psychiatry. Oxford: Oxford University Press, Introduction, http://www.academia.edu/1572771/The_Sublime_Object_of_Psychiatry_Schizophrenia_in_Clinical_and_C ultural_Theory, accessed 14 July 2013
} 
Schizophrenia has an episodic nature in that the individual experiences episodes of the positive and negative symptoms and episodes which are apparently symptom less. ${ }^{189}$ During periods where there is symptom presentation the hyperreflexivity is particularly severe and can result in the individual appearing to have distinct selves which are unrelated between the prodromal, risdual stages and the premorbid, schizophrenia stages. ${ }^{190}$ The next part of this chapter is divided into three parts: two examining perceptions of the self in someone with schizophrenia and the third proposing how the multiple selves' doctrine may offer coherency to a person with schizophrenia.

Two Perceptions of the Self with Schizophrenia

\section{The Expansive Approach or Ipseity Disturbance Account}

As has already been said, the disorder schizophrenia is a difficult subject because of the diversity of its expression. As such, having more than one collective account of the disorder should not be a surprise nor considered a weakness. Rather, it should be seen as an attempt to retain the breadth of the disorder.

As noted, for an individual experiencing schizophrenia there is a blurring between those impressions which belong to the internal world and those of the phenomenal world. Sass et al. (2003) described schizophrenia as having two distinct and complimentary aspects: hyperreflexivity and a distinct diminishing of self affection. ${ }^{191}$ Hyperreflexivity is when the experience the individual has of his/her self extends to include other aspects of the phenomenal world. Self-affection is the capacity to identify one's self as a distinct and unified subject of awareness. A diminishing of this capacity results in an incoherence of self identification. ${ }^{192}$ Hyperrefflectivity and self-affection are very similar distinctions to those made by the Self Criteria Two and Three.

Criterion Three is the ability to identify one's self as distinct from the world. Criterion Two is the faculty of reflective consciousness. This criterion is not as vital to hyperreflexivity and self-affection but is necessary for the expression of these ideas. That is, the reflective consciousness is at the root of considering objects beyond one's self as part of one's self. This transference can only occur if individuals feel they can reflect on the sensory data offered to them by this other object. The individual must feel that this object is a part of him/herself and therefore possible to reflect upon. The third criterion is

\footnotetext{
${ }^{189}$ Psychotherapy and Counselling: Schizophrenia DSM IV Definition. http://psychotherapyandcounseling.org/schizophrenia-and-related-psychotic-disorderscategory/schizophrenia, accessed on the 5 July 2013

${ }^{190}$ Ibid

191 Ibid

192 Ibid
} 
clearly an integral part of the discussion of schizophrenia because the ability to identify one's self as being such is the primary disturbance of an individual with schizophrenia. This disturbance appears in two forms. Firstly, an individual experiences objects outside of his/her internal worlds as within his/her internal world. In essence, individuals with this disturbance have an overactive inclusivity principle where they include parts of the external world within their conception of their self. Objects no longer reside firmly within the phenomenal world. ${ }^{193}$ The result of this inclusion is that individuals experience difficulty in creating a unified concept of their self. ${ }^{194}$ When someone attempts to unify or define something, he/she categorises similar experiences together; when someone includes parts of the phenomenal world in his/her internal description of self, the kind of material they are attempting to integrate is very diverse. Consequently the account of self which he/she attempts to form will differ drastically from classical descriptions such as those which arise using the Narrativity Thesis. ${ }^{195}$ The different account of self which people with schizophrenia form results in the common misconception that they have multiple personalities. This is not the case. However, it does lead to the interesting option whereby an episodic description of self may be a more coherent method by which they can establish a unified self concept.

\section{The Exclusive Approach}

This approach to the issue of the self for someone with schizophrenia is distinct in that it focuses on the nature of the two central relationships which break down for such a self. These are the relationship between the individual's self and his/her body, and the relationship between the self and objects (with the body offering a medium of expression). ${ }^{196}$ The notion of the body and the self having a necessary relationship is one offered as a premise for the expression of self in the first part of this dissertation. The body is a form through which behaviours attributed to the self can be analysed. In Part One many reasons were offered for the requirement of the body in connection to the self. One of these was the idea of 'presence'. Authors such as Descartes offer the idea that the self resides within the body ${ }^{197}$ and this is known by a sense of presence. We feel with conviction that the 'I' is within or of the body. Someone with schizophrenia experiences a

\footnotetext{
193 Ibid

${ }^{194}$ Haycock, D. A. Sense of Self and Emotions. http://www.netplaces.com/schizophrenia/impressions-ofschizophrenia/sense-of-self-and-emotions.htm, accessed on 23 July 2013

${ }^{195}$ Strawson, G., (2010). Narrativity and non-Narrativity. John Wiley \& Sons, Ltd.

${ }^{196}$ Stanghellini, G., (February, 2009). Embodiment and Schizophrenia. World Psychiatry, Vol. 8(No. 1): pp 56-59, http://www.ncbi.nlm.nih.gov/pmc/articles/PMC2652898/, accessed 15 July 2013

${ }^{197}$ Cottingham, J., Ed., (1996). Descartes: Meditations on First Philosophy: With Selections from the Objections and Replies. Cambridge University Press
} 
loss of this sense of presence; there is a sense of being a spectator, a remote observer of the body rather than the sense of residence or attachment with the body. ${ }^{198}$ This problem is particularly difficult for someone with schizophrenia in that it creates a sense of isolation and helplessness. Due to the third person connection between the self and its respective body, the self experiences a detachment between its desires and motivations and the behaviours of the body. The body appears to behave independently of the self's instruction.

The second relationship which experiences problems is that of the relationship between the individuals and objects. Objects have their meaning for any given individual in the utility that they provide to that individual. ${ }^{199}$ Individuals who experience a division from their body are removed from the interface which facilitates interactions with objects. Objects offer utility to the individual only in the nature of the physical world. A physical object offers little or no utility to someone who cannot interact with that world. Therefore the relevance of objects and other individuals (residents of the physical world) is very low for someone experiencing schizophrenia as they have no means of benefiting or interacting with them.

The combination of experiencing a division between the self/body and the body/objects results in a compounding effect of disconnect for an individual suffering from schizophrenia. The individual loses the perceived utility of objects within the phenomenal world, thus an appearance of apathy occurs. In the previous chapter it was discussed that an individual with autism appears to have no motivation to interact with other people, that he/she did not perceive the value of communication. Schizophrenia can have a similar effect in that the individual loses the realisation that the objects around him/her can have worth or value. This effect may arise from a disruption in sensory processing where previously stable physical properties of the phenomenal world change inexplicably. ${ }^{200}$ For instance, the individual's limbs may appear to change size independently of the rest of the body. When someone experiences a division from their body due to a loss of perceived presence the body becomes like a character in a play where the individual with schizophrenia is not the director. This loss also contributes to why the individual then loses an appreciation of object utility. The object only has utility to the individual in the manner of the interaction it has with the body, so if the individual is not connected with the body then the object has virtually no value. In fact, the object only becomes interesting in that it

\footnotetext{
${ }^{198}$ Haycock, D. A. Sense of Self and Emotions. http://www.netplaces.com/schizophrenia/impressions-ofschizophrenia/sense-of-self-and-emotions.htm, accessed on 23 July 2013

${ }^{199}$ Stanghellini, G., (February, 2009). Embodiment and Schizophrenia. World Psychiatry, Vol. 8(No. 1): pp 56-59, http://www.ncbi.nlm.nih.gov/pmc/articles/PMC2652898/, accessed 15 July 2013

${ }^{200}$ Haycock, D. A. Sense of Self and Emotions. http://www.netplaces.com/schizophrenia/impressions-ofschizophrenia/sense-of-self-and-emotions.htm, accessed on 23 July 2013
} 
shares the world with the body which the individual can or does not feel connected to. The individual experiencing this type of separation from the phenomenal world is said to attempt to create a hypothesis of this experience, to provide an explanation which makes sense of a world which has changed so drastically. ${ }^{201}$ These hypotheses or accounts can be seen in the types of hallucinations and delusions which occur as positive symptoms for a sufferer of schizophrenia. At times this type of separation can result in individuals believing that their body is another self because the behaviours and perceived motivations of the body are so separate from what the individual feels he/she is experiencing. ${ }^{202}$

\section{Multiple Selves - An Algorithm for Sense}

The diversity of expressions of the disorder schizophrenia result in wide and varying accounts of how it is best treated and understood. What is apparent in all of this is that one of the most debilitating aspects of the disorder is the confusion that arises in trying to offer an account of the different experiences which occur for the individual suffering from it. In both the Ipseity account and the Exclusive approach to describing the experiences of the self with schizophrenia, a sense that the individual experiences multiple selves is mentioned. The Multiple Selves Doctrine discussed in Chapter Three offers a description of the self which differs starkly from the Narrativity Thesis in that it allows for multiple selves within one individual without the idea being a debilitating or delusional thought. ${ }^{203}$ The idea that in each moment a self is distinct and that an infinite number of moments occur in any given lifetime means that multiple selves exist for each individual. These selves can be considered of one individual by their relative similarity to each other. ${ }^{204}$ This approach would mean that the individual with schizophrenia would only have to recognise a small percentage of his/her perceptions in order to unify his/her concept of self or collective self. So long as there is some psychological continuity and connectedness then a unified expression can be found for the individual with schizophrenia. The alternative, using the Narrativity approach to the self, would require the individual to absorb his/her perceptions and experiences, however strange, into a coherent and singular description of his/her self. Schizophrenia is an onset disorder in that rarely does someone experience the disorder during childhood. As such it is more than likely that the self perceptions have already become established. Consequently, the onset of schizophrenia can

\footnotetext{
${ }^{201}$ Stanghellini, G., (February, 2009). Embodiment and Schizophrenia. World Psychiatry, Vol. 8(No. 1): pp 56-59, http://www.ncbi.nlm.nih.gov/pmc/articles/PMC2652898/, accessed 15 July 2013

${ }^{202}$ Haycock, D. A. Sense of Self and Emotions. http://www.netplaces.com/schizophrenia/impressions-ofschizophrenia/sense-of-self-and-emotions.htm, accessed on 23 July 2013

${ }^{203}$ Strawson, G., (2010). Narrativity and non-Narrativity, John Wiley \& Sons, Ltd.

${ }^{204}$ Personal Identity. mind.ucsd.edu. accessed on the 17 June 2013
} 
be very frightening as the individual attempts to provide an account of his/her perceptions and experiences using his/her childhood method of self construction. It is possible that individuals suffering from schizophrenia may need to be taught different ways of perceiving the self so that the tool of self can become beneficial again. The self has been discussed as the tool which provides a reference point or method by which coherency can be found in the plethora of our perceptions. ${ }^{205}$ The individual with schizophrenia, like the child with autism, experiences an intensity of perceptions which are often overwhelming, resulting in some cases in a weakening of the self tool.

\section{Schizophrenia and the Self}

The remainder of the chapter will examine the question of whether someone with schizophrenia can be considered to have a self, by examining the disorder with respects to the three Self Criteria and the Self Premise.

\section{Schizophrenia and the Premise of the Self (the Body)}

In order for the self to be an informative concept and a productive aspect of what it is to be a person it must have expression within the world. The body is seen as the necessary aspect by which an expression of self can occur. Without the body the self has little relevance. A person with schizophrenia experiences disruptions in his/her perception of the body and the boundary where the internal and the external worlds meet through the body becomes ambiguous. ${ }^{206}$ While the boundaries between internal and external worlds are in no way clear and precise, common sense allows individuals to make the distinction between objects of the external phenomenal world versus the internal private world. It is the body which forms the perceived boundary between the two in that it offers a perceivable line. While this does not mean that the self is necessarily within the body, it does mean that the body offers a point of reference by which phenomenal input can be categorised. ${ }^{207}$ For someone with schizophrenia the sense of what is of the phenomenal world and what is of the internal world becomes dislodged. It is as if he/she loses the ability to make a common sense distinction and when dealing with the mass of phenomenal sensory input, he/she ascribes distinctions between the internal and external worlds without reflection of the bodily boundary. ${ }^{208}$

\footnotetext{
${ }^{205}$ Dennett, D. C., (2003). The Self as a Responding - and Responsible - Artefact. Centre for Cognitive Studies, New York academy of Sciences

${ }^{206}$ Mishara, A. L., (2004). Disconnection of External and Internal in Conscious experience of Schizophrenia: Phenomenological, Literary and Neuroanatomical Archaeologies of Self. Philosophica 73, pp. 87-126 ${ }^{207}$ Chapter Five

${ }^{208}$ Mishara, A. L., (2004). Disconnection of External and Internal in Conscious experience of Schizophrenia: Phenomenological, Literary and Neuroanatomical Archaeologies of Self. Philosophica 73, pp. 87-126
} 
Schizophrenia results in the loss of tools to maintain a coherent approach to the distinction between the internal and external worlds. ${ }^{209}$ While individuals with schizophrenia may experience a loss of apparent connection or identification with their body, they do not appear to lose a sense of self. They still use the body as a way of referencing themselves; they just do not perceive a unified relationship between the body and the self; instead the body can become a member of the external world. ${ }^{210}$ Likewise the body can appear to contain multiple other selves, in that the individual perceives him/herself and other selves as resident within the same body. This is different to the idea of Multiple Personality disorder in that for someone with schizophrenia these other selves can reside in the external world as well as the internal world rather than being specifically contained by the body. ${ }^{211212}$ It is the loss of a coherent method of distinguishing the internal from the external and thus the self from others which is distinct in the disorder of schizophrenia. So an individual experiencing schizophrenia may not prioritise his/her body as the interface for the self in the phenomenal world: the loss of this distinction is not sufficient for a loss of self; rather, it indicates the importance of understanding the criteria of the self.

\section{Criteria of the Self}

\section{Criterion One: Consciousness}

The first criterion of the self is that the individual is experiencing or conscious. They must be capable of experiencing phenomenal input and retaining the information. This is clearly identified in someone with schizophrenia; in fact the disorder is better described an inundation of sensory input as opposed to an absence of input.

Criterion Two: Reflective Consciousness

Reflective consciousness refers to the capacity to examine phenomenal input and make an assessment of this material. This capacity is seen in the ability to form ideas which in turn is reflected in people's behaviours. Delusions are a symptom of schizophrenia and are the product of an individual formulating explanations of experiences based on perceived phenomenal input. These reflections are considered delusional only when direct evidence to the contrary is not taken into consideration or is not given value by the individual. Symptoms such as delusions support the conclusion that an individual with

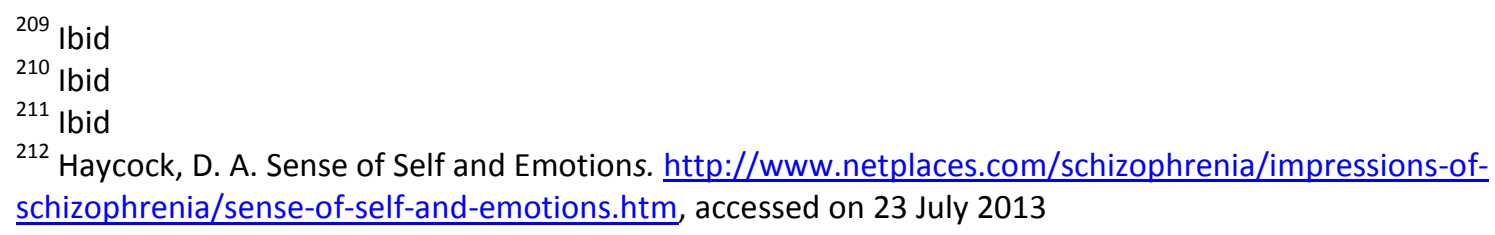


schizophrenia has a self. It is not, however, necessary that an individual with schizophrenia has delusions, so other evidence must be identified to support the idea that such individuals have a reflective consciousness. The episodic nature of schizophrenia allows for the observation of the individual while he/she is not experiencing a schizophrenic episode or schizophrenic symptoms. During these periods individuals can experience relatively normal functioning and as such their behaviours are very similar to those of a normal developmental and socially adjusted individual. As such their behaviours exhibit the ability to reflect on their consciousness.

Criterion Three: Awareness of Self as distinct from the Physical World

This is the final criterion of self and one which offers the most difficultly in the discussion of schizophrenia. Due to the nature of schizophrenia there is not a predictive pattern in how the individual will interpret their perceptions and as such many variants of expression of self occur. For some there appears to be a distinct presence of self in that the confusion lies not with the presence of his/her own self but with the presence of other selves and their relative influence on the world around them. The third criterion requires the ability for the individual to isolate his/her self as distinct in the world. An individual with schizophrenia can experience a variety of different expressions of the self in the phenomenal world. In some cases the self extends to include objects in the world as part of itself. In such cases the perception of the internal world expands to include parts of the phenomenal world and the individual believes that he/she experiences internal impressions from these objects. Other cases describe an individual with schizophrenia where the self has totally withdrawn into an almost purely theoretical expression excluding all of its perceptions including those of the body into an objectifiable world where it lacks the power to influence change. Still others are where the individual with schizophrenia experiences other selves (such as through auditory hallucinations) in addition to his/her own self moving indiscriminately over the boundaries between the internal and external worlds.

Typically an examination of behaviour and subjective accounts would provide a clear account of whether individuals can identify themselves as distinct from the world around them. Individuals with schizophrenia almost seem to have an over active capacity to identify themselves. Considering the case of schizophrenia is akin to watching the tides at a beach in that the boundaries between the self and the world are in constant flux. Sometimes they are very particular and narrow, whereby little of what is often included (such as the perceived relationship with the body) is absent; while at other times the self covers so much of the external world that it appears to expand in such a way that it is 
almost unidentifiable. At no point does there appear to be a complete absence of an external world or of the self even if the state or nature of each of these aspects changes. Therefore it can be concluded that individuals with schizophrenia can distinguish themselves as distinct from the external world. However, as the two worlds are in constant flux it can be very difficult to distinguish and rely on the self as a tool for coherency in perception and interpretation. 


\section{Chapter Nine}

\section{The Function of the Self}

The objective of this final main chapter is to consider the functional benefits of the self for the system that constitutes an individual. In Part One of this dissertation, the discussion has generally centred on an isolated individual and how the identification of self in that individual can be achieved. As the discussion has widened in Part Two to include those with psychological disorders, the effect another's perceptions can have on the development of the self has become apparent.

The nature of the self can be better understood through an examination of its expression within others' perceptions and within its environment. Its role can be fleshed out by the nature of those perceptions and beliefs about the individual. As individuals may not always perceive others within their environment, an examination of how the individual relates to his/her environment will also expand our understanding of the nature of the self. This chapter examines both the expression of the self in the relationship between an individual and others, as well as an individual and his/her environment.

While earlier chapters have established the theoretical nature of the self, discussion has persisted as to the measurable influences on the self, despite measurability usually being restricted to physical form. This section will look at the culmination of those influences on the expression of an individual and the measurability of this effect. This examination will focus significantly on others' perceptions of the individual. In discussing the self with particular reference to others' perceptions of it, there is the tendency to discuss the self with respect to its worth. However, this leads into the realm of self-worth literature. ${ }^{213}$ Such material focuses on gaining back ownership of esteem and worth evaluations through evolving a relationship with ourselves in an 'other' capacity. The process occurs through an internal assessment of the individual's values and beliefs. One of the primary aspects to this process is learning to devalue the idea that others dictate the respective value of an individual. ${ }^{214}$ This chapter is not about examining self-worth. In self-worth or esteem literature there is a focus on the content of the statements about individuals: whether they are produced by the individual or others. In contrast, this chapter will look at the fact the statements were made in the first place. The ability to make statements about one's own or another's self is the evidence required to validate the function of that self. Acknowledgement of an individual establishes their existence to a

\footnotetext{
${ }^{213}$ Branden, N. (1983). Honoring the Self: Self Esteem and Personal Transformation. Jeremy P. Tarcher, Inc. Los Angeles.

214 Ibid
} 
perceiver, and the ability to respond to this individual as distinct from oneself is one of the specific capabilities which a self offers to an individual.

The Self-a Cause or an Effect?

The theories which we have considered up to this point have not established whether a self evolves before social interaction or after; however, it is recognised that it goes through a process of development. ${ }^{215}$ Humans, as a species, require social interaction in order to survive. Without at least one other human to provide care, a human infant cannot survive. It would be reasonable to conclude that while the self may not be innate, it does develop in the presence of social interactions. If it emerges after social interactions begin then it can be stated that there is a correlation between the two phenomena of socialisation and self, but a conclusion cannot necessarily be made as to whether the socialisation is a cause of the self.

The question of cause and effect refers to the idea of whether the self develops before the individual can participate with intention and deliberation in social interactions, or after. Are the interactions an exchange of significant symbols (as opposed to an interaction of conversational gestures) or situations where one participant offers significant symbols while the other only conversational gestures? ${ }^{216}$ Proficiency in social interactions requires a self. Social interactions are proficient if they are effective in producing the desired outcomes of the individuals involved. Criterion Two states that the ability to reflect on our behaviours is an aspect of self. This capacity can inform us of future patterns of behaviour thereby allowing us to evolve the ability of prediction. Being able to predict patterns of behaviour in our own self can assist with decision making according to the type of outcome desired. If the self is coupled with Theory of Mind then this predictive capacity becomes even more useful, for it means that the behaviours of others can be anticipated allowing responses to be prepared in advance for possible outcomes. The self offers the individual the tools required to interpret behaviour patterns and respond in an informed manner. This type of skill is valuable when it comes to surviving one's environment. This was equally true of early humans as it is for humans today.

Others

Previously there was a discussion on the distinction between the self and the Theory of Mind. The self is, in brief terms, the establishment of the individual; specifically,

\footnotetext{
${ }^{215}$ Self-Other Differentiation, http://www.nature-nurture.org/index.php/ontogeneticdevelopment/development-of-sense-of-self/self-other-differentiation/, accessed 22 January 2013

${ }^{216}$ Cronk, G. (2005). George Herbert Mead (1863-1931), http://www.iep.utm.edu/mead/, accessed on 1 August 2013
} 
an identification of the individual's perceptions; a method of interpretation for those perceptions and an understanding of the independent existence of the individual. Theory of Mind is the transference of this state to other like individuals. When the idea of self is examined an assessment of its function or influence in its expression to the world must be considered. This expression can be best assessed through the relationships between the individual in question and others. The ability to identify others as individuals is not a faculty required in this dissertation's conditions of self. Rather it is a faculty (Theory of Mind) which develops in concert with or soon after the cognitive ability to perceive one's self as distinct from the surrounding world. These two cognitive abilities make a distinction similar to that made by George $\mathrm{H}$. Mead between the state of the social self and the self which responds to the social self - a reflection of self. ${ }^{217}$ The previous chapters on autism and schizophrenia illustrate why it is not wise to assume that because an individual develops one faculty another similar faculty will also develop. It does demonstrate why each apparently simple faculty is necessary to integrate comfortably within community. Different behaviours are not treated with equity when it comes to social interactions. This can be seen in historical cases of discrimination.

\section{In Relationship}

The concept of relationship becomes important because it is in relationships that individuals make judgements on their perceptions. The individual in question has a self, and as he/she assesses the world he/she can perceive it in at least two ways. Firstly, the perceiving individual may not have evolved a Theory of Mind and consequently may not interpret other individuals as having selves. This does not mean that he/she only experiences one self; it is possible that he/she may experience multiple selves personal to his/her internal world. ${ }^{218}$ The second form of perception which the individual may have is that if he/she has developed a Theory of Mind then he/she can perceive the self in others. When individuals make a judgement on their environment, to distinguish its members into categories (specifically whether the items considered are other selves or objects), they do so within a relationship to their environment. In Chapter Eight the idea of an object's worth was described through its utility to the individual. Likewise, whether an individual distinguishes other selves or not, the parts of its environment are judged on their perceived utility. Other selves offer utility in a multitude of ways: they can offer opportunities for communion, knowledge, resources and protection, to name a few. If other selves are not

\footnotetext{
${ }^{217}$ Cronk, G. (2005). George Herbert Mead (1863-1931). http://www.iep.utm.edu/mead/, accessed on 1 August 2013

${ }^{218}$ An idea evolved from Chapter Three in the Multiple Selves Doctrine.
} 
identified it does not mean the other individuals lose their utility. Rather their utility is not as wide ranging or beneficial because the other individuals become less predictable or controllable. Having a self and being able to observe other selves is valuable because it opens up the potential for communication and mutually beneficial relationships.

When considering the question of what we perceive in other people, a series of observations can be made. Firstly, the physical aspects of an individual can vary and are an unreliable measure of what it is to be that person. There is an argument in which a pile of sand is named and a discussion had by two individuals which, in this case, will be called the teacher and the pupil. The teacher asks the pupil whether the pile of sand is, in fact, a pile of sand. The pupil answers that the sand is, indeed, a pile. The teacher proceeds to remove a grain of sand from the pile and repeats the question to the pupil. The pupil's answer is the same. The teacher continues to remove sand a grain at a time each time asking the pupil if there is still a pile of sand. The pupil continues to answer in the affirmative. Eventually the teacher will remove all the sand and the pupil will answer that there is no longer a pile of sand, but at what point does the sand cease to be a pile? While parts can be removed, the pile is not, in fact, the sand but a concept of what a pile is like. The concept of the pile of sand can be likened to the physical body. The body is not the person; rather it is the physical image of what the person is like. The body is like an object; its worth is found only in its utility. The self which resides with the body is what is identified when we perceive other individuals (in most cases). The self elevates the body from being an object to being the physical representation of a person. This self is identified or recognised by another self through the identification of similarities, a shared nature. The self is the aspect which resonates within the beholder. The Self Criteria and the Theory of Mind imply that while all other aspects of an individual may change what is particular to identifying others as similar to one's self is the identification of their selves. For this reason the self is valuable as it identifies us; it allows us a reference point for relationship.

Other individuals are important to the discussion of self regardless of whether the self in question can identify them because an item's value is measured by its benefits to the individual and to others. If the self acts as a necessary predicating faculty for identifying other selves, then it is important in that it allows an individual the tools necessary for communicating with those others which, in turn, allows for the development of relationships and finally, the formation of cooperative groups. These cooperative groups or communities function as necessary features for human survival. There are two ways in which the identification of self in others can be described. It can be the process of the individual recognising aspects of his/her own self in the other or it can be the experience of 
identifying another individual self by its shared traits with his/her own in their behaviour and expression. The distinction between the two is that in the first scenario what is recognised is the uniqueness of the beholder's self while in the other what is recognised is the similarity between two selves. We value the idea of other selves because being in relationships affirms the existence of our own self and, likewise, the other selves are also affirmed.

\section{The Self's Role in Communication}

The interaction between selves (by way of communication) will become integral to understanding the value of self as a tool. Communication forms the basis for the social process. Mead offers a tripartite description of the nature of communication. The first aspect of the process is an initiating gesture by the individual (aspect one) followed by a response to that gesture (aspect two) offered from the other; that gesture must be a result of the initial gesture (the third aspect) of the tripartite. When a conversation of gestures gains intentionality it progresses from a general action to a significant symbol. Language marks a transition from basic gestures to significant symbols. Language can be formed in a variety of different ways, not always verbal. Sometimes language is mostly gestures as in the case of sign language for the deaf. What makes the actions, verbal or otherwise, into language is that they become significant symbols carrying meaning. Once meanings are attached to the actions, an individual can respond to the meanings in actions offered by other individuals. Thus the tripartite process of communication begins. For Mead this process of developing significant symbols and meanings happens through social exposure. It is possible that during this process the individuals could develop significant symbols with meaning unrelated to those meanings commonly ascribed by their social group. Therefore an individual may not appear to communicate or seem to have extremely limited communications as a result of a different set of transcribed meanings. For instance, in Chapter Seven, in the discussion of the idios kosmos, four functions of the internal world of an individual were described. One of these functions was an Ethical Option which describes how people with autism move away from common sense perceptions and interpretations of the world resulting in behavioural peculiarities. ${ }^{219}$

Mead supports an emergent self; that is, he anticipates that the self is a product of social interaction. The self, according to Mead, organises our perceptions. The unique nature of the self is its reflective process; it perceives itself as an object. Other objects such as the body do not perceive themselves as objects in that they cannot reflect on their full

\footnotetext{
${ }^{219}$ Stanghellini, G., \& Ballerini, M., (September, 2004). Autism: Disembodied Existence. Philosophy, Psychiatry, \& Psychology, Vol 11, No. 3. DOI: 10.1353/ppp.2004.0069, pp 259-268
} 
selves rather just aspects of themselves. The reflective process or consciousness occurs when individuals enter their consciousness as an object. There they consider themselves as an other within their internal perceptions. This process is akin to projecting the idea of oneself into the perception so that it becomes a subject to be examined like an object. In order to achieve this third person-like perception an individual must use his/her experiences of the social environment containing other individuals as a model of how to perceive his/her own self. ${ }^{220}$ For Mead, the self evolves social presence before it can identify its self. It does so by having a social expression and then reflecting on this expression thus identifying its self. A self offers improved social engagement and control. When it can perceive itself it begins to develop a comprehensive understanding of how others may think. The third person perception of self coupled with social experiences of other individuals assists an individual toward becoming skilled in the behaviours of others; a valuable ability for a social species such as humans whose ability to survive is increased with the formation of community groups.

\section{Society's View on the Self}

During an individual's development, specifically in his/her younger years, he/she is surrounded by societal interactions - some directed at him/her and others just within his/her environment. In early childhood while the self has yet to fully develop, the individual is afforded the lenience that the promise or potential to have a self gives. This promise is sufficient to be treated as if one has a self already. For instance, there are expectations regarding the standards of treatment and care of that individual that presuppose an ethical problem. The infant may be present in a society or community but his/her inclusion is dependent on his/her developing a self. During the pre-self years the child is accepted in the society through personification and the understood pattern of self development seen in others' behaviours. However, should the development process be abnormal or, after a period of time, the individual's behaviour starts to deviate from recognised patterns, then there is a problem. The self is valuable because it facilitates the ability to reflect on our own actions which allows us to establish patterns of behaviour which, in turn, help us to anticipate behaviours and outcomes. An individual whose development, as seen by his/her behaviours, is abnormal ceases to be predictable to his/her peers. This can result in the peers failing to identify any similar aspects to themselves in the individual which, in turn, is expressed in their belief that the individual does not share the same type of self. If the self is that which is recognised by the beholder as the identifying feature required for

\footnotetext{
${ }^{220}$ Cronk, G. (2005). George Herbert Mead (1863-1931). http://www.iep.utm.edu/mead/, accessed on 1 August 2013
} 
inclusion in the beholder's community, then a self that is unrecognisable will experience exclusion. The beginning of this dissertation discussed the idea that definitions are established by grouping categories with the same or similar features. It was established that a different method would need to be used when attempting to define what made each individual particular because similarities are not what makes an individual unique. Consequently, it was decided that what made people different would be examined. This idea can be applied to the case of the individual with the unrecognisable self. It is not the form of expression of the self that is important but rather the faculties which underlie the expression. An understanding of these faculties is needed if people are going to relearn how to identify other selves. The automated response, a product of the tendency to personify, to identify an individual by his/her similarities to one's self is to limit others' selves and possibly exclude them unfairly.

\section{The Value of the Self}

In considering the self, two additional aspects have been identified that magnify its value. While the self is of significance to the individual alone it is made more valuable with the presence of other selves, especially other selves which can be identified by the individual self. This is heightened again when the self is combined with a Theory of Mind (a simple concept once the self has already been established) for then there is a distinct increase in the capabilities of the individual. These capabilities form valuable assets contributing to successful communities.

The self is a complex idea and in many ways it acts like a foundation for more advanced human activities such as relationships and communities. It can therefore be considered the nexus of a person. Many other functions stem from its base principles; one of the most valuable being a Theory of Mind. An individual with a self has the essence of what it is to be a person even if his/her functions cease to evolve after the self's development. The self is the foundation of our expression in the world. 


\section{An Enquiry into the Self: Thoughts Based on the Individual and the Perceptions of the Other}

A final examination must be given to the conclusions reached within this dissertation. I shall review the criteria necessary for the self together with the symbiotic necessity for the self's expression established in Part One. A summary of the expression of the self within the perceptions of others follows - specifically, how the self is expressed within cases offered to us by psychology.

Insight through the Individual

Three criteria of self have been established and one symbiotic necessity for the expression of self.

Expression of Self:

As the examination of the self progressed through this dissertation one fact remained constant: that the self never appeared without the body. While the exact nature of the relationship between the body and the self was not established, it can be stated with certainty that the self's relationship with the body is necessary for its expression. It is in the behaviour of the body that the self is identified, thus the body and the self are fundamentally linked.

\section{The Criteria of the Self}

Three necessary and sufficient criteria for the self were established:

1. The being is conscious (awake and experiencing).

In order for an individual to satisfy the first criterion of the self he/she must have the basic condition of consciousness. He/she must be capable of receiving perceptual input from the physical world and responding to this input. This requirement is of basic physical feedback and does not require any semblance of reasoning; rather it is a case of there being evidence of reactions to external stimuli.

2. A reflective consciousness; the consciousness which can be reflected upon.

The second necessary requirement of self is that the individual in addition to being conscious has a reflective consciousness. Reflective consciousness occurs when the individual examines the contents of his/her perceptions and chooses informed responses to them. This state differs from basic consciousness in that the reactions often illustrate evidence of reasoning and learning; that is, the reflective consciousness can allow the 
individual to respond in an informed manner to a totally novel experience using tools gained from previous similar experiences. The criterion of reflective consciousness allows for the internal examination of the content of perceptions and therefore of the potential to learn and evolve a collection of interpretations of one's perceptions. Reflective consciousness is the nature of an individual's ideas and thoughts.

3. Awareness; the being is aware that it is him/herself that contains the first two consciousnesses and not just that the universe is as such.

The final necessary criterion of the self is the ability of the individual to distinguish him/herself as separate from the world; that is, that the individual's internal contemplations of the world are specific to him/herself and not just of the world. In order for this to occur the individual must realise that his/her conscious and reflective consciousness is of him/herself and that the other items within the world are not of the same contemplations but may have contemplations or natures of their own. That is, that the external world has its existence independent of the individual and, therefore, the individual, rather than being the orchestrator of the world, is, in fact, a member of the world. Thus a personal concept of the individual's self must evolve. The individual must isolate his/herself as distinct from the environment and, therefore, come to believe that there is something that it is to be like him/her. The individual must identify his/her distinct quiddity.

$$
\text { Insight through the Other }
$$

\section{Function}

The self offers the function of providing meaning in the orientation of the individual within the world. A self who holds onto its distinctiveness from the world can make the move to intentional expressions within the world thus opening up opportunities for language and eventually community.

\section{Autism}

An examination of the disorder autism provided a study of the process of identifying the self criteria within an individual's expression in the world. In so doing it highlighted the difference between the self criteria and the Theory of Mind thesis. In this example a case was made for the presence of all three self criteria in the person but an absence of the Theory of Mind. It was seen that this absence of what appears to be a simple faculty can have far reaching effects as society often assumes that the person's capacity for self is absent as well. 
The case of schizophrenia exemplifies the clouding effect which people's behaviour has on the perception of others regarding an individual's relative selfhood. While it was identified that an individual with schizophrenia has a self, its expression can be so diverse that it is commonly unrecognised. Traditionally, society or others identify a self in an individual through a progression of assumptions. Firstly, there is a personification and then a person isolates similar traits between him/herself and the individual thus imputing selfhood to the beheld individual. This method does not work in the case of an individual with schizophrenia as the episodic nature of the disorder distorts the traits of the individual. Consequently it impresses the value of a different approach to the imputation of self to another; that is, to identify the self on the grounds of its cognitive functions necessary for the criteria, not on the content of those criteria's expressions.

\section{The Final Overture}

This dissertation's position is that an individual may have a self if and only if they have a body giving the self a means of expression within the world. Further, I have argued that the individual must have these three faculties: consciousness, reflective consciousness and awareness. Each of these four aspects is necessary for the existence of a self within an individual. In order for each of these criteria to be identified informed examination must occur of an individual whereby his/her behaviour is perceived without the prejudice of societal expectation and convention. Anticipation and expectation of certain behaviours can lead to detrimental clouding of the truth of a situation. To not allow an individual the opportunity of self is to deny them the chance of community. The behaviours of individuals must be elucidated to locate the nature of each of their expressions so that a position can be established regarding the individual's relative selfhood. A self gives an individual the capacity to navigate and excel in his/her presence in the world both with others and with him/herself. 
Anscombe, G. E. M., (1975). The First Person. In Samuel Guttenplan, ed.. Mind and Language. Oxford: Clarendon Press

Argument By Analogy. http://www.unc.edu/ theis/phil32/argsbyanalogy.html, accessed 22 January 2013

Armstrong, D. M., (1981). Minds, Bodies, and Persons. The Nature of Mind and Other Essays, Cornell University Press, pp 295-302

Avicenna, F. Rahman. ed. (1952). Avicenna's Psychology. An English translation of Kitāb al-Najāt. Book II, Chapter VI, with Historico-Philosophical Notes and Textual Improvements on the Cairo edition. London: Oxford University Press, Geoffrey Cumberlege

Baker, D. B. (Ed), (2012). The Oxford Handbook of the History of Psychology: Global Perspectives. Oxford University Press

Baren-Cohen, S., Leslie, L. \& Firth, U. (1985). Does the Autistic Child have a Theory of Mind?. Cognition, 21, pp 37-46

Barlow, D. H.; Durand, V. M., (2009). Abnormal Psychology: An Integrative Approach Firth Edition. Wadsworth Cengage Learning

Blackburn, S., (2005). Oxford Dictionary of Philosophy. Oxford University Press

Branden, N. (1983). Honoring the Self: Self Esteem and Personal Transformation. Jeremy P. Tarcher, Inc. Los Angeles.

Bronstein, J., Mutualism and Symbioses, http://www.oxfordbibliographies.com/view/document/obo-9780199830060/obo9780199830060-0006.xml, accessed 25 June 2013

Copeland, J., (1993). Artificial Intelligence: A Philosophical Introduction. Blackwell Publishing, p 135

Cottingham, J., Ed., (1996). Descartes: Meditations on First Philosophy: With Selections from the Objections and Replies. Cambridge University Press

Cronk, G. (2005). George Herbert Mead (1863-1931), http://www.iep.utm.edu/mead/, accessed on 1 August 2013

Dainton, B. (2004). The Self and the Phenomenal. Ratio: An International Journal of Analytic Philosophy, 17: 365-389

Dennett, D. C., (2005). Sweet Dreams. Philosophical Obstacles to a Science of Consciousness. The MIT Press, Cambridge

Dennett, D. C., (2003). The Self as a Responding - and Responsible - Artefact. Centre for Cognitive Studies, New York academy of Sciences 
Dissociative Identity Disorder. http://behavenet.com/dissociative-identity-disorder, accessed 13 November 2012

Droege, P., (2005). Higher-Order Theories of Consciousness.

http://www.iep.utm.edu/consc-hi/, accessed 8 July 2013

Encyclopædia Britannica Online. Centre of Gravity.

http://www.britannica.com/EBchecked/topic/242556/centre-of-gravity, accessed 13

November 2012

Erikson, E., (1965). Childhood and Society. Harmondworth, UK: Penguin Books

Festinger, L. and Carlsmith, J. M., (1959). Cognitive Consequences of Forced

Compliance. Journal of Abnormal and Social Psychology. 58

Frith, U., Morton, J., \& Leslie, A. M., (1991). The Cognitive Basis of a Biological Disorder: Autism, Perspectives on Disease. TINS, Vol. 14, No. 10

Giles, J., (Apr., 1993). The No-Self Theory: Hume, Buddhism, and Personal Identity, Philosophy East and West, Vol. 43, No. 2, pp. 175-200

Goff, P., (2009). Why Panpsychism doesn't Help Us Explain Consciousness. Blackwell Publishing Ltd., Oxford

Haycock, D. A.. Sense of Self and Emotions.

http://www.netplaces.com/schizophrenia/impressions-of-schizophrenia/sense-of-selfand-emotions.htm, accessed 23 July 2013

Hobson, R. P., (1990). On the Origins of Self and the Case of Autism. Development and Psychopathology. 2, pp 163-181. DOI:10.1017/S0954579400000687.

http://www.muslimphilosophy.com/ei2/nafs.htm: NAFS - from the Encyclopaedia of Islam (1999) Koninklijke Brill NV, Leiden, The Netherlands, accessed 14 October 2012

Hubbard, T. L.; Hutchison, J. L.; Courtney, J. R., (2010). Boundary Extension: Findings and Theories. The Experimental Psychology Society. pp 1-28

Hume, D., (2000). A Treatise of Human Nature. Oxford University Press

Internet Encyclopaedia of Philosophy, John Locke 1632-1704, (2001) www.iep.utm.edu/locke/, accessed 1 April 2013

Jablensky, A., (September, 2010). The Diagnostic Concept of Schizophrenis : Its History, Evolution, and Future Prospects. Dialogues Clin Neurosci; 12(3): 271287,http://www.ncbi.nlm.nih.gov/pmc/articles/PMC3181977/, accessed 23 July 2013

Lewis, D., (2003, online \& 1983, print). Survival and Identity. Philosophical Papers Volume 1. Oxford Scholarship Online, DOI: 10.1093/0195032047.003.0005, accessed 17 June 2013 
Locke, J., (1996). An Essay Concerning Human Understanding. Kenneth P. Winkler (ed.), Hackett Publishing Company, Indianapolis, IN

Lowe, E. J., (October, 1993). Mind. The Causal Autonomy of the Mental. Vol. 102, 408, Oxford University Press

Lowe, E. J., (2006). Non-Cartesian Substance Dualism and the Problem of Mental Causation. Erkenntnis, Springer, DOI: 10.1007/s 10670-006-9012-3, pp 5-23

McGinis, J., (2010). Avicenna. Oxford Scholarship Online. http://www.oxfordscholarship.com.helicon.vuw.ac.nz

McInerny, R. and O'Callaghan, J., (Winter 2010 Edition). Saint Thomas Aquinas. The Stanford Encyclopedia of Philosophy. Edward N. Zalta (ed.), URL = <http://plato.stanford.edu/archives/win2010/entries/aquinas/>.

Miller, Y., (April 2007). A Phenomenological Exploration of Brief Art Therapy through Folding Two-Dimensional Drawings Created by an Adult Population. http://idea.library.drexel.edu/bitstream/1860/2959/1/Miller.pdf, Thesis: Drexel University

Mishara, A. L., (2004). Disconnection of External and Internal in Conscious Experience of Schizophrenia: Phenomenological, Literary and Neuroanatomical Archaeologies of Self. Philosophica 73, pp. 87-126

Nagel, T., (1979). Panpsychism. In Mortal Questions. Cambridge: Cambridge University Press

Oxford Reference. Conjunctive Symbiosis. www.oxfordreference.com/view/10.1093/oi/authority.20110803095632415, accessed 19 June 2013

Skrbina, D., (2007). Panpsychism. http://www.iep.utm.edu/panpsych/, accessed 17 June 2013

Parfit, D., (Jan 1971). Personal Identity. The Philosophical Review. Vol. 80, No. 1

Parfit, D. (1984). Reasons and Persons. Part Three, Clarendon Press, Oxford

Parfit on What Matters. The Phantom Self: A Case for Conceptual Reform. http://phantomself.org/parfit-on-what-matters/, accessed 18 June 2013

Personal Identity. http://mind.ucsd.edu/syllabi/03-04/phil1-spring/readings/parfit.pdf, accessed 17 June 2013

Psychotherapy and Counselling: Schizophrenia DSM IV Definition. http://psychotherapyandcounseling.org/schizophrenia-and-related-psychoticdisorders-category/schizophrenia, accessed 5 July 2013 
Reddy, V.; Williams, E.; Costantini, C., \& Lan, B. (2010). Engaging with the self: Mirror Behaviour in Autism, Down Syndrome and Typical Development. Autism. 14 (5), 531-546 DOI: 10.1177/1362361310370397

Reflections on the Soul. Avicennian Psychology of the Soul and its Relation to Similar Discourses from Al-Farabi. St Thomas Aquinas and Aristotle. http://arabicphilosophyjkh.wordpress.com/category/st-thomas-aquinas-and-thenature-of-the-soul/, accessed 5 June 2013

Rensink, R. A., J. K. O’Regan, and J. J. Clark, (September, 1997). To See or Not to See: The Need for Attention to Perceive Changes in Scenes. Psychological Science. vol. 8 no. 5

Richer, J., (1978). Autism: A Reappraisal of Concepts and Treatment. The Partial Noncommunication of Culture to Autistic Children-An Application of Human Ethology, Springer US, DOI: 10.1007/978-1-4684-0787-7_3, pp47-6

Richter, D., (2012). The First Person. G. E. M. Anscombe (1919-2001). http://www.iep.utm.edu/anscombe/, accessed 30 May 2013

Robinson, H., (Winter 2012 Edition). Dualism. The Stanford Encyclopaedia of Philosophy. Edward N. Zalta (ed.), URL = http://plato.stanford.edu/archives/win2012/entries/dualism/, accessed 11 June 2013

Ryle, G., (1949). The Concept of Mind. Barnes \& Noble Inc, New York

Sass, L. A.; Whiting, J.; Parnas, J., (2000). Mind, Self and Psychopathology: Reflections on Philosophy. Theory and the Study of Mental Illness. Sage Publications, Vol. 10(1): pp 87-98

Sass, L. A. \& Parnas, J. (2003). Schizophrenia. Consciousness and the Self. Schizophrenia Bulletin, Vol. 29, No. 3, pp 427-444

Schwerin, A., (2007). Hume and the Self: A Critical Response. Monmouth University, Volume 5, DOI 10.3366/jsp.2007.5.1.15, ISSN 1479-6651, pp 15-30

Searle, J. R.. Why I Am Not A Property Dualist. http://faculty.wcas.northwestern.edu/ paller/dialogue/propertydualism.pdf, accessed 10 June 2013

Self-Other Differentiation. http://www.nature-nurture.org/index.php/ontogeneticdevelopment/development-of-sense-of-self/self-other-differentiation/, accessed 22 January 2013

Siegel, L., (1991). Net of Magic: Wonders and Deceptions in India. Univ. of Chicago Press, p 425 
Stanghellini, G., \& Ballerini, M., (September 2004). Autism: Disembodied Existence.

Philosophy, Psychiatry, \& Psychology, Vol 11, No. 3, DOI: 10.1353/ppp.2004.0069, pp 259-268

Stanghellini, G., (February 2009). Embodiment and Schizophrenia. World Psychiatry, Vol. 8(No. 1): pp 56-59, http://www.ncbi.nlm.nih.gov/pmc/articles/PMC2652898/, accessed 15 July 2013

Strawson, G., (2005). The Self?. Blackwell Publishing

Strawson, G., (2010). Narrativity and non-Narrativity. John Wiley \& Sons, Ltd., http://idea.library.drexel.edu/bitstream/1860/2959/1/Miller.pdf, Thesis: Drexel University

The Incredible Case of Phineas Gage. http://neurophilosophy.wordpress.com/2006/12/04/the-incredible-case-of-phineasgage/., accessed 23 January 2013

Waskan, J., (2010) Connectionism, http://www.iep.utm.edu/connect/\#H7, accessed 31 May 2013

Williamson, G., (July 2013). Autism and the Theory of Mind. http://www.sltinfo.com/autism-and-theory-of-mind.html, accessed 8 July 2013

Woodman, G. F.; Luck, S. J. (2003). Dissociations among Attention, Perception, and Awareness during Object Substitution Masking. Psychological Sciences, Vol. 14, No. 6. American Psychological Society

Woods, A., (2011). The Sublime Object of Psychiatry: Schizophrenia in Clinical and Cultural Theory, International Perspectives in Philosophy and Psychiatry. Oxford: Oxford University Press, Introduction, http://www.academia.edu/1572771/The_Sublime_Object_of_Psychiatry_Schizophre nia_in_Clinical_and_Cultural_Theory, accessed 14 July 2013 